\title{
Diversity, external morphology and 'reverse taxonomy' in the specialized tadpoles of Malagasy river bank frogs of the subgenus Ochthomantis (genus Mantidactylus)
}

\author{
Roger-Daniel Randrianiaina ${ }^{1,2,5}$, Axel Strauß ${ }^{1}$, Julian Glos ${ }^{3}$, Frank Glaw ${ }^{4}$, Miguel Vences ${ }^{1}$ \\ ${ }^{1}$ Division of Evolutionary Biology, Zoological Institute, Technical University of Braunschweig, Spielmannstr. 8, \\ 38106 Braunschweig, Germany \\ ${ }^{2}$ Département de Biologie Animale, Université d'Antananarivo, BP 906, Antananarivo 101, Madagascar \\ ${ }^{3}$ Zoological Institute, University of Hamburg, Martin-Luther-King Platz 3, 20146 Hamburg, Germany \\ ${ }^{4}$ Zoologische Staatssammlung München, Münchhausenstr. 21, 81247 München, Germany \\ ${ }^{5}$ E-mail: roda.randrianiaina@googlemail.com
}

Key words: Amphibia, Mantellidae, Madagascar, tadpole morphology, DNA barcoding.

\begin{abstract}
We provide detailed morphological descriptions of the tadpoles of Malagasy river bank frogs of the subgenera Ochthomantis and Maitsomantis (genus Mantidactylus, family Mantellidae), and data on relative abundance and habitat preferences of $O c h$ thomantis species from Ranomafana National Park in southeastern Madagascar. Our study includes the tadpoles of six described and four undescribed candidate species. Eight of these larvae were previously unknown. Tadpoles were identified by DNA barcoding. Due to the very rudimentary taxonomic knowledge on Ochthomantis, we followed a 'reverse taxonomy' approach in which adult classification was to a great part determined on the basis of larval differences. By this procedure we even identified one candidate species whose adults remain still unknown. The majority of tadpoles in Ochthomantis and Maitsomantis have a rather similar body shape and they usually have similar habitat requirements. However, on the basis of the structure of their oral disk we identified three distinct groups: the first includes the femoralis-like tadpoles of Mantidactylus femoralis, M. ambreensis, M. zolitschka, M. argenteus, and of the candidate species named $M$. sp. $42, M$. sp. 43 and $M$. sp. 47. They all have a reduced oral disk with poorly keratinized jaw sheaths and labial teeth. The mocquardi-like tadpoles of $M$. mocquardi and $M$. sp. 64 are placed in the second group and are characterized by a further reduction of oral disk structures, i.e. a complete lack of labial teeth. The third group includes only $M$. majori and is characterized by the transformation of the upper jaw sheath into three thorn-shaped projections. Based on a preliminary molecular phylogenetic analysis the reduction of keratinized oral structures in M. majori may have occurred convergently to that in $M$. mocquardi. The ecological data indicate that the tadpoles of the three most abundant species in Ranomafana (M. femoralis, M. majori and M. sp. 47) do not obviously differ in their choice of microhabitat although the differences in their oral structures indicate that they might use different food resources. They all show a preference for the stream areas with slow current and leaf litter substrate.
\end{abstract}

\section{Contents}

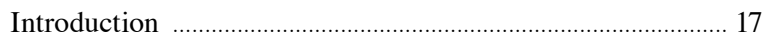

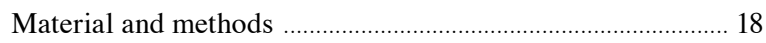

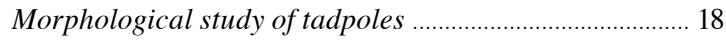

Molecular analyses .......................................................... 19

Habitat preference analysis ................................................ 20

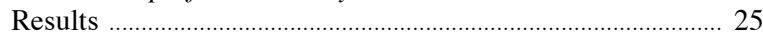

Larval and adult diversity in Ochthomantis ................... 25

Ecological analysis .......................................................... 34

Discussion ............................................................................... 35

Specialization of the oral disk in Ochthomantis tadpoles 35

Comparisons with other mantellid tadpoles .................... 38

Habitat selection and ecology of Ochthomantis tadpoles 38

Acknowledgements .................................................................... 40

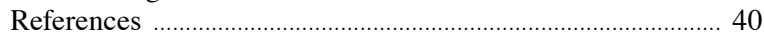

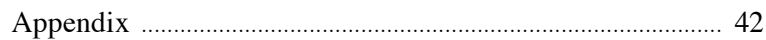

\section{Introduction}

In the Malagasy family Mantellidae, frogs of the genus Mantidactylus form one of the most diverse groups especially in terms of their larval morphology. While the phylogenetic relationships among the various subclades (subgenera and species groups) of Mantidactylus are relatively well understood due to the application of molecular phylogenies (e.g. Glaw and Vences 2006; Glaw et al., 2006), their species-level systematics are very poorly explored, and numerous candidate species await formal description (e.g. Vieites et al., 2009). Within Mantidactylus, the subgenus Ochthomantis, according to the latest revisions by Glaw and Vences $(2004,2006)$ currently consists of five valid species: Mantidactylus ambreensis Mocquard, 
1895; M. femoralis (Boulenger, 1882); M. majori Boulenger, 1896; M. mocquardi Angel, 1929; and M. zolitschka Glaw and Vences, 2004. Within this subgenus there is strong evidence for additional cryptic diversity, and numerous new candidate species have already been identified (Glaw and Vences, 2004; Rabibisoa et al., 2008; Vieites et al., 2009). At present, three distinct species in the subgenus are relatively easy to diagnose: M. ambreensis, M. majori and M. zolitschka. In contrast, M. femoralis and M. mocquardi as currently understood are complexes of multiple species (Glaw and Vences, 2007).

Anuran larvae show many special and characteristic features which are distinctly different from those of the adult frog stage, encompassing ecology, morphology and habits (McDiarmid and Altig, 1999). These features can also be very diverse among tadpoles, and likely are the results of adaptation to their environment. However, tadpole characters also are partly determined by the phylogenetic history of the respective species, and have successfully been used for phylogenetic reconstruction (Haas, 2003).

Descriptions of anuran species, as a rule almost without exception, are based on type material in the metamorphosed, usually adult, stage. In fact, for many species - possibly from the majority of frog species worldwide - the larval stages are not reliably known. Only recently has the identification of different lifehistory stages of an organism by matching their DNA sequences become possible, a technique usually called DNA barcoding (Hebert et al., 2003). The application of this technique to amphibians is promising (Thomas et al., 2005; Vences et al., 2005) and allows efficient surveys of the species and larval diversity of tropical frog communities (Vences et al., 2008). In some taxonomically poorly studied frog groups the paradoxical result might be that the tadpoles are better known than the adults, both regarding their ecology and their morphology.

In other poorly known organisms such as the meiobenthic fauna, studies often end up with many taxa being only identified via their DNA sequences and not by their morphology, an approach for which Markmann and Tautz (2005) proposed the term 'reverse taxonomy'. Such a situation applies to the frogs in the subgenus Ochthomantis. These frogs are rather inconspicuous regarding adult morphology, and candidate species have largely been identified on the basis of DNA sequences (Vieites et al., 2009). Several of the described Ochthomantis species and most candidate species appear to be diagnosable as adults only by the application of detailed morphometric analyses (Rabibisoa et al., 2008). The morphology of tadpoles has not been assessed for most species of Ochthomantis, and it is thus far unknown whether tadpole characters might perform better in species discrimination than adult morphology. So far, only tadpoles assigned to M. femoralis have been briefly described by Blommers-Schlösser (1979) and a larva of an unidentified species from the Chaines Anosyennes (1060 m a.s.l.), probably referable to the subgenus Ochthomantis, was briefly characterized by Blommers-Schlösser and Blanc (1991).

In contrast to the uniform and inconspicuous adult morphology of Ochthomantis, their tadpoles have unique specialized mouthparts which make them easy to distinguish from tadpoles of other mantellid genera and subgenera. Their oral disk is characterized by (1) a strong reduction of the number of labial tooth rows and the density of labial teeth, and (2) a reduction of the keratinisation of the jaw sheaths. Such divergent oral disk structures probably are specializations either on particular food items and/or feeding behaviour. In general, such specialized larval adaptations may be one key to understand the high diversity of tropical amphibian communities (Strauß et al., 2010).

In this study, we provide descriptions of the external morphology of the tadpoles of ten species of Mantidactylus (Ochthomantis and Maitsomantis), eight of them for the first time. We here do not include details of buccal anatomy or microstructures such as labial teeth on which we will focus in a future comprehensive survey of tadpole buccal cavities in the Mantellidae. We assign species and candidate species to three separate morphological clysters on the basis of external tadpole morphology, and discuss the evolution of specialization of oral structures in Ochthomantis as well as the advantages of DNA barcoding for identifying tadpoles.

\section{Material and methods}

\section{Morphological study of tadpoles}

Tadpoles were collected using different types of nets having mesh sizes from 2 to $5 \mathrm{~mm}$, depending on the size of the streams, the strength of the current and the type of substrate. They were euthanized by immersion in chlorobutanol solution, and immediately sorted into homogeneous series based on morphological characters. From each series one specimen was selected and a tissue sample from its tail musculature or fin taken 
and preserved in $99 \%$ ethanol. This specimen is here called 'DNA voucher'. All detailed morphological tadpole characterizations and drawings are based on this DNA voucher, whereas observation for the variation refer to further DNA voucher specimens from the same locality or from different localities, and sometimes to the non-sequenced specimens of the same series. After tissue collection, all specimens were preserved in 5\% formalin or $70 \%$ ethanol. Specimens were deposited in the Zoologische Staatssammlung München, Germany (ZSM). When referring to voucher specimens the original field numbers (FG/MV, FAZC, FGZC, T, TAD, ZCMV) are usually provided together with the final ZSM catalogue numbers. Tadpoles were identified using a DNA barcoding approach (see below). Tadpoles studied in this paper are listed in Tables 1-2 including data concerning the site and its coordinates, the date of the capture and the collectors.

For detailed morphological examination, especially to determine developmental stages and assess characters of the oral disk, preserved tadpoles were stained slightly with methylene blue. Tadpoles were examined under water and few drops of methylene blue were applied to the oral disk, hind limb, spiracle narial opening and vent tube for having a better view of their structure. Developmental stages are determined following Gosner (1960). Description, measurements and drawings were done on digital pictures of the preserved tadpoles taken with a Stereomicroscope Zeiss Discovery V12 connected to a computer, following the landmarks, terminology and definitions of McDiarmid and Altig (1999). New landmarks are also introduced herein (Fig. 9). Developmental stages are described following Gosner (1960). The formula of labial tooth rows (LTRF) is given according to Altig and McDiarmid (1999). Labial teeth are also referred to as keratodonts following Dubois (1995). When describing interruptions of keratodont rows we considered these as scattered when they have more than a single medial interruption. Drawings of the preserved tadpoles are shown in the Appendix. When categorizing morphometric ratios, we consider them as 'almost equal' if ratios of the measured values are $95-96 \%$ or $104-105 \%$, as 'equal' if they are in the range $97-103 \%$, as 'almost in the middle' if they are in the range $45-46 \%$ or $54-55 \%$ and as 'in the middle' if they are in the range $47-53 \%$.

The following abbreviations are used (see also fig. 9): $\mathrm{A}_{1}$ (first upper keratodont row), $\mathrm{A}_{2}$ (second upper keratodont row), $\mathrm{A}_{\text {2gap }}$ (medial gap in $\mathrm{A}_{2}$ ), $\mathrm{A}_{3}$ (third upper keratodont row), $\mathrm{A}_{1-3 \text { den }}$ (density of the keratodonts in row $A_{1-3}$ ), $A_{1-3 \text { len }}$ (length of $A_{1-3}$ ), $A_{1-3 \text { num }}$ (number of keratodonts in $\mathrm{A}_{1-3}$ ), $\mathrm{BH}$ (maximal body height), $\mathrm{BL}$ (body length), BW (maximal body width), DF (dorsal fin height at midtail), DG (size of the dorsal gap of marginal papillae), DMTH (distance of maximal tail height from the tail-body junction), ED (eye diameter), $\mathrm{EH}$ (eye height - measured from the lower curve of the belly), HAB (height of the point where the axis of the tail myotomes contacts the body - measured from the lower curve of the belly), IND (inter-narial distance), IOD (inter-orbital distance), JW (maximal jaw sheath width), MC (medial convexity of the upper sheath), MCL (length of the medial convexity of the upper sheath), MP (marginal papillae), MTH (maximal tail height), ND (naris diameter), NH (naris height - measured from the lower curve of the belly), NP (naris-pupil distance), OD (oral disk), ODW (maximum oral disk width), $\mathrm{P}_{1}$ (first lower keratodont row), $\mathrm{P}_{2}$ (second lower keratodont row), $\mathrm{P}_{3}$ (third lower keratodont row), $\mathrm{P}_{1-3 \text { den }}$ (density of the keratodonts in $\mathrm{P}_{1-3}$ ), $\mathrm{P}_{1-3 \text { len }}$ (length of $\mathrm{P}_{1-3}$ ), $\mathrm{P}_{1-3 \text { num }}$ (number of keratodonts in $\mathrm{P}_{1-3}$ ), $\mathrm{R} / \mathrm{L}$ (right/left), RN (rostro-narial distance), $\mathrm{SBH}$ (distance between snout and the point of maximal body height), SBW (distance between snout and the point of maximal body width), SE (snout-eye distance), SH (spiracle height - measured from the lower curve of the belly), SL (spiracle length), SMP (submarginal papillae), SS (snout-spiracle distance), SV (spiracle-vent distance), TAL (tail length), TH (tail height at the beginning of the tail), THM (tail height at mid-tail), Thorn-pap (thorn-shaped papillae), TL (total length), TMH (tail muscle height at the beginning of the tail), TMHM (tail muscle height at mid-tail), TMW (tail muscle width at the beginning of the tail), LR (number of the lower rows of keratodonts), UR (number of the upper rows of keratodonts), VF (ventral fin height at midtail), VG (size of the ventral gap of marginal papillae), VL (vent tube length).

\section{Molecular analyses}

DNA barcoding was based on a fragment of the mitochondrial 16S rRNA gene, which is known to be sufficiently variable among species of Malagasy frogs (Vences et al., 2005). We amplified a fragment of ca. 550 bp using primers $16 \mathrm{Sar}-\mathrm{L}$ and $16 \mathrm{Sbr}-\mathrm{H}$ from $\mathrm{Pa}-$ lumbi et al. (1991), or a shorter fragment of ca. $400 \mathrm{bp}$ using the newly developed specific mantellid primers 16S-Frog-L1 (CAT AAT CAC TTG TTC TTT AAA) and 16S-Frog-H1 (GAT CCA ACA TCG AGG TCG). PCR was carried out with standard protocols (Vences et al., 2003) and sequences resolved on automated 
sequencers. Sequences were preliminarily identified using BLAST searches against a near-complete database of sequences of adult Malagasy frog species. Results were subsequently verified by manually aligning and comparing sequences to the closest hits in the data base. Identification was considered to be unequivocal when the tadpole sequence was $99-100 \%$ identical to an adult specimen from the same geographical region, and clearly less similar to all sequences from other species. When no identity with adult specimens was found and divergence was $>3 \%$ we considered the corresponding tadpoles to belong to additional candidate species, a situation that arose in a single case. DNA sequences were deposited in GenBank (accession numbers of newly determined DNA sequences HQ610836HQ610924; see also Table 2).

To visualize the molecular relationships among adult and larval Ochthomantis, sequences were aligned by eye. We performed a Bayesian phylogenetic analysis using the program Mrbayes 3.1 (Ronquist and Huelsenbeck, 2003). We used MrModeltest version 2.2 (Nylander, 2004) to choose the appropriate model of sequence evolution. Analyses consisted of four Markov chains that ran for 5 millions of generations, sampled every 1000 generations, with a random starting tree and default priors. The burn-in was empirically estimated by plotting $-\ln \mathrm{L}$ against the generation number, and the trees corresponding to the first 4 million generations discarded. Based on more extensive studies of the phylogeny of mantellids (Glaw and Vences, 2006; Glaw et al., 2006) we included in our analysis Mantidactylus (Maitsomantis) argenteus which is closely related to Ochthomantis, and used Mantidactylus (Hylobatrachus) cowanii as the outgroup because Hylobatrachus has been recovered previously as member of the sister clade of Ochthomantis+Maitsomantis (Glaw et al., 2006).

\section{Habitat preference analysis}

In the framework of a study on stream tadpole communities in the Ranomafana National Park (RNP) in the Southern Central East of Madagascar, breeding site choice and tadpole microhabitat preferences were evaluated at 33 stream sections.

To evaluate the correlation of habitat (stream) characteristics with breeding site choice of Ochthomantis species (i.e. tadpole occurrence), the following habitat variables of the streams and their surrounding forest area were recorded: slope, width, depth, overhanging

Table 1. Localities of the tadpoles included in this study.

\begin{tabular}{|c|c|c|c|c|c|}
\hline Locality & Site & Species & Coordinates & Date & Collectors \\
\hline Ambohitsara & & M. mocquardi & $\begin{array}{l}21^{\circ} 21.431^{\prime} \mathrm{S} \\
47^{\circ} 48.941^{\prime} \mathrm{E} \\
294 \text { m a.s.1. }\end{array}$ & 03.iii.2007 & $\begin{array}{l}\text { R.D. Randrianiaina, } \\
\text { T. Rasolonjatovo- H., } \\
\text { S. Ndriantsoa, E. Reeve, } \\
\text { A. Strauß, J. Glos, M. Vences }\end{array}$ \\
\hline An'Ala & Andohanisity & $\begin{array}{l}\text { M. argenteus } \\
\text { M. femoralis } \\
\text { M. mocquardi } \\
\text { M. zolitschka }\end{array}$ & $\begin{array}{l}18^{\circ} 55.156^{\prime} \mathrm{S} \\
48^{\circ} 29.277^{\prime} \mathrm{E} \\
889 \mathrm{~m} \text { a.s.1. }\end{array}$ & 08.ii.2006 & $\begin{array}{l}\text { R.D. Randrianiaina, } \\
\text { L. Raharivololoniaina, } \\
\text { D.R. Vieites, J. Patton, } \\
\text { C. Patton, M. Vences }\end{array}$ \\
\hline Isalo National Park & $\begin{array}{l}\text { South of Tevan'ny } \\
\text { mpiolitsa }\end{array}$ & M.femoralis & $\begin{array}{l}22^{\circ} 30.085^{\prime} \mathrm{S} \\
45^{\circ} 17.177^{\prime} \mathrm{E} \\
869 \mathrm{~m} \text { a.s.1. }\end{array}$ & 04.iv.2007 & $\begin{array}{l}\text { R.D. Randrianiaina, } \\
\text { S. Ndriantsoa }\end{array}$ \\
\hline Mahasoa & & M. mocquardi & $\begin{array}{l}17^{\circ} 17.861^{\prime} \mathrm{S} \\
48^{\circ} 42.119^{\prime} \mathrm{E} \\
1032 \mathrm{~m} \text { a.s. } 1 .\end{array}$ & 13.ii.2008 & $\begin{array}{l}\text { M. Vences, } \\
\text { D.R. Vieites, P. Bora, } \\
\text { J. Patton, C. Patton }\end{array}$ \\
\hline $\begin{array}{l}\text { Marojejy } \\
\text { National Park }\end{array}$ & Camp Mantella & $\begin{array}{l}\text { M.femoralis } \\
\text { M.sp. } 43\end{array}$ & $\begin{array}{l}14^{\circ} 26.0972^{\prime} \mathrm{S} \\
49^{\circ} 47.214^{\prime} \mathrm{E} \\
327 \mathrm{~m} \text { a.s.l. }\end{array}$ & 19.ii.2005 & $\begin{array}{l}\text { R.D. Randrianiaina, } \\
\text { M. Vences, F. Glaw }\end{array}$ \\
\hline $\begin{array}{l}\text { Montagne d'Ambre } \\
\text { National Park }\end{array}$ & $\begin{array}{l}\text { Voie des milles } \\
\text { arbres }\end{array}$ & $\begin{array}{l}\text { M. ambreensis } \\
\text { M. sp. } 42\end{array}$ & $\begin{array}{l}12^{\circ} 31.616^{\prime} \mathrm{S} \\
49^{\circ} 10.316^{\prime} \mathrm{E} \\
1050 \mathrm{~m} \text { a.s. } 1 .\end{array}$ & 17.ii.2003 & $\begin{array}{l}\text { R.D. Randrianiaina, } \\
\text { F. Glaw }\end{array}$ \\
\hline
\end{tabular}


Table 1, continued.

\begin{tabular}{|c|c|c|c|c|c|}
\hline Locality & Site & Species & Coordinates & Date & Collectors \\
\hline \multirow[t]{5}{*}{ Ranomafana } & RNP Sahamalaotra & M. majori & $\begin{array}{l}21^{\circ} 14.112^{\prime} \mathrm{S} \\
47^{\circ} 23.767^{\prime} \mathrm{E} \\
1124 \text { m a.s.l. }\end{array}$ & 25.ii.2006 & $\begin{array}{l}\text { R.D. Randrianiaina, } \\
\text { L. Raharivololoniaina, } \\
\text { A.F. Ranjanaharisoa }\end{array}$ \\
\hline & RNP Talatakely & $M$. sp. 47 & $\begin{array}{l}21^{\circ} 15.846^{\prime} \mathrm{S} \\
47^{\circ} 25.161^{\prime} \mathrm{E} \\
966 \mathrm{~m} \text { a.s.l. }\end{array}$ & 24.ii.2006 & $\begin{array}{l}\text { T.J. Razafindrabe, } \\
\text { D.R. Vieites, J. Patton, } \\
\text { C. Patton, M. Vences }\end{array}$ \\
\hline & RNP Maharira & $M$. sp. 47 & $\begin{array}{l}21^{\circ} 19.547^{\prime} \mathrm{S} \\
47^{\circ} 24.147^{\prime} \mathrm{E} \\
1200 \mathrm{~m} \text { a.s.l. }\end{array}$ & 26.i.2004 & $\begin{array}{l}\text { M. Vences, } \\
\text { I. De la Riva }\end{array}$ \\
\hline & Vohiparara & M. femoralis & $\begin{array}{l}21^{\circ} 14.143, \mathrm{~S} \\
47^{\circ} 23.152^{\prime} \mathrm{E} \\
1118 \mathrm{~m} \text { a.s.l. }\end{array}$ & 20.ii.2006 & $\begin{array}{l}\text { R.D. Randrianiaina, } \\
\text { L. Raharivololoniaina, } \\
\text { A.F. Ranjanaharisoa, } \\
\text { T.J. Razafindrabe, } \\
\text { D.R. Vieites, J. Patton, } \\
\text { C. Patton, M. Vences }\end{array}$ \\
\hline & Ranomafana village & M. sp. 64 & $\begin{array}{l}21^{\circ} 15.699^{\prime} \mathrm{S} \\
47^{\circ} 27.571^{\prime} \mathrm{E} \\
619 \mathrm{~m} \text { a.s.1. }\end{array}$ & 21.ii.2006 & $\begin{array}{l}\text { R.D. Randrianiaina, } \\
\text { L. Raharivololoniaina, } \\
\text { D.R. Vieites, J. Patton, } \\
\text { C. Patton, M. Vences }\end{array}$ \\
\hline Vevembe forest & & $\begin{array}{l}\text { M. femoralis } \\
\text { M. majori }\end{array}$ & $\begin{array}{l}22^{\circ} 47.686, \mathrm{~S} \\
47^{\circ} 11.228^{\prime} \mathrm{E} \\
581 \mathrm{~m} \text { a.s.1. }\end{array}$ & 10.ii.2004 & M. Vences \\
\hline
\end{tabular}

Table 2. Collection numbers and GenBank accession numbers of the tadpoles studied, as well as of the adult specimens included in the molecular analysis (marked with an asterisk). Collection acronyms are as follows: FG/MV, FGZC, TAD, ZCMV (field numbers), ZSM (Zoologische Staatssammlung München). Missing accession numbers indicate that sequences were too short or of poor quality and were therefore not submitted to GenBank.

\begin{tabular}{|c|c|c|c|}
\hline Locality & Species & ZSM- and Field number & Accession number \\
\hline Ambohitsara & M. mocquardi & $\begin{array}{l}\text { ZSM 72/2008-ZCMV } 4936 \\
\text { ZCMV 5866* }\end{array}$ & $\begin{array}{l}\text { GU975710 } \\
\text { HQ610919 }\end{array}$ \\
\hline Ambohitantely & M.femoralis & $\begin{array}{l}\text { FGZC 2124* } \\
\text { FGZC } 2144 * \\
\text { FGZC } 2145^{*} \\
\text { FGZC } 2169^{*} \\
\text { FGZC } 2170^{*} \\
\text { FGZC } 2171^{*} \\
\text { FGZC } 2187 * \\
\text { FGZC } 2118^{*} \\
\text { FGZC } 2119^{*}\end{array}$ & $\begin{array}{l}\text { HQ610904 } \\
\text { HQ610905 } \\
\text { HQ610906 } \\
\text { HQ610907 } \\
\text { HQ610908 } \\
\text { HQ610909 } \\
\text { HQ610910 } \\
\text { HQ610911 } \\
\text { HQ610912 }\end{array}$ \\
\hline \multirow[t]{2}{*}{ An'Ala } & M. argenteus & $\begin{array}{l}\text { ZSM 1573/2007-ZCMV } 3575 \\
\text { ZSM 1815/2007-ZCMV } 3516 \\
\text { ZSM 1849/2007-ZCMV } 3566\end{array}$ & $\begin{array}{l}\text { HQ610836 } \\
--- \\
---\end{array}$ \\
\hline & M.femoralis & $\begin{array}{l}\text { ZSM 1736/2007-ZCMV } 3431 \\
\text { ZSM 1554/2007-ZCMV } 3536 \\
\text { ZSM 1555/2007-ZCMV } 3537 \\
\text { ZSM 1733/2007-ZCMV } 3428 \\
\text { ZSM 1781/2007-ZCMV } 3476 \\
\text { ZSM 1834/2007-ZCMV } 3554 \\
\text { ZSM 1848/2007-ZCMV } 3572\end{array}$ & $\begin{array}{l}\text { HQ610837 } \\
\text { HQ610838 } \\
\text { HQ610839 } \\
\text { HQ610840 } \\
\text { HQ610841 } \\
\text { HQ610842 } \\
\text { HQ610843 }\end{array}$ \\
\hline
\end{tabular}


Table 2, continued.

\begin{tabular}{|c|c|c|c|}
\hline Locality & Species & ZSM- and Field number & Accession number \\
\hline & M. mocquardi & $\begin{array}{l}\text { ZSM 1540/2007-ZCMV } 3511 \\
\text { ZSM 1539/2007-ZCMV } 3510 \\
\text { ZSM 1541/2007-ZCMV } 3513 \\
\text { ZSM 1746/2007-ZCMV } 3441 \\
\text { ZSM 1761/2007-ZCMV } 3457 \\
\text { ZSM 1771/2007-ZCMV } 3469 \\
\text { ZSM 1805/2007-ZCMV } 3447 \\
\text { ZSM 1813/2007-ZCMV } 3509 \\
\text { ZSM 1844/2007-ZCMV } 3567 \\
\text { ZSM 1846/2007-ZCMV } 3570 \\
\text { ZCMV 2493* } \\
\text { ZCMV 2494 }\end{array}$ & $\begin{array}{l}\text { HQ610852 } \\
\text { HQ610853 } \\
\text { HQ610854 } \\
\text { HQ610855 } \\
\text { HQ610856 } \\
\text { HQ610857 } \\
\text { HQ610858 } \\
\text { HQ610859 } \\
\text { HQ610860 } \\
\text { HQ610861 } \\
\text { HQ610920 } \\
\text { HQ610922 }\end{array}$ \\
\hline & M. zolitschka & $\begin{array}{l}\text { ZSM 1843/2007-ZCMV } 3565 \\
\text { ZSM 1741/2007-ZCMV } 3436 \\
\text { ZSM 1759/2007-ZCMV } 3455 \\
\text { ZSM 1768/2007-ZCMV } 3464 \\
\text { ZSM 1841/2007-ZCMV } 3563\end{array}$ & $\begin{array}{l}\text { HQ610863 } \\
\text { HQ610864 } \\
\text { HQ610865 } \\
\text { HQ610866 } \\
\text { HQ610867 }\end{array}$ \\
\hline Andringitra & M.femoralis & ZCMV 5874* & HQ610918 \\
\hline Ifanadiana & M.femoralis & ZCMV $370^{*}$ & HQ610914 \\
\hline Isalo National Park & M.femoralis & ZSM 1928/2007-T 558 & HQ610844 \\
\hline Mahasoa & M. mocquardi & $\begin{array}{l}\text { ZSM 686/2008-ZCMV } 8094 \\
\text { ZCMV 8818* }\end{array}$ & $\begin{array}{l}\text { HQ610862 } \\
\text { HQ610921 }\end{array}$ \\
\hline Manantantely & M.femoralis & FGZC $271 *$ & HQ610913 \\
\hline Manombo & M.femoralis & ZCMV 464* & HQ610916 \\
\hline \multirow[t]{3}{*}{ Marojejy National Park } & M.femoralis & ZSM 1630/2007-FGZC 2955 & HQ610845 \\
\hline & $M$. sp. 43 & $\begin{array}{l}\text { ZSM 1610/2007-FGZC } 2928 \\
\text { ZCMV 2042* }\end{array}$ & $\begin{array}{l}\text { HQ610868 } \\
\text { HQ610903 }\end{array}$ \\
\hline & M.sp. 62 & $\begin{array}{l}\text { FGZC 2875* } \\
\text { FGZC 2885* } \\
\text { FGZC 2886* } \\
\text { ZCMV 2020* } \\
\text { ZCMV 2021* } \\
\text { ZCMV 2023* } \\
\text { ZCMV 2025* } \\
\text { ZCMV 2007* } \\
\text { ZCMV 2008* } \\
\text { ZCMV 2009* } \\
\text { ZCMV 2022* }\end{array}$ & $\begin{array}{l}\text { HQ610898 } \\
\text { HQ610899 } \\
\text { HQ610900 } \\
\text { HQ610892 } \\
\text { HQ610893 } \\
\text { HQ610901 } \\
\text { HQ610902 } \\
\text { HQ610894 } \\
\text { HQ610895 } \\
\text { HQ610896 } \\
\text { HQ610897 }\end{array}$ \\
\hline \multirow[t]{2}{*}{ Montagne d'Ambre National Park } & M. ambreensis & ZSM 762/2004-FG/MV 2002.1950 & HQ610870 \\
\hline & $M$. sp. 42 & ZSM 774/2004-FG/MV 2002.1957 & HQ610869 \\
\hline Ranomafana National Park & M.femoralis & $\begin{array}{l}\text { ZSM 1198/2004-TAD 2004/1385 } \\
\text { ZSM 396/2008-ZCMV } 2640 \\
\text { ZSM 1643/2007-ZCMV } 3708 \\
\text { ZSM 1696/2007-ZCMV } 3773\end{array}$ & $\begin{array}{l}--- \\
\text { HQ610846 } \\
\text { HQ610847 } \\
---\end{array}$ \\
\hline
\end{tabular}


Table 2, continued.

\begin{tabular}{|c|c|c|c|}
\hline Locality & Species & ZSM- and Field number & Accession number \\
\hline & & ZSM 188/2008-ZCMV 3821 & --- \\
\hline & & ZSM 192/2008-ZCMV 3825 & --- \\
\hline & & ZSM 257/2008-ZCMV 3675 & HQ610848 \\
\hline & & ZSM 439/2008-ZCMV 2684 & HQ610849 \\
\hline & & ZSM 472/2008-ZCMV 3703 & HQ610850 \\
\hline & & ZCMV $3095^{*}$ & HQ610915 \\
\hline & M. majori & ZSM 1684/2004-ZCMV 3761 & --- \\
\hline & & ZSM 42/2007-ZCMV 4155 & HQ610871 \\
\hline & & ZSM 93/2007-ZCMV 4132 & GU975191 \\
\hline & & ZSM 335/2007-T 172 & GU975194 \\
\hline & & ZSM 379/2007-ZCMV 4235 & GU975188 \\
\hline & & ZSM 495/2007-ZCMV 4699 & GU975187 \\
\hline & & ZSM 502/2007-ZCMV 4517 & GU975185 \\
\hline & & ZSM 609/2007-T 410 & GU975195 \\
\hline & & ZSM 682/2007-ZCMV 5391 & GU975189 \\
\hline & & ZSM 954/2007-ZCMV 5979 & GU975190 \\
\hline & & ZSM 1062/2007-T 32 & HQ610872 \\
\hline & & ZSM 1063/2007-T 168 & HQ610873 \\
\hline & & ZSM 1078/2007-T 38 & GU975192 \\
\hline & & ZSM 1285/2007-ZCMV 4417 & GU975184 \\
\hline & & ZSM 1328/2007-T 156 & GU975193 \\
\hline & & ZSM 1382/2007-ZCMV 4534 & GU975186 \\
\hline & & ZSM 1653/2007-ZCMV 3722 & HQ610874 \\
\hline & & ZSM 1676/2007-ZCMV 3749 & HQ610875 \\
\hline & & ZSM 1684/2007-ZCMV 3761 & HQ610876 \\
\hline & & ZSM 1699/2007-ZCMV 3776 & -- \\
\hline & & ZSM 1700/2007-ZCMV 3777 & --- \\
\hline & & ZSM 1701/2007-ZCMV 3778 & --- \\
\hline & & ZSM 171/2008-ZCMV 3806 & --- \\
\hline & & ZSM 202/2008-ZCMV 3835 & --- \\
\hline & & ZSM 203/2008-ZCMV 3836 & HQ610877 \\
\hline & & ZSM 229/2008-ZCMV 3627 & HQ610878 \\
\hline & & ZSM 256/2008-ZCMV 3672 & HQ610879 \\
\hline & & ZSM 429/2008-ZCMV 2674 & HQ610879 \\
\hline & & ZSM 441/2008-ZCMV 2686 & HQ610880 \\
\hline & & ZSM 447/2008-ZCMV 2694 & HQ610881 \\
\hline & & ZSM 445/2008-ZCMV 2690 & HQ610882 \\
\hline & & ZSM 455/2008-ZCMV 2698 & HQ610883 \\
\hline & & ZSM 473/2008-ZCMV 3704 & HQ610884 \\
\hline & M.sp. 47 & ZSM 456/2008-ZCMV 2699 & HQ610886 \\
\hline & & ZSM 1697/2007-ZCMV 3774 & --- \\
\hline & & ZSM 254/2008-ZCMV 3669 & HQ610887 \\
\hline & & ZSM 315/2008-ZCMV 3620 & HQ610888 \\
\hline & & ZSM 478/2008-ZCMV 3724 & HQ610889 \\
\hline & & ZSM 506/2008-ZCMV 3791 & --- \\
\hline & & ZCMV 2838* & HQ610923 \\
\hline & M.sp. 64 & ZSM 401/2008-ZCMV 2646 & HQ610890 \\
\hline & & ZCMV 9291 (to be catalogued in ZSM) & HQ610891 \\
\hline Torotorofotsy & M.femoralis & ZCMV 937* & HQ610917 \\
\hline Vevembe forest & M.femoralis & ZSM 1385/2004-TAD 2004/07 & HQ610851 \\
\hline & M.sp. 64 & ZCMV $644 *$ & HQ610924 \\
\hline & M. majori & ZSM 1384/2004-TAD 6 Vevembe & HQ610885 \\
\hline
\end{tabular}




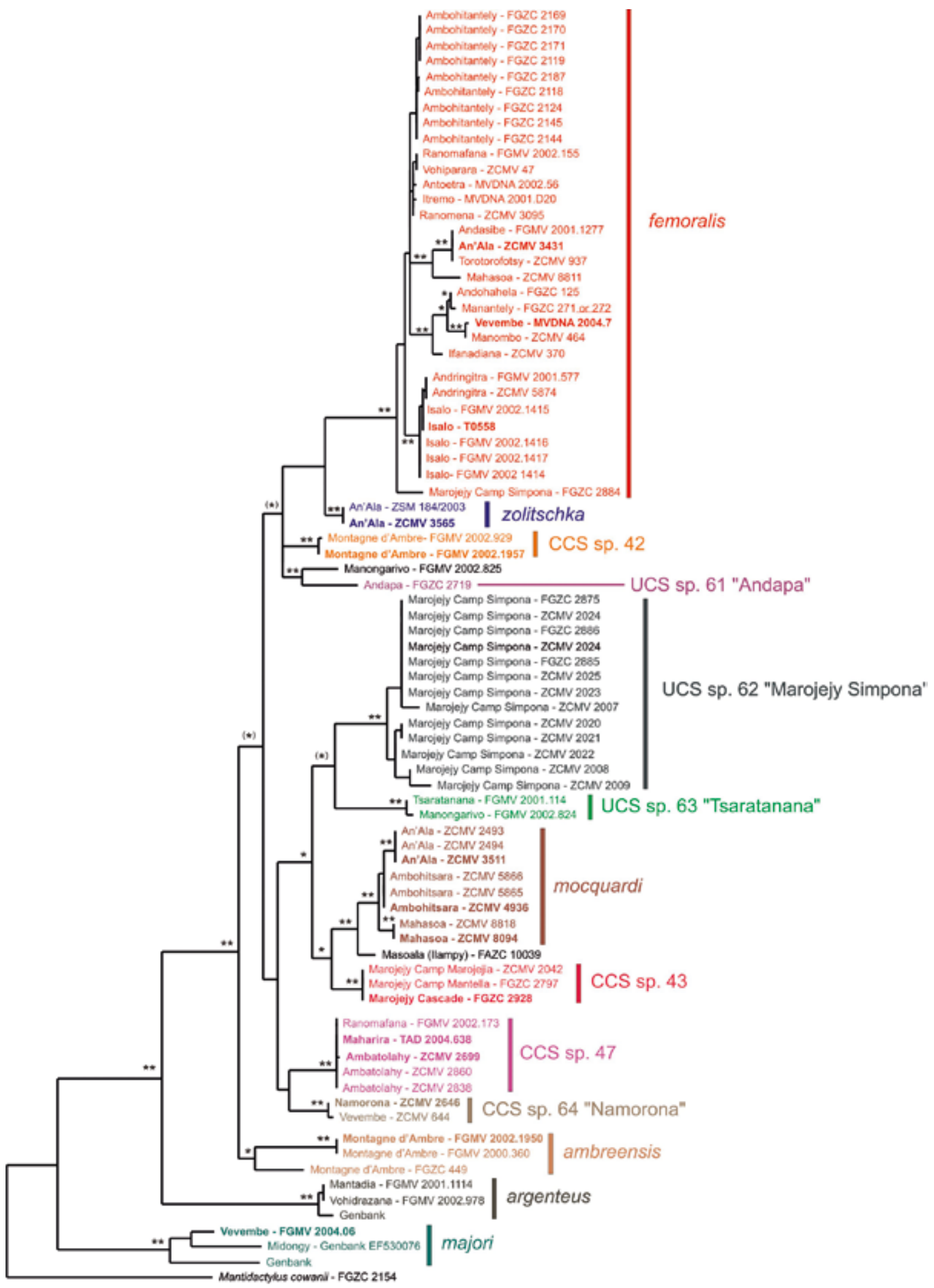

- 0.005 substitutions/site 
vegetation, and canopy cover of the stream; the density of shrubs, small trees, large trees, depth of forest floor leaf litter, slope of the forest floor, and canopy cover of the forest (exact definitions of these variables are in Strauß et al., 2010).

For each stream, $30 \mathrm{~m}$ long stream sections were as exhaustively as possible sampled for tadpoles, separately for all available microhabitats within the section. These microhabitats were predefined based on the structure of the ground substrate (categories rock, gravel, leaves, sand) and by stream velocity, with the categories 'fast' (obviously running) and 'slow' (almost stagnant) resulting in eight different possible types of microhabitat. To test for microhabitat preferences, the frequency of the microhabitats available was recorded for each stream. For details of sampling methods see Strauß et al. (2010).

Tadpole sampling was conducted in the wet season (January and February) 2008 and repeated in a subset of the streams during the dry season (July) 2008. Statistical analyses were exclusively based on data from the rainy season as both the presence and abundance of Ochthomantis tadpoles during the dry season were very limited. Analysis were performed in R 2.9.2 (R Development Core Team, 2009) including library car (Fox, 2008).

To identify the habitat variables of the stream and the surrounding forest that correlate with the presence of Ochthomantis tadpoles (all species pooled), first a principal component analysis (PCA) was performed. PCA was performed on the correlation matrix in order to standardise for the influence of unequal variance. To evaluate data outliers and linear interdependence of variables, box-plots and pair-plots (Zuur et al., 2007) were used. As PCA requires multinormality of data, box-cox-power-transformations (Box and Cox, 1964) were applied when necessary. The significance of the PC loadings was assessed based on the bootstrappedeigenvector method as suggested by Peres-Neto et al. (2003). The number of meaningful PCs was estimated by a scree plot (Zuur et al., 2007). A multiple logistic regression (generalized linear model, GLM, with bino- mial errors) with the first three PCs as independent variables and the presence/absence of Ochthomantis tadpoles as binary dependent variable was performed to extract the key habitat variables important for breeding site choice of Ochthomantis frogs. Independent terms and interaction terms were deleted sequentially from the full model based on the Akaike Information Criterion (Burnham and Anderson, 1998) until the minimum adequate model was reached. In order to quantify microhabitat preference of Ochthomantis tadpoles within streams, Ivlev's electivity index E (Ivlev, 1961) was calculated for each Ochthomantis species occurring in RNP. $E$ is defined as $E=(r-p) /(r+p)$ with $r$ being the proportions of the microhabitats used (using tadpole abundance) and $p$ the proportion of microhabitats available. To test whether the E values differ between the single species, a factorial ANOVA was run with $\mathrm{E}$ as dependent variable and the factors 'species' and 'microhabitat' as independent variables. This provides information whether $\mathrm{E}$ is different for the different microhabitats and whether observed differences vary between species. Only the three abundant species were included in this analysis.

\section{Results}

\section{Larval and adult diversity in Ochthomantis}

The molecular tree of 81 adults and larvae of the Mantidactylus subgenera Ochthomantis and Maitsomantis (Fig. 1) supports previous conclusions (Glaw and Vences, 2004; Vieites et al., 2009) of a high undescribed species diversity of Ochthomantis. Adult specimens of all described species in the genus $(M$. ambreensis, M. femoralis, M. majori, M. mocquardi, $M$. zolitschka) were recovered as monophyletic and genetically distinct groups, together with their respectively assigned tadpoles. In addition, several clusters were identified that we here define as candidate species according to the terminology and criteria of Vieites et al. (2009). Although the tree provides

Fig. 1. Bayesian inference tree calculated on the basis of up to 500 base pairs of the mitochondrial 16S rRNA gene. Asterisks denote Bayesian posterior probability values: $(*),>90 \% ; *>95 \%, * *>99 \%$. Different species and candidate species are indicated by different colours. Sequences from tadpoles are in bold. The tree shows clusters of individuals (adults and tadpoles) assigned to species and candidate species based on their mitochondrial similarity, but was not primarily reconstructed to assess the phylogeny among Ochthomantis for which a more extensive multi-gene dataset would be necessary. Note that the tree does not include a few available sequences (M. majori, adults from Ranomafana and tadpole ZCMV 3761 from Ranomafana; M. femoralis, tadpole ZCMV 2640 from Ranomafana) because these contained too many missing data; species identification on the basis of these short sequences was, however, unambiguous in analyses based on an adjusted alignment of ca. $200 \mathrm{bp}$. Two adult specimens were not assigned to species or candidate species: FAZC 10039 (possibly M. mocquardi), FG/MV 2002.825 (possible additional UCS from Manongarivo). 
significant Bayesian posterior probabilities for various relationships among species in the subgenus Ochthomantis, we emphasize that its purpose is not to provide a phylogenetic hypothesis but merely to visualize molecular differentiation among clusters of individuals that correspond to species and candidate species.

Because we were able to assign adult specimens (Fig. 2) and larvae (Fig. 3) to most of the molecular clusters, we understand which of these are supported as evolu- tionary independent units by the congruence of independent data sets, mainly larval morphology and mitochondrial DNA sequences. Consequently, we defined as confirmed candidate species (CCS) those where congruent molecular and morphological results were available. Others were only identified as molecular clusters (with pairwise 16S divergences of $>3 \%$ to other clusters; Vieites et al., 2009) without additional evidence from morphology of tadpoles, or morphology or bioacoustics

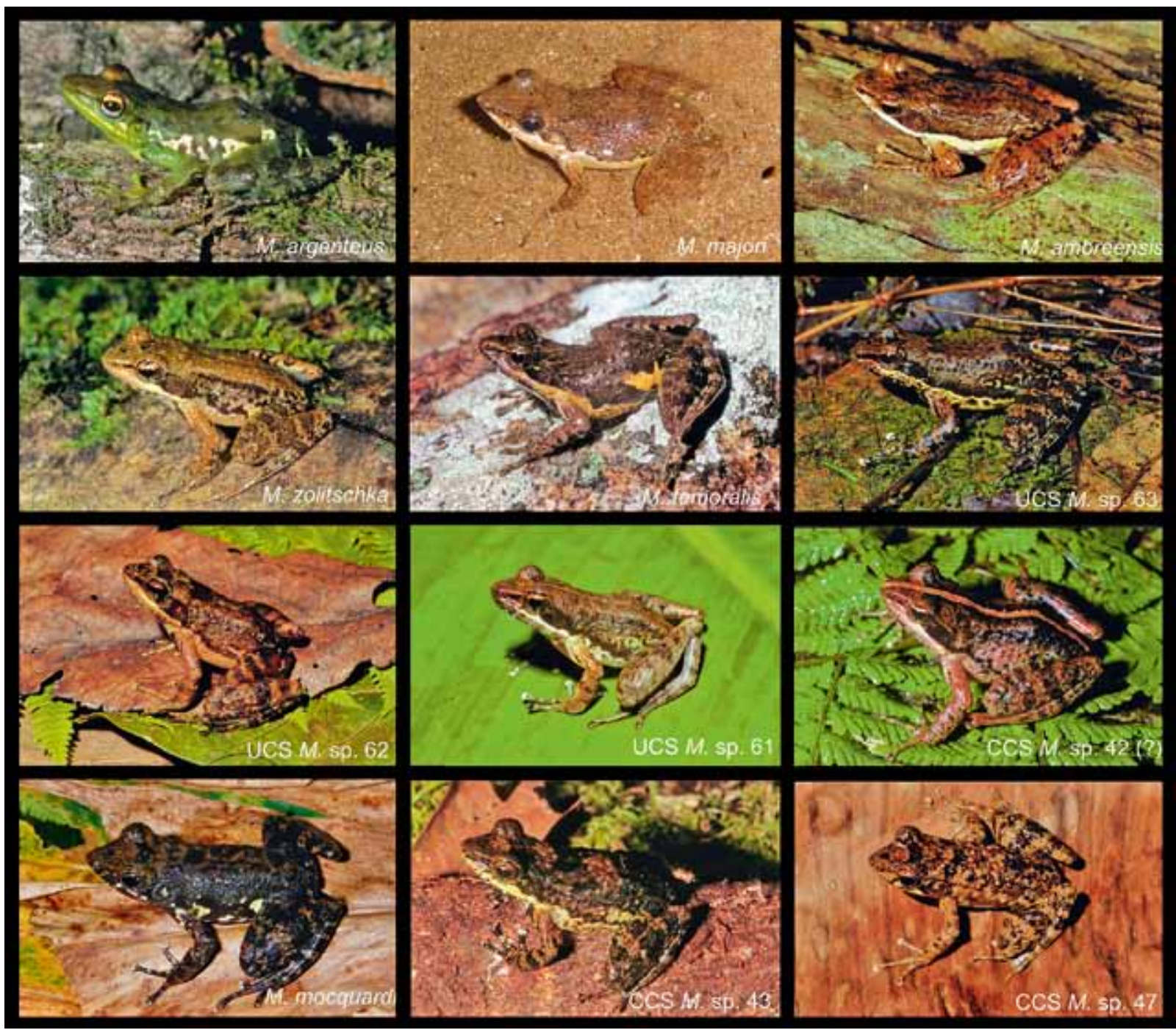

Fig. 2. Diversity of adults in the Mantidactylus subgenera Maitsomantis (M. argenteus) and Ochthomantis. Morphological identification of several species is unambiguous: Mantidactylus argenteus (FG/MV 2002.537 from Ranomafana), M. majori (specimen from Ranomafana, not collected), M. ambreensis (specimen from Montagne d'Ambre), M. zolitschka (paratype ZFMK 60116 from An'Ala). Others were identified by DNA barcoding, i.e., on the basis of the molecular tree in Fig. 1: M. femoralis (FG/MV 2002.56 from Antoetra); M. mocquardi (ZCMV 5865 from Ambohitsara), M. sp. 63 (specimen from Tsaratanana), M. sp. 62 (ZSM 309/2005-FGZC 2885 from Marojejy, Camp Simpona), M. sp. 61 (ZSM 221/2005-FGZC 2719 from Andapa), M. sp. 42 (specimen from Montagne d'Ambre, assignment to this confirmed candidate species is tentative and not based on molecular data), M. sp. 43 (ZSM 253/2005-FGZC 2797 from Marojejy Camp Mantella), M. sp. 47 (specimen from Ambatolahy). 
of adults, and are therefore defined as unconfirmed candidate species (UCS). Both CCS and UCS were named following Vieites et al. (2009) who numbered all candidate species in Mantidactylus from 1-60. The four additional candidate species identified herein are consecutively numbered 61-64. While the present study was under review, a publication by Padial et al. (2010) proposed a new scheme for naming candidate species. We endorse this new proposal and will apply it in further studies, but have here refrained to apply it yet to candidate species in Ochthomantis because we felt that consistency with the candidate species names of Vieites et al. (2009) is preferable at this point of time.

The following accounts briefly characterize the various species and candidate species by their larval and adult morphology, as far as currently possible. Detailed descriptions of the tadpoles are provided in the appendix, measurements and morphometric ratios of DNA voucher specimens in Tables 3-4, a comparison of the main morphological features of the different species in Table 5, and a summary of collection localities and specimens examined in Tables 1-2. Interestingly, in Ochthomantis, larval characters especially of the oral disk proved to be highly derived in all species and provided various clear morphological differences among species, whereas morphological differentiation of adults is more subtle (see also Glaw and Vences, 2004; Rabibisoa et al., 2008). In the following, species are therefore roughly listed by their degree of larval specialization. We first provide some detailed morphological data for one of the least specialized species, Mantidactylus femoralis, and then highlight distinctive features and specializations of the other species.

Mantidactylus femoralis. - Following Glaw and Vences (2004) we define M. femoralis as the most widespread and most common species in the subgenus Ochthomantis. Adults of this species are characterized by medium size, a more or less tubercular back, and a distinct and often rather large yellow inguinal patch (Fig. 2). According to the molecular data herein, this species is known from the South East (Andohahela, Manantantely, Vevembe, Manombo) to the North East (Marojejy), including many localities in the intervening areas (in a south-north direction: Andringitra; Isalo; Antoetra; Itremo; Ifanadiana; Ranomafana including Vohiparara, Ranomena and other sites; An'Ala; Andasibe; Torotorofotsy; Ambohitantely; Mahasoa).

The tadpole of M. femoralis (based on ZSM 1736/ 2007-ZCMV 3431, Gosner stage 28 from An'Ala (see appendix and Fig. 10 for preserved tadpole) and on ZSM 188/2008-ZCMV 3821 from Ranomafana (Fig. 3 for tadpole in life) has an elliptical body, a narrowly rounded snout in dorsal view and a constriction behind the point where the maximal body width is attained (between the proximal $2 / 5$ and $3 / 5$ of the body). In lateral view the body is depressed; the maximal body height is attained between the proximal $3 / 5$ and $4 / 5$ of the body; and the snout is narrowly rounded. Eyes are small, not visible in ventral view, positioned high dorsally and directed laterally, and situated between the proximal 3/10 and 4/10 of the body. The distance between the eyes is moderately wide. Nares are small, rounded, marked with a marginal rim, positioned high dorsally and oriented anterolaterally, situated nearer to snout than to eye and below eye level. The distance between nares is moderately wide. A red patch is present on the back of the nares. The spiracle is sinistral, moderately large, directed posteriorly, visible from dorsal and ventral views, and perceptible from lateral view. Its inner wall is free from the body and formed such that the aperture opens posteriorly. The opening is rounded, situated between the proximal $3 / 5$ and 4/5 of the body, located high and at the height of the point where the axis of the tail myotomes contacts the body. The vent tube is dextral, moderately long, attached to the ventral fin and its inner wall is present. The tail is short; the caudal musculature is moderately developed; the tail muscle reaches the tail tip. Fins are very low; the dorsal fin originates on the tail muscle on the proximal $1 / 5$ of the tail and the ventral fin originates at the ventral terminus of the body. The maximal tail height is located at a position after the proximal $2 / 5$ of the tail. The lateral tail vein and the myosepta are slightly visible on the proximal $3 / 4$ of the tail musculature, the point where the axis of the tail myotomes contacts the body is high and the axis of the tail myotomes is parallel with the axis of the trunk. The tip of the tail is narrowly rounded.

The oral disk (Fig. 4) is moderately large, reduced, not emarginated, positioned ventrally, and directed anteroventrally. It is visible in dorsal view and the upper labium is a continuation of the snout. There is a single row of marginal papillae interrupted by a wide gap on the upper labium and the gap on the lower labium is absent. There are 59 marginal papillae and 69 submarginal papillae which are complete on the lower labium and laterally on the upper labium. Very short but moderately wide papillae with rounded tips exist and the longest marginal and submarginal papillae measure $0.08 \mathrm{~mm}$. Papillae are visible in dorsal view. LTRF is 
$3(2-3) / 3(1-2) . A_{1}$ is moderately long and the density of its keratodonts is $39 / \mathrm{mm}$. The gap in the first upper interrupted row is wide. Lower keratodont rows form a chevron, $\mathrm{P}_{1}$ and $\mathrm{P}_{2}$ are interrupted and $\mathrm{P}_{2}$ and $\mathrm{P}_{3}$ are scattered. Keratodonts are very short and distinguishable. Distal keratodonts have the same lengths as those in the centre. There is considerable space between marginal papillae and keratodont rows. Jaw sheaths are moderately wide and poorly keratinized. The upper sheath has a short widely rounded medial convexity. The edge of the medial convexity is black coloured and the remainder is whitish. Serrations are finely pointed. The lower sheath is $\mathrm{V}$-shaped, partially keratinized and totally hidden by the upper one.

In life, the tadpole is generally uniformly dark (Fig. 3). Dorsal sides of the head and trunk are covered by dark patches and gold blotches. Ventrally, oral disk and gular regions are transparent, the branchial region is reddish, and the abdominal surface is transparent. The tail musculature is yellow-reddish and covered by brown reticulations. Fins are transparent and the dorsal fin has brown reticulations. In preservative, the tadpole is uniformly dark brown. Brown pigment is positioned in deep integumental layers and covers the dorsum and flank of the body. Some dark brown patches are scattered on the dorsal skin. Ventrally, the oral disk, gular and branchial regions are patched; the abdominal surface is pale. The intestinal coils are perceptible and regular spiral shaped. The lower part of the flanks has the same colouration as ventrally and the intestinal coils are perceptible laterally. The tail musculature is overlain by dark brown reticulations. Fins are pale; the dorsal fin is covered with sparse brown reticulations.

Six DNA voucher specimens from the same locality, eight DNA voucher specimens from Ranomafana National Park, one DNA voucher specimen from Vevembe forest and one DNA voucher specimen from Isalo National Park attributed to M.femoralis show the same oral disk morphology (Fig. 4), but one tadpole from Ranomafana National Park differs by its LTRF of 2(2)/3(1-2). A single tadpole from Marojejy National Park assigned to M.femoralis (by molecular data) differs by some variables like its lower numbers of only 43 marginal and 30 submarginal papillae.

Mantidactylus ambreensis. - A species easily recognizable by its adult colouration (Fig. 2), with a rather uniform dark brown dorsum with a continuous white (rarely yellowish) lateral line. This species is known from the North (Montagne d'Ambre) and Sambirano regions (Benavony, western slope of the Tsaratanana massif; Glaw and Vences, 2007). We have also recently collected specimens from the western slopes of the Makira plateau near Mandritsara (unpublished data). The tadpole of this species (based on ZSM 762/2004FG/MV 2002.1950, Gosner stage 25 from the type locality Montagne d'Ambre National Park; see Figs 4 and 11) is differentiated from M. femoralis by its beige-brownish colouration in preservative (no data on

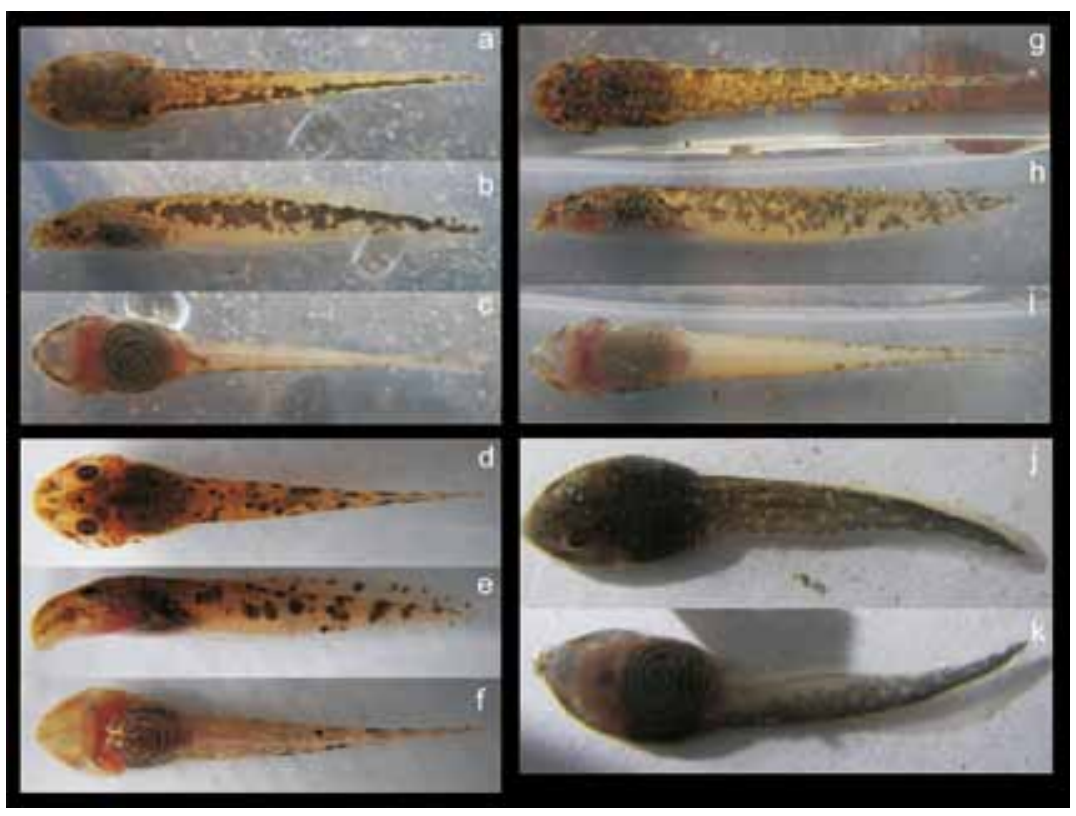

Fig. 3. Colouration in life of tadpoles of four species in the Mantidactylus subgenus Ochthomantis, all collected in Ranomafana National Park and surroundings. M. femoralis (ZCMV 3821 ZSM 188/2008) - (a) dorsal view, (b) lateral view, (c) ventral view. M. majori (T 09/746, to be catalogued in ZSM) - (d): dorsal view, (e) lateral view, (f) ventral view. $M$. sp. 47 (ZCMV 3791 - ZSM 506/2008) - (g) dorsal view, (h) lateral view, (i) ventral view. $M$. sp. 64 (ZCMV 9291, to be catalogued in ZSM) - (j) dorsal view, (k) ventral view. 
life colouration is available). The dorsal sides of the head and trunk and the higher part of the flank are beige with light brown reticulations between nares and eyes, on the frontal and along the vertebral area. The tail musculature is beige with brown blotches which fuse in some areas to form a network. Differences are also found regarding the body form in dorsal view, the size of the eyes and nares, the distance between the eyes and between the nares, the direction of the spiracle, the location of the spiracle opening, the length of the vent tube and the tail, the origin of the dorsal fin, the size of the caudal musculature, the visibility of the myosepta and the oral disk, the number of papillae, the state of $\mathrm{P}_{2}$, the LTRF which is $2(2) / 3(1-2)$, the density of keratodonts in $\mathrm{A}_{1}$, the size of the gap in $\mathrm{A}_{2}$, and the shape of the medial convexity. The examination of four additional specimens belonging to the same series (but not identified by DNA barcoding) revealed similar morphological characteristics, mainly in the oral structure, but the LTRF showed some variation: 2(2)/3(1-2) and $3(2-3) / 3(1-2)$.

Mantidactylus zolitschka. - So far this species, characterized mainly by its rather small adult size and low sexual size dimorphism (Glaw and Vences, 2004) is only known from its type locality, An'Ala. Its tadpole (based on ZSM 1843/2007-ZCMV 3565, Gosner stage 27 from An'Ala; see Figs 4 and 12) is characterized by the faintness of the pigmentation of the keratodonts and the narrow elongated shape of the upper jaw sheath. The external morphology of the tadpoles differs from that of the tadpoles of $M$. ambreensis by body size, external pattern and colouration, LTRF, number of papillae and the configuration of the medial convexity. The tadpoles of $M$. zolitschka are similar to those of $M$. femoralis by the presence of a small constriction at midbody, but they can be differentiated by their colouration in preservative (no data on life colouration is available). Mantidactylus zolitschka tadpoles are generally beige-brownish with a light brown network of pigments positioned in deep integumental layers. These pigments cover the major surface of the dorsal sides of the head and trunk and the flank. Dark brown spots form patches which are scattered on the dorsal skin. Dark brown spots coalesce to form networks which are scattered irregularly on the tail musculature. Further differences to M. femoralis are the shape of the snout, the size and the direction of the eyes, the presence of reddish patches on the back of the nares, the distance between the nares and their direction, the location of the spiracle opening, the size of the caudal musculature, the origin of the dorsal fin, the visibility of the myosepta and the lateral tail vein, the shape of the tail tip, the direction of the oral disk, the size of the dorsal gap of the marginal papillae, the number of marginal and submarginal papillae, the shape and the size of papillae, the density of keratodonts on $A_{1}$, the state of $P_{2}$, and the size and shape of the upper jaw sheath. Four DNA voucher specimens from the same locality attributed to M. zolitschka show the same oral disk configuration and pigmentation, one tadpole having a different LTRF, 2(2)/3(1-2).

Mantidactylus argenteus. - This species, classified in a separate subgenus Maitsomantis, is characterized by a very distinct adult morphology with a small body size, greenish dorsal colour, and very large and semitransparent tympanum in males. However, its larva (already described previously by Vejarano et al., 2006) is in general similar to that of species of Ochthomantis: The tadpole (based on ZSM 1573/2007-ZCMV 3575, Gosner stage 27 from An'Ala; see Figs 4 and 13) is characterized by (1) its unique colouration: presence of transversal clear bands between nares and eyes, between eyes and spiracle and before the body-tail junction, and a longitudinal clear band on the tail dorsum, (2) the protuberated snout, and (3) its small eyes and short spiracle. This tadpole is similar to that of femoralis-like tadpoles (and differs from the mocquardilike, $M$. mocquardi and $M$. sp. 64, and the majori tadpoles) by the presence of labial teeth. The general configuration of the oral disk of $M$. argenteus tadpoles is similar to that of femoralis-like tadpoles (M. femoralis, M. ambreensis, M. zolitschka, M. sp. 42, M. sp. 43 and $M$.sp. 47), except a few characteristics, like the low number of papillae. The LTRF (2(2)/3(1-2) is similar to that of $M$. ambreensis and $M$. sp. 43, but the upper sheath configuration (narrowly pointed) is similar to that of M. zolitschka.

Mantidactylus sp. 42. - This candidate species has so far been recorded only from Montagne d'Ambre. Diagnostic features of the adult are not well understood since it cannot be excluded that more than one species of the subgenus Ochthomantis occur in Montagne d'Ambre (in addition to $M$. ambreensis). The single tadpole assigned to $M$. sp. 42 (ZSM 774/2004-FG/MV 2002.1957, Gosner stage 28 from Montagne d'Ambre National Park; see Figs 4 and 14) resemble M.femoralis tadpoles regarding the LTRF (3(2-3)/3(1-2)) and its general colouration except the low density of the reticulations on the tail musculature and the clear surface on 
the dorsum in preservative (no data on life colouration is available). Some parameters like the shape of the snout in lateral view, the location of the spiracle opening, the tail length, the origin of the dorsal fin, the direction of the oral disk, the size of the dorsal gap of the papillae, the low number of papillae, the shape and the size of the papillae, the size of $A_{1}$ and the density of its papillae, and the size of the gap on the $\mathrm{A}_{2}$ also appear to differentiate the tadpoles of these two species. Mantidactylus sp. 42 tadpoles have high similarities to those of M. ambreensis in their external pattern and colouration but they can be differentiated generally by larger body size, the LTRF with three instead of two upper keratodont rows, and the number of papillae. Mantidactylus sp. 42 tadpoles can be distinguished from those of $M$. zolitschka by their external colouration and pattern and relevant differences in keratodont density and papillae number, but they have the same LTRF. Mantidactylus sp. 42 is also characterized by its keratodont rows which do not form a real chevron pattern as in other femoralis-like tadpoles.

Mantidactylus sp. 43. - A species phylogenetically close to M. mocquardi but differing in its tadpole morphology. We found adult and larval specimens at lowland sites in the Marojejy massif, and similar to $M$. mocquardi, adults had conspicuous silvery colour with a black pattern on the venter (Fig. 2). The single tadpole assigned to this candidate species (ZSM 1610/ 2007FGZC 2928, Gosner stage 25 from Marojejy National Park; see Figs 4 and 15) is easily distinguished from $M$. femoralis, M. ambreensis, M. zolitschka and M. sp. 42 tadpoles by its uniformly pale colouration in preservative (no data on life colouration is available). Dorsal surface of body and of tail muscle are flecked. Speckles are positioned in deep integumental layers, darker patches dissipate between eyes and along the vertebral area and brown spots disperse on dorsal and dorsolateral parts of body. The tail musculature has brown mottles which coalesce in some areas to form sparse reticulations. Fins are pale, with speckles especially on the proximal $1 / 4$ of the dorsal fin. This tadpole is characterized by the scattered state of $\mathrm{A}_{1}$, and its LTRF differs from those of M. femoralis, M. zolitschka and $M$. sp. 42 (but not from M. ambreensis) by having two instead of three upper rows of keratodonts. The presence of keratodonts makes it also easy to differentiate it from M. mocquardi (which lacks keratodonts).

Mantidactylus sp. 47. - This confirmed candidate species is known from various sites in the Ranomafana region. Especially at Ambatolahy it is a very common species in a fast-flowing large stream where adult males and females are regularly found on large boulders next to the water. Females are much larger than males. In the adult stage, the ventral side is not conspicuously silvery, and there is no large and distinct yellow inguinal patch (Fig. 2). The tadpole of Mantidactylus sp. 47 (based on ZSM 456/2008-ZCMV 2699, Gosner stage 31 from Ambatolahy next to Ranomafana National Park; see Figs 3, 4 and 16) has a small constriction anterior to the point where the maximal body width is attained. It shares the LTRF with $M$. femoralis, $M$. zolitschka and $M$. sp. 42 tadpoles (with three upper keratodont rows), but differs from M. ambreensis and $M$. sp. 43 (with only two upper rows). It can also be differentiated from the tadpoles of $M$. femoralis, $M$. ambreensis and $M$. sp. 42 by its variegated light brown colouration. It is characterized by the presence of slightly visible domino-like structure on the dorsum. In life, the body is covered by brown patches in deep integumental layers that are condensed especially between the eyes and on the vertebral region. Some dark brown and golden patches spread over the skin. Ventrally, gular region beige, branchial region reddish and abdominal surface transparent. Tail musculature beige with dark brown dots forming patches. Fins transparent, dorsal fin with many patches than the ventral fin. In preservative, it is largely brownish. Light brown pigment in deeper integument layers covers the dorsum and flanks of the body. Dark brown patches disperse on the skin. Brown spots coalesce to form networks which spread irregularly on the tail musculature. Fins are pale and the dorsal fin has some brown reticulations. Five additional DNA voucher specimens attributed to this species from the same locality and many additional specimens belonging to these series agree in most cases with the typical oral disk configuration (Fig. 4) and the external pigmentation of this species. The LTRF shows some variation: 2(2)/3(1-2) and 3 (2-3)/3(1-2).

Mantidactylus mocquardi. - We consider as M. mocquardi a species characterized, in the adult stage, by a relatively large size, especially of some females, a somewhat tubercular dorsum, small and indistinct yellow inguinal patch, and distinct silvery belly (with or without black pattern; Fig. 2). We confirm the taxonomic rationale of Glaw and Vences (2004) in assigning the nomen mocquardi to this species, because in the Northern Central East of Madagascar where the type locality of $M$. mocquardi is located, no other species except the 
one with silvery bellies was found which would be characterized by a large size of females and thus would morphologically conform with the $M$. mocquardi holotype (which is a large-sized female as well). Based on molecular data, we observed M. mocquardi at Ambohitsara, An'Ala, and Mahasoa forest.

The tadpole of Mantidactylus mocquardi (based on ZSM 1540/2007-ZCMV 3511, Gosner stage 25 from An'Ala; see Figs 4 and 17) is characterized by its light beige-brownish colouration in preservative, no data of the life colouration is available. Light brown blotches positioned in deep integumental layers form dark patches between nares and eyes and along the vertebral area and flank of the body. Some dark brown patches are scattered irregularly on the skin. The tail musculature is beige with a few patches which are dissipated irregularly. Fins are pale, with brown blotches in the dorsal fin. A reddish patch on the back of the nares is present. This tadpole has a very characteristic oral disk. It has a long narrowly pointed medial convexity, no keratodonts, a few short to moderately long and moderately large papillae, but no dorsal gap of marginal papillae (Fig. 4). In comparison with the femoralis-like tadpoles, the main difference is the absence of keratodonts and the state of the papillae. Nine additional DNA voucher specimens from the same locality and one DNA voucher specimen from Ambohitsara-Tsitola assigned to this species show the same characteristic oral disk configuration and the same external pigmentation.

Tadpoles (ZSM 686/2008-ZCMV 8094; Fig. 18) collected at Mahasoa forest differed by several external parameters but are here preliminarily assigned to M. mocquardi because genetically, this population is very similar to the other populations examined. The lack of keratodonts allows distinguishing these tadpoles from those of $M$. sp. 43 (the next closest relative of $M$. mocquardi). The tadpole has a rather large size in comparison to all other tadpoles studied, and a palebrownish colouration in preservative (no data on life colouration is available). Light pale brown pigment covers the dorsum and is condensed especially behind the eyes, on the vertebral region and on the flank of the body. Some dark brown patches are scattered on the skin. The tail musculature has light brown speckles and dark brown spots which form patches. Fins are pale and the dorsal fin has brown spots which group to form patches. On the ventral fin, patches spread around tail tip. It has also the typical M. mocquardi oral disk. It furthermore is the only tadpole with a position of the maximal body height in the distal $1 / 4$. Differences to
M. mocquardi are in the shape of the snout in lateral view, the configuration and the form of the spiracle opening, the length of the tail, the origin of the dorsal fin, the location of the maximal tail height, the position and the direction of the oral disk, the low number of papillae, and the size of the medial convexity. Four additional specimens belonging to the same series (but not identified by DNA barcoding) have the same external morphology as the voucher specimen including oral disk configuration.

Mantidactylus sp. 64. - This candidate species was first discovered by its deviant tadpole morphology, based on specimens from the Ranomafana area. So far, nothing is known about its adult morphology, although one adult has been collected at Vevembe (not available for morphological examination in the framework of this study). Based on mitochondrial DNA sequences this species appears to be closely related to $M$. sp. 47 (Fig. 1). Its tadpole (based on ZSM 401/2008-ZCMV 2646, Gosner stage 39 from Ranomafana National Park (Figs 4, and 19) for the preserved tadpole and on ZCMV 9291 - not yet catalogued in ZSM (Fig. 3) for the living tadpole) is characterized by its reddish-brown colouration in life. The body and the tail are covered by brown blotches which are condensed and give a dark brown colouration to the tadpole. Ventrally, gular region beige, branchial regions reddish, abdominal surface beige. In preservative, it is dark. Brown pigment covers the dorsum and flank of the body, and dark brown patches are scattered on the skin. The tail musculature is pale and covered by dark brown reticulations. Fins are pale and have brown reticulations close to the tail tip. This tadpole is similar to that of $M$. mocquardi (and differs from the femoralis-like tadpoles) by the configuration of its oral disk, i.e. absence of keratodonts and of a dorsal gap of marginal papillae. However, the pigmented and moderately wide oral disk with rather small and short conical papillae is unique to this species. There are further morphological differences to $M$. mocquardi, like the uniformly dark colouration that the tadpoles of this species have. In lateral view, the snout is narrowly rounded (broadly rounded in $M$. mocquardi). The eyes are situated between the proximal $2 / 10$ and $3 / 10$ of the body (vs. between the proximal $3 / 10$ and 4/10 in $M$. mocquardi). The vent tube is moderately long, the tail is long, tail musculature is moderately developed and the tail tip is narrowly rounded, and the medial convexity is short and widely rounded (vs. short vent tube, short 


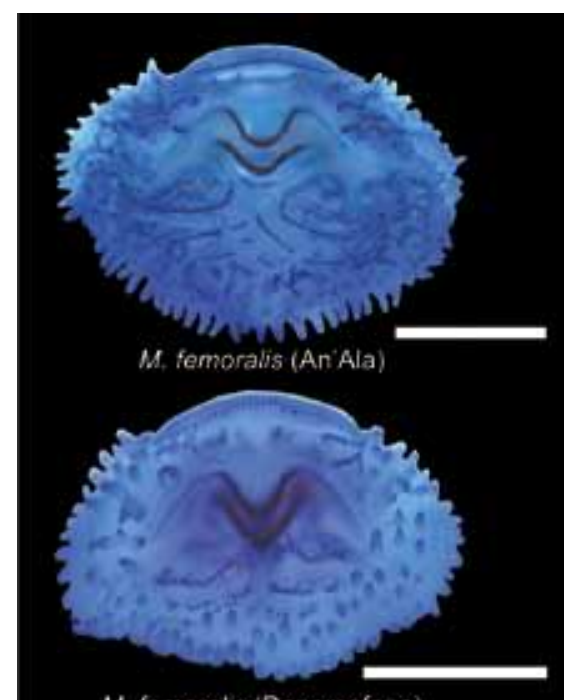

M. femoralis (Ranomafana)

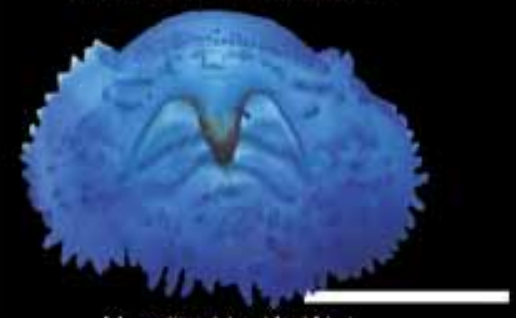

M. zolitschka (An'Ala)

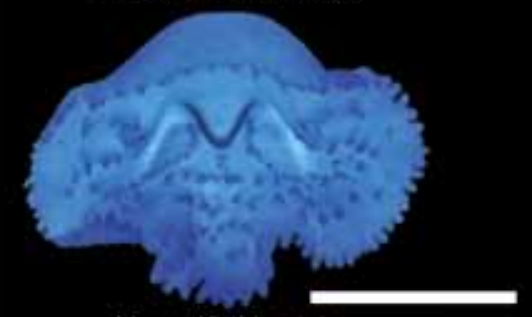

M. sp. 43 (Marojejy)

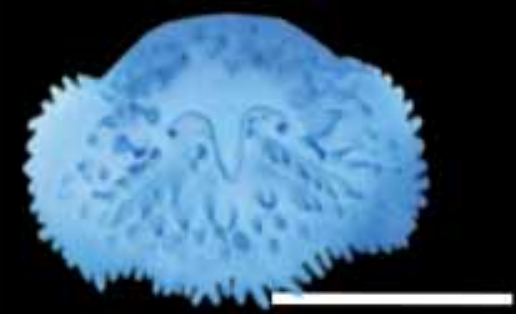

M. mocquardi (Ambohitsara)

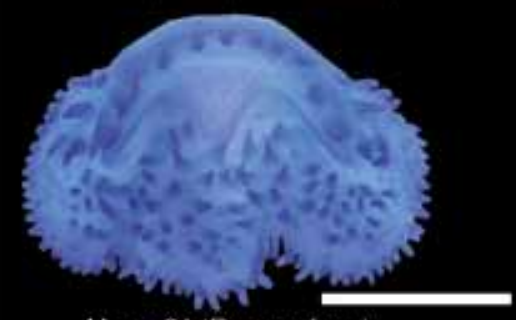

M. sp. 64 (Ranomafana)
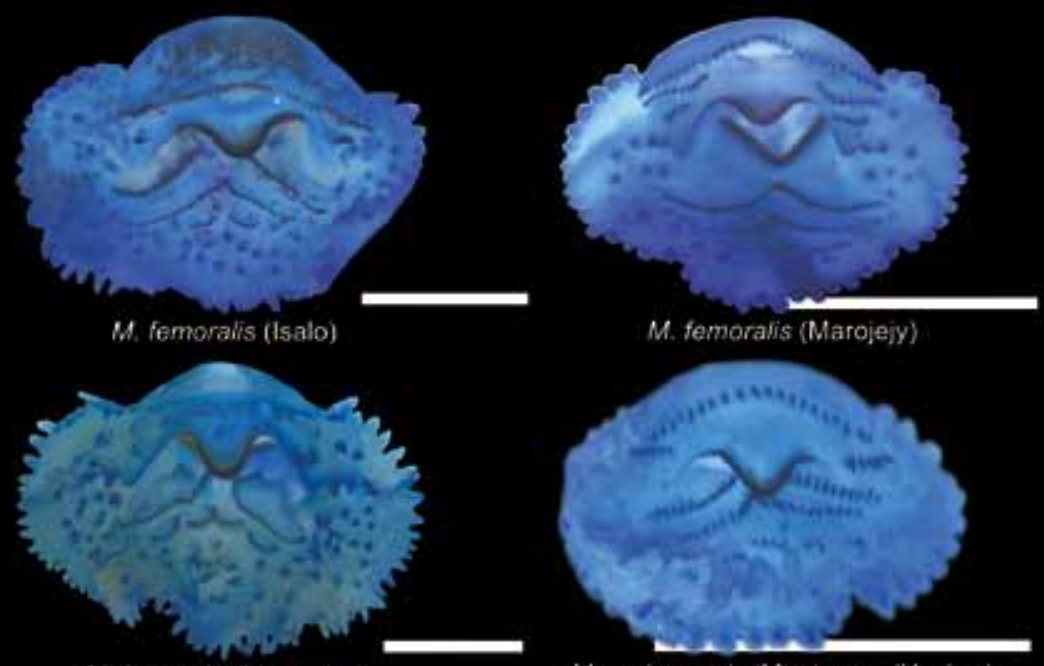

M. femoralis (Vevembe)
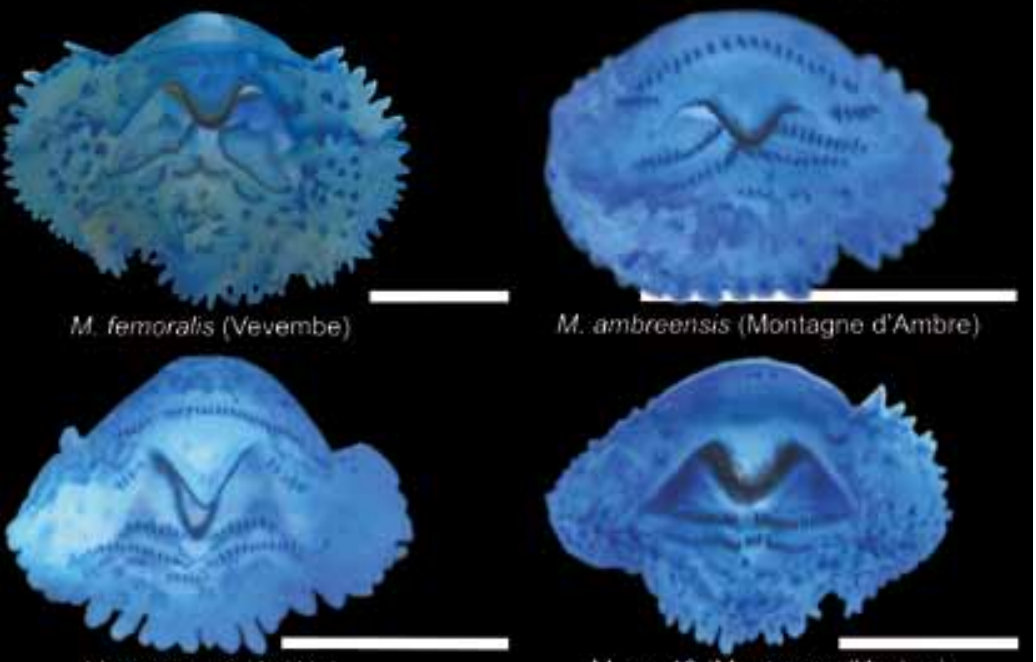

$M$ argenteus (An Ala)

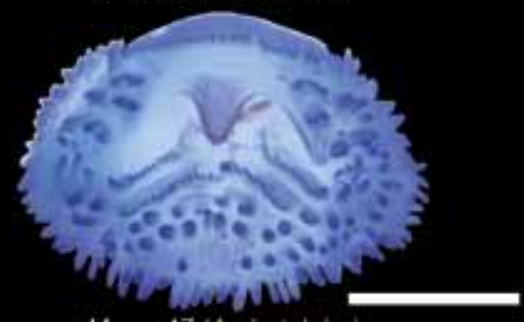

M. sp. 47 (Ambatolahy)

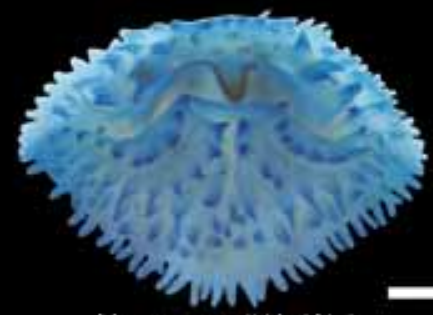

M. mocquardi (An'Ala)

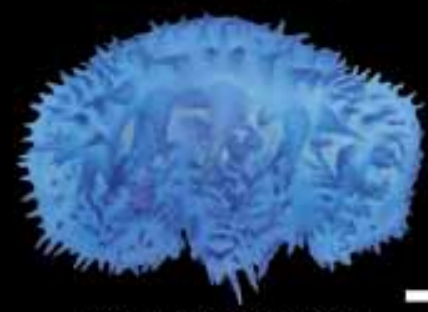

M. majori (Ranomafana)

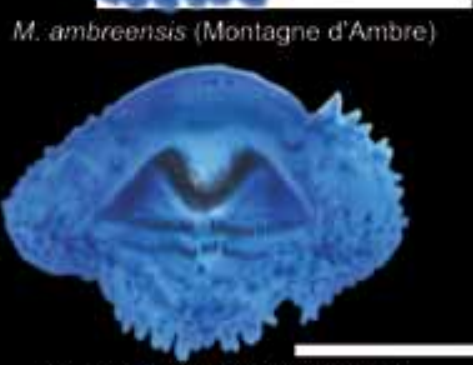

M. sp. 42 (Montagne d'Ambre)

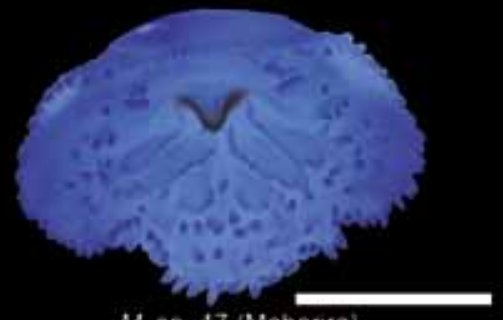

M. sp. 47 (Maharira)

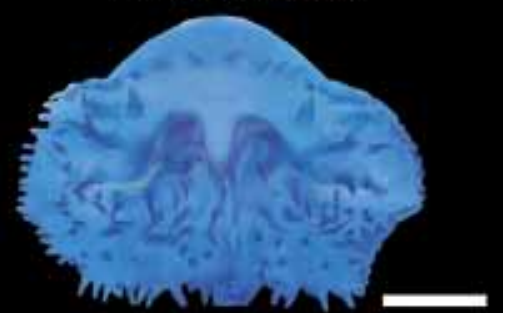

M. mocquardi (Mahasoa)

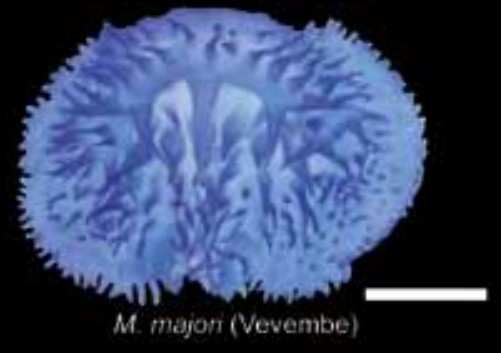


tail, developed tail musculature and pointed tail tip, and long and narrowly pointed medial convexity in M. mocquardi). The dorsal fin originates at the proximal $1 / 10$ of the caudal musculature (vs. on the dorsal body-tail junction in $M$. mocquardi). One further uncatalogued DNA voucher specimen (ZCMV 9291) from Sakaroa in Ranomafana National Park attributed to this species displays the same external pigmentation in preservative. A more detailed examination of its oral disk was not possible because the specimen was not available for further examination.

Mantidactylus majori. - This species is in its adult phase easily recognizable by the rather uniform light brown dorsal colouration bordering at the flanks rather sharply to the white venter, absence of a yellow inguinal patch, a smooth dorsum, and a pointed snout (Fig. 2). The species is common in the Southern Central East and South East; based on molecular identification, we confirm its occurrence in the Ranomafana region, Vevembe, and Midongy du Sud; recently, it has also been found in Sahafina in the Northern Central East (Gehring et al., 2010). As reported by Lehtinen (2003), Vences and De la Riva (2005), and Altig (2008), this species deposits eggs on leaves overhanging streams, guarded by the male. We confirm this reproductive mode by molecular identification of clutches, and also confirm that in these clutches, small tadpoles develop which eventually drop into the stream (Fig. 5). The tadpoles of M. majori (based on ZSM 1684/2007-ZCMV 3762 Gosner stage 29 and T 09/746 Gosner stage 25 from Ranomafana National Park; see Figs 3, 4, and 20) have the most derived oral disk among Ochthomantis, lacking all keratinized components (keratodonts and jaw sheath). The upper jaw sheath is transformed into three very large flexible, slightly curved and thorn-shaped projections and a dozen of large papillae are situated near the base of what appears to be a non-pigmented, non-keratinized, non-serrated lower jaw sheath that is totally hidden by the upper jaw sheath (Fig. 4).

In life, colouration of these tadpoles is beige-orange with brown patches. Light brown patches are positioned in deep integumental layers are between the eyes and on the vertebral region. Dark brown and golden patches spread over the skin. Ventrally, gular region beige, branchial region reddish, abdominal surface transparent with golden patches, intestinal coil visible with regular spiral-shaped intestine. Tail musculature is orange-yellowish with light brown dots arranged in patches. Fins are transparent. The dorsal fin has more patches than the ventral fin.

In preservative, colouration is generally yellowish with brown patches between the eyes and the nares that are positioned in deep integumental layers. Light brown patches disperse on the dorsum and the upper part of the flank and dark brown blotches dissipate on the dorsum and the flank. Tail musculature is pale with light brown dots that fuse in some areas and form patches towards the tail tip. Fins are transparent, the dorsal fin and the distal part of the ventral fin have the same colouration as the tail muscle. The external morphology of this tadpole differs from that of the M. mocquardi tadpole by the remarkable ovoid body form in dorsal view, the lateral eye direction, the wide distance between the eyes, the moderately sized and the elliptical shape of the opening of the nares, the moderately wide distance between the nares, the configuration of the spiracle opening, the size of the vent tube and the tail, the origin of the dorsal fin, and the shape of the tail tip. Thirty-two additional DNA voucher specimens from the same locality and one voucher specimen from Vevembe forest attributed to this species reveal the same characteristic oral disk configuration, the external pigmentation, and all other morphological characteristics of this species.

Three further candidate species of the subgenus Ochthomantis are only known from adults so far and are here considered as UCS: Mantidactylus sp. 61 from Andapa is known to us from a single specimen with a distinct frenal stripe, smooth dorsal skin and a rather pointed head. Mantidactylus sp. 62 from higher elevations of the Marojejy massif (ca. $1100 \mathrm{~m}$ a.s.l., at a site locally known as Camp Simpona) is a rather characteristic species with smooth skin, large-sized females, and a more or less uniform beige venter without whitesilvery colour. Mantidactylus sp. 63 from the Tsaratanana and Manongarivo massifs in the Sambirano region is a relatively large species with a discontinuous yellowish lateral line bordered dorsally by areas of black skin, and with a venter with yellow colour and a distinct pattern of black spots.

Fig. 4. Photographs of the oral disk of the preserved voucher specimens of Mantidactylus subgenus Ochthomantis and Maitsomantis tadpoles described in this paper (stained with methylene blue). The scale bars represent $1 \mathrm{~mm}$. 


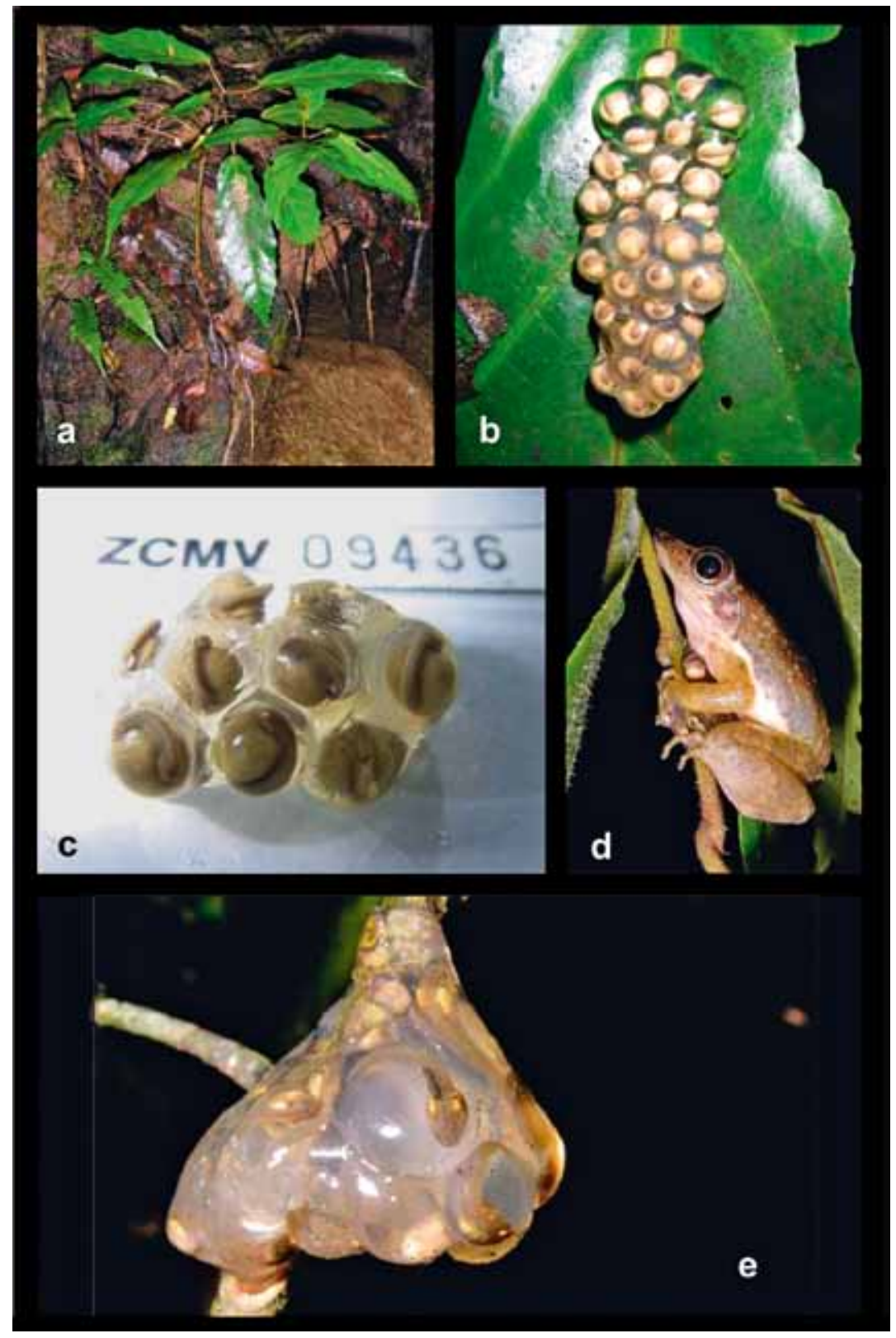

Fig. 5. Clutches and egg guarding behaviour of Mantidactylus majori. (a) and (b) show a clutch (ZCMV 9436) attached to a leaf, $40 \mathrm{~cm}$ above water body (Ranomafana, Ambatovory Barrage), (c) shows a part of the same clutch, (d) shows an adult $M$. majori guarding a clutch attached to vegetation about $80 \mathrm{~cm}$ above water body (Ranomafana, Ambatolahy), (e) shows a clutch of $M$. majori (ZCMV 9537, no ZSM) with well developed tadpoles attached to a branch about $1 \mathrm{~m}$ above water body (Ranomafana, Sahamalaotra bridge).

\section{Ecological analysis}

In Ranomafana National Park, during the rainy season, tadpoles of 44 species were found in streams including four species of the subgenus Ochthomantis: Mantidactylus femoralis, M. majori, $M$. sp. 47 and $M$. sp. 64. Ochthomantis tadpoles were found in 20 out of 33 streams, and often tadpoles of different species occurred together in the same streams. They were never the most abundant species but three of the species rep- resented in some streams a considerable proportion of the overall number of tadpole specimens collected. Mantidactylus femoralis occurred in seven streams with a mean of five specimens per $30 \mathrm{~m}$ sample transect (range: 1 to 13 specimens), M. majori occurred in eleven streams with a mean of 16 specimens (1 to 68), and $M$. sp. 47 occurred in 16 streams with a mean of 6 specimens (1 to 25$), M$. sp. 64 was only found with a single specimen at one stream. For M. majori, several observations on clutches and embryonal development 
were made (Fig. 5). One clutch with about 40 embryos was found attached to a leaf $40 \mathrm{~cm}$ above a stream. Further two clutches with already well developed tadpoles were found attached to a branch of a shrub and attached to a Pandanus leaf, respectively, both about $1.2 \mathrm{~m}$ above another stream. Tadpoles were hatching from the jelly immediately after induced vibrations. An adult M. majori male was observed guarding an egg clutch that was attached to a leaf $80 \mathrm{~cm}$ above a stream.

During the dry season, congruent with the generally low number of tadpole specimens of mantellid species in this area and season, Ochthomantis tadpoles were present but in only very low numbers. Out of 13 sampled streams, Mantidactylus femoralis occurred in one stream with two specimens, M. majori occurred in three streams with a mean of nine specimens per $30 \mathrm{~m}$ transect (range: 2 to 20 specimens), and $M$. sp. 47 occurred in five streams with a mean of four specimens (1 to 9). No tadpoles of $M$. sp. 64 were found in the dry season; however, none of the streams where they have been observed before were sampled. In four streams, tadpoles of two Ochthomantis species (M. femoralis and $M$. sp. 47) were observed in the dry but not in the rainy season.

In our statistical analyses of habitat choice (Fig. 6-8) we first compared breeding site choice of Ochthomantis species on the spatial level of Ranomafana NP, i.e. the distribution of tadpoles between 33 different streams, applying data ordination (principal component analysis; PCA) and subsequently including the PC factors as independent variables in a generalized linear model (GLM). PCA on the original habitat (stream) variables and the surrounding forest resulted in three PCs, explaining together $67.6 \%$ of the variation in the data. Based on the loadings of the PCs and the results of the bootstrapped-eigenvector method (Peres-Neto et al., 2003) we identified the following habitat variables being well represented ('+' positive correlation, '-' negative correlation): PC1 (33.9\%) slope $(+)$, canopy cover of forest $(+)$ and stream $(+)$, overhanging vegetation (+), width (-) and depth (-) of the stream. The variables that contributed the most to PC2 (18.0\%) were slope of the stream (+), the number of shrubs in the forest (+), number of trees (-) and leaf litter depth (-) in the forest. The number of small trees and shrubs in the forest $(+)$ and overhanging vegetation $(+)$ contributed to PC3 (15.7\%). However, according to bootstrapped-eigenvector method both PC2 and PC3 do not well represent the above mentioned habitat variables.

The presence or absence of Ochthomantis tad- poles was negatively correlated with PC1 (Fig. 6; GLM with binomial error distribution; residual deviance $=26.6$ on 31df, $p=0.009$ ), all other PCs as well as interactions could be removed from the model. Therefore, Ochthomantis species prefer larger streams with an open canopy directly at the stream and also a relatively open canopy in the surrounding forest, and with a gentle slope (i.e., slow running streams; see also Fig. 8).

Second, we compared microhabitat choice of Ochthomantis species on the spatial level of each stream, i.e. the distribution of tadpoles within each stream. The tadpoles were not found in all microhabitats that were available in the streams. Most of the specimens were found in those areas of a stream with leaves or sand as substrate combined with slow moving to almost stagnant water (Fig. 7A). In detail, Ochthomantis tadpoles avoided most microhabitats including all microhabitats in fast moving water $\left(\mathrm{E}<0\right.$; factorial ANOVA, $\mathrm{F}_{7,233}=26.93$, fast rock $(\mathrm{E}$ $=-1 \pm 0.14$; mean $\pm \mathrm{SE})$, fast gravel $(\mathrm{E}=-0.95 \pm 0.096)$, fast sand $(\mathrm{E}=-0.87 \pm 0.13)$, fast leaves $(\mathrm{E}=-0.77 \pm 0.13)$, slow rock $(E=-0.79 \pm 0.14)$ and slow gravel $(E=-1 \pm$ 0.15 , p always $<0.001$ ) (Fig. 7B). We also detected a nonsignificant trend of avoidance for the microhabitat slow sand $(E=-0.17 \pm 0.09, p=0.063)$. Slow leaves was the only microhabitat significantly preferred by Ochthomantis tadpoles $(\mathrm{E}>0$; factorial ANOVA, $\mathrm{E}=$ $0.33 \pm 0.09, \mathrm{p}<0.001)$. It needs to be noted, however, that the general strong avoidance values can partly be caused by a high number of non-occurrence events in the specific microhabitats in some streams. As all microhabitatspecies interactions could be removed from the model, our data do not show significant differences in the choice of microhabitat for the three most abundant Ochthoman$t i s$ species. Due to their low abundance, no index of preference was calculated for $M$. sp. 64 tadpoles. However, the few specimens were exclusively found in slow leaves microhabitat.

\section{Discussion}

Specialization of the oral disk in Ochthomantis tadpoles

Ochthomantis tadpoles have morphological characters showing a high degree of specialization, which are (1) reduction and (2) change in the components of the oral disk. Because of the character reduction seen in some species, the states of many characters cannot be assessed which makes some inter-species comparisons difficult. The general external morphology of these 


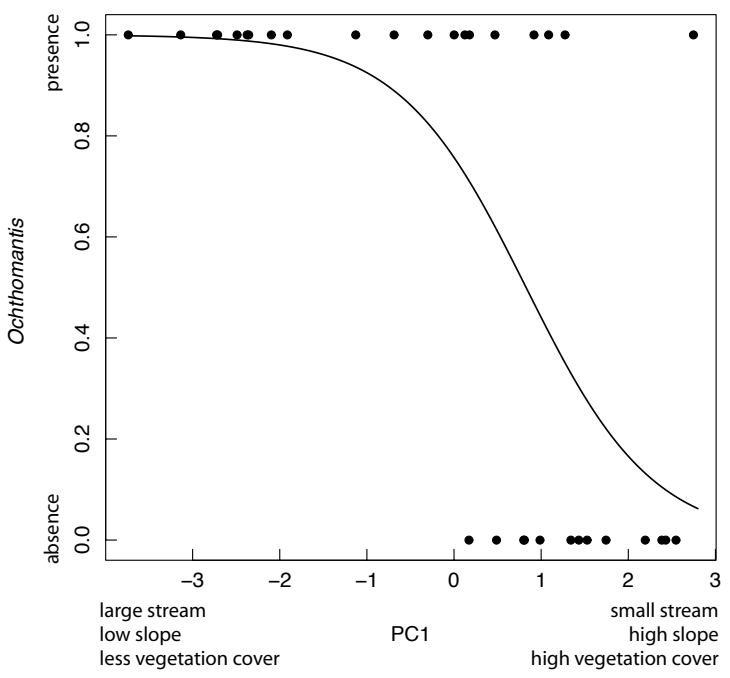

Fig. 6. Presence and absence of Mantidactylus subgenus Ochthomantis tadpoles in streams of RNP along the PC1 gradient. PC1 explains $34 \%$ of the variation in the original data. Each point represents a stream, the regression line of the logistic regression is plotted.

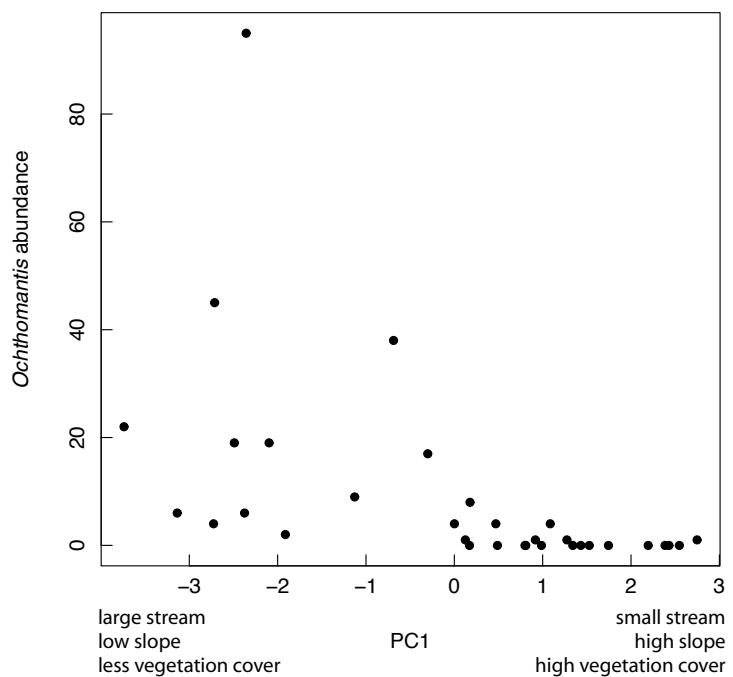

Fig. 8. Abundance of Mantidactylus subgenus Ochthomantis tadpoles in streams of RNP along the PC1 gradient. PC1 explains $34 \%$ of the variation in the original data. Each point represents a stream.

tadpoles shows no large differentiation. They are in general tadpoles with a rather low dorsal fin and were all collected in flowing waters. Only few external characters other than the mouthparts show differences among species, such as the position of the spiracle and the colour.

Summarizing the most relevant variation, it is possi-
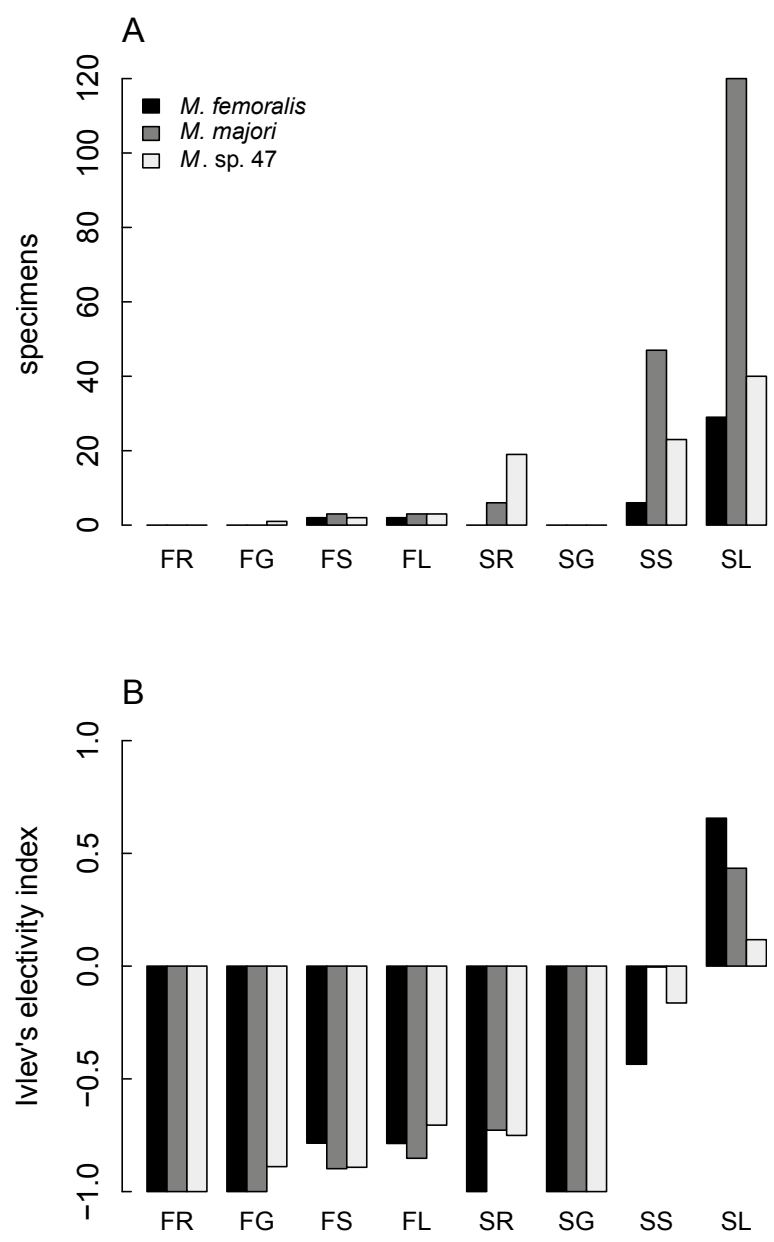

Fig. 7. Habitat use and habitat preferences of the three abundant species of Mantidactylus subgenus Ochthomantis sampled in January and February 2008 in Ranomafana National Park. Plotted is (a) the distribution of specimens and (b) Ivlev's electivity index (Ivlev, 1961) across eight microhabitats (FR = fast rocks, $\mathrm{FG}=$ fast gravel, $\mathrm{FS}=$ fast sand, $\mathrm{FL}=$ fast leaves, $\mathrm{SR}=$ slow rocks, $\mathrm{SG}=$ slow gravel, $\mathrm{SS}=$ slow sand, $\mathrm{SL}=$ slow leaves). Negative values show avoidance, positive values preferences for the respective microhabitat. $\mathrm{N}_{M \text {.femoralis }}=7, \mathrm{~N}_{\text {M. majori }}=11$, and $\mathrm{N}_{M \text {.sp. 47 }}=16$ ( $\mathrm{N}$ is the number of streams where the species was found). The general low values in (b) are caused by a high number of non-occurrence events in the specific microhabitats in some streams.

ble to distinguish three main morphological clusters of Ochthomantis tadpoles that probably represent different evolutionary steps of reduction and change in the oral disk:

(1) Mantidactylus femoralis, M. ambreensis, $M$. zolitschka, $M$. sp. $42, M$. sp. 43 and $M$. sp. 47 possess reduced jaw sheaths and keratodonts. Summarizing 
morphological characters, these tadpoles are characterized by a small to moderately wide oral disk (ODW 32 to $47 \%$ of BW), moderately wide and poorly keratinized jaw sheaths (JW 35 to 54\% of ODW), an upper jaw sheath having a short to long, narrowly to widely, pointed or rounded medial convexity (MCL 17 to $31 \%$ of JW) and many finely pointed serrations, a lower jaw sheath totally hidden by the upper ones, very few (MP 31 to 71 , SMP 18 to 59) short (MP 0.08 to $0.12 \mathrm{~mm}$, SMP 0.08 to $0.20 \mathrm{~mm}$ ) and moderately large conical papillae with rounded tips, a moderately wide dorsal gap of papillae (DG 45 to $66 \%$ of ODW), an absence of ventral gap of papillae, a LTRF of 2(2)/3(1-2) or 3(23)/3(1-2), small keratodonts $(0.04$ to $0.09 \mathrm{~mm})$, lower keratodont rows forming a chevron and $\mathrm{P}_{2}$ and $\mathrm{P}_{3}$ are usually scattered, a wide $A_{2}$ gap (61 to $82 \%$ of $A_{2}$ ). All of these tadpoles show what we interpret as the first step of reduction of keratinized structures, namely (1) the jaw sheath is not fully keratinized (i.e., only at the edge) and has a medial convexity, and (2) there are only few upper keratodont rows (usually three, further reduced to only two in $M$. ambreensis and $M$. sp. 43), there are only relatively low numbers of keratodonts per row, the second lower tooth row is interrupted (uninterrupted in generalized mantellid tadpoles), and all lower rows are scattered and form a chevron. In addition, $M$. zolitschka shows a reduction of the keratinisation of the keratodonts which become difficult to recognize without using a staining agent such as methylene blue. Also M. sp. 43 has reduced the keratodonts on $\mathrm{A}_{1}$.

(2) The second group contains M. mocquardi and $M$. sp. 64. These tadpoles are characterized by a small to moderately wide oral disk (ODW 34 to $47 \%$ of BW), moderately wide and poorly keratinized jaw sheaths (JW 32 to $55 \%$ of ODW), an upper jaw sheath having a long to very long narrowly pointed medial convexity (MCL 21 to $57 \%$ of JW) and many finely pointed serrations, a lower jaw sheath totally hidden by the upper ones, few (MP 64 to 89, SMP 77 to 104) and very short to long (MP 0.09 to $0.25 \mathrm{~mm}$, SMP 0.12 to $0.35 \mathrm{~mm}$ ) and large conical to elongated papillae with rounded (MP) and pointed (SMP) tips, an absence of dorsal and ventral gaps of papillae, and an absence of keratodonts (LTRF 0/0). In terms of reduction of keratinized structures, the jaw sheaths in these species have the same state as found in the first morphological group but the keratodonts are completely reduced and many submarginal papillae are present in the area occupied by keratodont rows in the other species. The row of marginal papillae is complete (i.e., there is no dorsal gap). These tadpoles have long and moderately large elongated papillae, mainly in $M$. mocquardi from Mahasoa whose submarginal papillae show similarities to those of M. majori.

(3) The third group only contains the highly modified tadpoles of M. majori which are characterized by a small oral disk (ODW 38 to $40 \%$ of BW), an upper jaw sheath transformed into three thorn-shaped papillae (projections), a lower jaw sheath totally hidden by the upper ones, moderately many (MP 72 to 105 , SMP 135 to 201) long to very long (MP 0.22 to $0.25 \mathrm{~mm}$, SMP 0.41 to $0.52 \mathrm{~mm}$ ) and very large elongated papillae with pointed tips, an absence of dorsal and ventral gaps of papillae, an absence of keratodonts (LTRF $0 / 0$ ). The modification of the area of the jaw sheaths in this species is extreme and besides the three very large flexible slightly curved thorn-shaped papillalike structures there are some large elongated papillae projecting from near the base of what appears to be a non-pigmented, non-keratinized, non-serrated lower jaw sheath.

The phylogenetic tree shown here (Fig. 1) needs to be considered as tentative because it is based on a rather short fragment of only one mitochondrial gene. We therefore refrain from a detailed discussion here but just mention some aspects that seem to be well supported (Bayesian posterior probabilities of $>0.95$ ). However, the phylogenetic relationships proposed in this tree are in need of further confirmation by a forthcoming multi-gene analysis. First, it seems clear that M. majori is the most divergent Ochthomantis and may even be more distant to other Ochthomantis than is Mantidactylus (Maitsomantis) argenteus. This could indicate that the reduction of keratinized oral structures in M. majori occurred convergently to what is observed in the M. mocquardi-like species. Second, it seems clear that Ochthomantis cannot be simply divided into two clades, one with a $M$. femoralis-like tadpole morphology and one with a (more specialized) $M$. mocquardi-like morphology. This situation is exemplified by the clade containing $M$. mocquardi and $M$. sp. 43 on one hand, and the clade containing $M$.sp. 47 and $M$. sp. 64 (which however is not strongly supported) on the other hand: In fact, $M$. mocquardi and $M$. sp. 64 show a full loss of keratodonts which is not shown by their respective sister taxa (M. sp. 43 and $M$. sp. 47), indicating that this loss may have occurred convergently in the two lineages. The tendency of keratodont loss on $\mathrm{A}_{1}$ of $M$. sp. 43 nevertheless indicates an early tendency of loss of keratodonts in this lineage. 


\section{Comparisons with other mantellid tadpoles}

A convergence in the reduction of the oral disk in mantellid tadpoles is found between the subgenus Ochthomantis and the genus Boophis (B. majori; Schmidt et al., 2008, and pers. obs.). Boophis majori tadpoles have a small oral disk, a poorly keratinized jaw sheath with a very long narrowly pointed medial convexity and finely pointed serrations, a wide dorsal gap of marginal papillae an absent ventral gap of papillae. The difference is that $B$. majori tadpoles do not possess any conspicuous modifications of the keratodonts. They have one interrupted lower row as it is typical for many Boophis tadpoles, and their LTRF are 4(1-4)/3(1) (Schmidt et al., 2008 , pers. obs.) or 5(2-5)/3(1) (pers. obs.). The tadpoles of B. picturatus (Altig and McDiarmid, 2006; pers. obs. of many DNA voucher specimens from Ranomafana National Park) show the most extreme evolutionary specialization in having an extraordinary reduction of various oral disk characters.

Mantidactylus argenteus is classified in the subgenus Maitsomantis because of its largely arboreal habits in the adult stage which is unique in Mantidactylus (Glaw and Vences, 2006). Its tadpoles are easy to recognize because of the bands on the body, but the oral disk is femoralis-like with a LTRF of 2(2)/3(1-2) (see Fig. 4). This would imply that the ancestor of Maitsomantis and Ochthomantis probably had femoralis-like tadpole features. There is a further tendency of specialization in the mouthparts of the mocquardi-like lineage. According to the molecular tree presented here, the subgenus Ochthomantis would be paraphyletic, with M. majori being sister to a clade of all other Ochthomantis, plus M. (Maitsomantis) argenteus. However, because this tree is based on only few sequences, we consider this grouping as in need of confirmation. So far, no comprehensive phylogenetic analysis of morphological character states of mantellid tadpoles have been published, but an own study in progress indicates that various of the states of Ochthomantis and Maitsomantis (e.g. the reduction of keratodont rows) are derived, indicating that tadpole characters may provide support for their phylogenetic relationships. A further derived character state shared by M. majori and M. argenteus is the male eggguarding of eggs deposited on leaves overhanging running water (Vences and De la Riva, 2005; Glaw and Vences, 2007; Altig, 2008). Vejarano et al. (2006) reported the presence of three interrupted lower rows (2(2)/3(1-3)) in M. argenteus tadpoles, but based on our data presented herein, we assume that it normally has only two interrupted lower rows, i.e. an LTRF of
2(2)/3(1-2) (as indicated by the intact state of $\mathrm{P}_{3}$ of the specimens examined herein; Fig. 4). The data of Vejarano et al. (2006) might be due to the fact that the lower rows, mainly the third, are scattered in $M$. argenteus, similar to the situation in all femoralis-like tadpoles. Taking into account that $M$. argenteus tadpoles still have an uninterrupted third lower row agrees with the state in the first group of Ochthomantis tadpoles.

Previous descriptions of tadpoles of Ochthomantis have not been based on DNA barcoding, and given the high similarity among adults, species identification in these previous works is doubtful. Blommers-Schlösser (1979 in her Figs 9-10) provides a brief description of a tadpole assigned to be $M$. femoralis which shows scattered keratodonts on $\mathrm{P}_{2}$. The tadpole has poorly keratinized jaw sheaths which are typical in Ochthomantis, but the combination of having both complete marginal papillae rows and keratodonts does not fit any femoralis-like tadpoles, since according to our observations only the tadpoles which have no keradotonts present no dorsal gap of marginal papillae (mocquardi-like tadpoles). Also, the LTRF 0/2+2 does not correspond with any femoralis-like nor mocquardi-like tadpoles. Maybe this is due to the captive rearing of the tadpoles by Blommers-Schlösser (1979), or an artefact in the observation, or these tadpoles belong to yet another Ochthomantis candidate species that is not present in our samples.

Altig and McDiarmid (2006) described a tadpole from Ranomafana with strongly reduced keratinized structures in the oral disk and assigned it tentatively to Mantidactylus guttulatus, the largest mantellid frog whose life history is so far largely unknown. However, a comparison of the description and drawing with our study leaves little doubts that the authors in fact described the tadpole of M. majori. Altig and McDiamid (2006) had based their tentative identification on the morphology of juveniles which however can be very similar among M. majori and M. guttulatus.

Habitat selection and ecology of Ochthomantis tadpoles

Ochthomantis tadpoles are almost omnipresent in stream communities in the mid-elevational rainforests of Madagascar. Some Ochthomantis species can be found in many streams with considerable abundances, however, by far they do not represent the most common species (own unpublished data). Ochthomantis tadpoles occur throughout the year but with a strongly reduced abundance in the dry season. As all streams sampled 
were permanently water-bearing the reduced abundance may be caused by the low temperature, which is a main factor for frog reproduction in RNP (Andreone, 1996). The presence of Ochthomantis species in four streams in the dry season where this species was not found in the preceding rainy season indicates that reproduction occurs throughout the year.

Ochthomantis tadpoles avoid small, fast running streams surrounded by dense vegetation for reproduction. This may partly conflict with the fact that adults of at least M. majori attach eggs on vegetation above the water. However, these structures are obviously not a limiting resource even in the larger streams. A dense vegetation above the stream, here measured as overhanging vegetation and canopy cover, may cause decreasing light, lower dissolved oxygen, reduced temperature and reduced availability of food for tadpoles in ponds (Werner and Glennemeier, 1999) and influence periphyton growth and thus food availability in streams (Altig et al., 2007; Mallory and Richardson, 2005). However, given that Ochthomantis tadpoles most probably live and feed among dead leaves on the ground of the streams, it is unlikely that periphyton growth would have strong influences on the amount of food available to them. Since the adults of Ochthomantis typically are found along or at few meters distance from the streams, dense vegetation along the streams might influence adults rather than tadpoles. Testing this hypothesis would require an analysis of the habitat preferences of adult Ochthomantis which so far has not been carried out.

Within a stream, Ochthomantis tadpoles of the three most abundant species do not obviously differ in their choice of microhabitat based on the rather rough microhabitat categories distinguished in our sampling scheme. They prefer those areas of a stream with a slow current and an abundance of leaf litter. The same microhabitat preference was observed for tadpoles in the Mantidactylus subgenus Chonomantis (Grosjean et al., 2011). In general, microhabitat choice of tadpoles can be related to oral disk characteristics and therefore feeding mode (Altig and Johnston, 1989). The fact that these morphologically very different tadpoles (i.e., Chonomantis have funnel-shaped oral disks) show a similar habitat choice indicates that this might be a general pattern for most mantellid stream tadpole species that have no obvious adaptations to strong water currents (like e.g. some Boophis, Glos et al., 2007). As all other substrates in the slow running areas of the streams have been avoided, the strength of the water current may be only one important factor for microhabitat choice. It is there- fore the combination of low water current and the high availability of nutrients within the leaf litter that is of importance for the preference for this microhabitat.

However, because Ochthomantis tadpoles occurring in Ranomafana show distinct tadpole morphologies and that some of them have unique oral disks (especially those of M. majori) it is unlikely that all of them use precisely the same food resources, despite a general agreement in rough microhabitat categories. Certainly, the species with the most derived oral disks (the second and third guild as defined above), without keratodonts and partly with modified jaw sheaths, are not able any more to graze and scrape as generalized tadpoles do, but it is uncertain whether tadpoles of the first group might show such a behaviour or feed differently.

Although larvae of Ochthomantis and Chonomantis also share a similar choice of rough microhabitat categories (Grosjean et al., 2011) it is almost certain that these taxa will not use the same nutrient resources. Their very different and specialized oral disk structures strongly suggest different feeding behaviour, e.g. Chonomantis tadpoles may feed at least partly from the water surface as is known from other funnel-mouthed tadpoles (Grosjean et al., 2011), so that competition for food is not necessarily to be expected. In general, the high amount of morphological larval variation among Ochthomantis tadpoles stands in stark contrast to the situation in Chonomantis which show a very limited morphological differentiation although up to five Chonomantis species have been detected syntopically (Grosjean et al., 2011).

Tadpoles of the different species of Ochthomantis (and Chonomantis) often occurred together in the same stream, which demonstrates that they are not excluding each other and indicates that direct competition might be of minor importance. We assume that rather habitat characteristics and drift events determine the presence, abundance or absence of a species in a stream. Further insights into resource partitioning among these tadpoles will require detailed behavioural and ecological studies focusing on intestine contents, feeding behaviour and feeding microhabitat, and activity periods.

Applying the definitions of ecomorphological tadpole guilds proposed by Altig and Johnston (1989) is generally difficult in Malagasy tadpoles because of the lack or different expression of some of the characters that these authors have used (Randrianiaina et al., 2009). Therefore, none of the guilds defined by these authors, nor the ones defined by Raharivololoniana $e t$ al. (2006) for Boophis tadpoles, are fully applicable to tadpoles of Ochthomantis. Based on our assumption 
that the different morphologies of the oral disk might correspond to the use of different nutrient resources, the three morphological clusters of Ochthomantis tadpoles defined above might in the future be considered as three ecomorphological guilds. However, such definitions will make more sense if proposed in the context of a future more comprehensive analysis of the morphology of mantellid tadpoles.

'Reverse taxonomy', i.e. the initial survey of the diversity of a group of organisms via DNA barcoding only, has been introduced for cases where taxon diversity cannot be handled with traditional approaches (Markmann and Tautz, 2005). Although such cases will usually refer to groups of insufficiently assessed taxa such as meiobenthos or nematodes (Blaxter, 2004; Markmann and Tautz, 2005), our example shows that it may also be fruitful in generally better studied groups such as vertebrates.

\section{Acknowledgements}

We are grateful to L. Raharivololoniaina, A.F. Ranjanaharisoa, T.J. Razafindrabe, P. Bora, H.T. Rasolonjatovo, S. Ndriantsoa, I. De la Riva, E. Reeve, D.R. Vieites, J. Patton, and C. Patton who assisted some fieldworks of this study. We thank MICET, Valbio biological station, and Madagascar National Parks for their invaluable help with field work logistics. We furthermore acknowledge the painstaking, constructive and helpful reviews provided by Stéphane Grosjean and two anonymous reviewers. This study was carried out in the framework of a cooperation accord between the Département de Biologie Animale of the University of Antananarivo, Madagascar and the Zoologische Staatssammlung, München, Germany. Financial support was granted by the Volkswagen Foundation to MV, FG and RDR, the Deutsche Forschungsgemeinschaft to AS and JG, and by the Deutscher Akademischer Austauschdienst to RDR.

\section{References}

Altig R. 2008. Notes on the breeding biology of four species of mantellid frogs from Madagascar. Tropical Zoology 21: 187-194.

Altig R, Johnston GF. 1989. Guilds of anuran larvae: Relationships among developmental modes, morphologies, and habitats. Herpetological Monographs 3: 81-109.

Altig R, McDiarmid RW. 2006. Descriptions and biological notes on three unusual mantellid tadpoles (Amphibia: Anura: Mantellidae) from southeastern Madagascar. Proceedings of the Biological Society of Washington 119: 418425.

Altig R, Whiles MR, Taylor CL. 2007. What do tadpoles really eat? Assessing the trophic status of an understudied and imperiled group of consumers in freshwater habitats. Freshwater Biology 52: 386-395.
Andreone F. 1996. Seasonal variations of the amphibian communities in two rainforests of Madagascar. Pp 397-402 in: Lourenço WR, eds, Biogéographie de Madagascar. Paris: Editions de l'ORSTOM.

Angel MF. 1929. Description de trois Batraciens nouveaux appartenant aux genres Mantidactylus et Gephyromantis. Bulletin du Muséum national d'Histoire Naturelle, Paris, ser. 2, 1: 358-362.

Blaxter ML. 2004. The promise of a DNA taxonomy. Philosophical Transactions of the Royal Society B 359: 669-679.

Blommers-Schlösser RMA. 1979. Biosystematics of the Malagasy frog. I. Mantellinae (Ranidae). Beaufortia 29: 1-77.

Blommers-Schlösser RMA, Blanc CP. 1991. Amphibiens (première partie). Faune de Madagascar 75: 1-379.

Boulenger GA. 1882. Catalogue of the Batrachia Salientia S. Caudata in the collection of the British Museum. Addenda.

Boulenger GA. 1896. Descriptions of two new frogs of obtained in Madagascar by Dr. Forsyth Major. Annals and Magazine of Natural History, ser. 6, 18: 420-421.

Box GEP, Cox DR. 1964. An analysis of transformations. Journal of the Royal Statistical Society. Series B (Methodological) 26: 211-252.

Burnham KB, Anderson DR. 1998. Model Selection and Inference. A Practical Information-Theoretic Approach. Heidelberg: Springer Verlag.

Dubois A. 1995. Keratodont formulae in anuran tadpoles: Proposal for standardisation. Journal of Zoological Systematics and Evolutionary Research 33: i-xv.

Fox J. 2008. CAR: Companion to applied regression, R Package version 1.2-16. Online at http://cran.r-project.org/web/ packages/car/index.html.

Gehring P-S, Ratsoavina FM, Vences M. 2010. Filling the gaps - amphibian and reptile records from lowland rainforests in eastern Madagascar. Salamandra 46: 214-234.

Glaw F, Hoegg S, Vences M. 2006. Discovery of a new basal relict lineage of Madagascan frogs and its implications for mantellid evolution. Zootaxa 1334: 27-43.

Glaw F, Vences M. 2004. A preliminary review of cryptic diversity in frogs of the subgenus Ochthomantis based on mtDNA sequences and morphology (Anura, Mantellidae, Mantidactylus). Spixiana 27: 83-91.

Glaw F, Vences M. 2006. Phylogeny and genus-level classification of mantellid frogs (Amphibia, Anura). Organisms, Diversity and Evolution 6: 236-253.

Glaw F, Vences M. 2007. A Field Guide to the Amphibians and Reptiles of Madagascar. Third edition. Köln: Vences und Glaw Verlag.

Glos J, Teschke M, Vences M. 2007. Aquatic zebras? The tadpoles of the Madagascan treefrog Boophis schuboeae Glaw and Vences 2002 compared to those of B. ankaratra Andreone 1993. Tropical Zoology 20: 125-133.

Gosner KL. 1960. A simplified table for staging anuran embryos and larvae with notes on identification. Herpetologica 16: 183-190.

Grosjean S, Strauß A, Glos J, Randrianiaina RD, Ohler A, Vences M. 2011. Morphological uniformity in the surfacefeeding tadpoles of Malagasy litter frogs, subgenus Chonomantis. Zoological Journal of the Linnean Society, in press.

Haas A. 2003. Phylogeny of frogs as inferred from primarily larval characters (Amphibia: Anura). Cladistics 19: 23-90. 
Hebert PDN, Cywinska A, Ball SL, deWaard JR. 2003. Biological identification through DNA barcodes. Proceedings of the Royal Society of London, Series B 270: 313-321.

Ivlev VS. 1961. Experimental Ecology of the Feeding of Fishes. New Have: Yale University Press.

Lehtinen RM. 2003. Parental care and reproduction in two species of Mantidactylus (Anura: Mantellidae). Journal of Herpetology 37: 766-768

Mallory MA, Richardson JS. 2005. Complex interactions of light, nutrients and consumer density in a stream periphyton-grazer (tailed frog tadpoles) system. Journal of Animal Ecology 74: 1020-1028.

Markmann M, Tautz D. 2005. Reverse taxonomy: an approach towards determining the diversity of meiobenthic organisms based on ribosomal RNA signature sequences. Philosophical Transactions of the Royal Society B: Biological Sciences 360: 1917-1924.

McDiarmid RW, Altig R, eds, 1999. Tadpoles: The Biology of Anuran Larvae. Chicago: Chicago University Press.

Methuen PA. 1920 [1919]. Descriptions of a new snake from Transvaal, together with a new diagnosis and key of the genus Xenocalamus, and of some batrachia from Madagascar. Proceedings of the Zoological Society of London 25: 349-355.

Mocquard MF. 1895. Sur les reptiles recueillis a Madagascar par M. M. Alluaud et Belly. Bulletin de la Société philomatique de Paris, ser. 8, 7: 112-136.

Nylander JA. 2004. MrModeltest v2. Program distributed by the author, Evolutionary Biology Centre, Uppsala University.

Padial JM, Miralles A, De la Riva I, Vences M. 2010. The integrative future of taxonomy. Frontiers in Zoology 7: 16.

Palumbi SR, Martin A, Romano S, McMillian WO, Stine L, Grabowski G. 1991. The simple fools guide to PCR, v.2.0. Honolulu: Department Zoology, Kewalo Marine Laboratory, University of Hawaii.

Peres-Neto PR, Jackson DA, Somers KM. 2003. Giving meaningful interpretation to ordination axes: assessing loading significance in principal component analysis. Ecology 84: 2347-2363.

Rabibisoa N, Ramilijaona RO, Raxworthy CJ. 2008. Diversité spécifique et endémisme inattendus dans le Nord de Madagascar: résultats biogéographiques préliminaires de Mantidactylus sous-genre Ochthomantis. Pp 197-2113 in: Andreone F. ed., A Conservation Strategy for the Amphibians of Madagascar. Monografie del Museo Regionale di Scienze Naturali di Torino 45.

Raharivololoniaina L, Grosjean S, Raminosoa, NR, Glaw F, Vences M. 2006. Molecular identification, description, and phylogenetic implications of the tadpoles of 11 species of Malagasy treefrogs, genus Boophis. Journal of Natural History 40: 1449-1480.

Randrianiaina RD, Raharivololoniaina L, Preuss C, Strauß A, Glaw F, Teschke M, Glos J, Raminosoa N, Vences M. 2009. Descriptions of the tadpoles of seven species of Malagasy treefrogs, genus Boophis. Zootaxa 2021: 23-41.

R Development Core Team. 2009. R: A language and environment for statistical computing. R Foundation for Statistical Computing, Vienna, Austria.
Ronquist F, Huelsenbeck JP. 2003. MrBayes3: Bayesian phylogenetic inference under mixed models. Bioinformatics 19 : 1572-1574.

Schmidt H, Strauß A, Reeve E, Letz A, Ludewig AK, Neb D, Pluschzick R, Randrianiaina RD, Reckwell D, Schröder S, Wesolowski A, Vences M. 2008. Descriptions of the remarkable tadpoles of three treefrog species, genus Boophis, from Madagascar. Herpetology Notes 1: 49-57.

Strauß A, Reeve E, Randrianiaina R, Vences M, Glos J. 2010. The world's richest tadpole communities show functional redundancy and low functional diversity: ecological data on Madagascar's stream-dwelling amphibian larvae. $B M C$ Ecology 10: 12

Thomas M, Raharivololoniaina L, Glaw F, Vences M, Vieites DR. 2005. Montane tadpoles in Madagascar: molecular identification and description of the larval stages of Mantidactylus elegans, Mantidactylus madecassus, and Boophis laurenti from the Andringitra Massif. Copeia 2005: 174-183.

Vejarano S, Thomas M, Glaw F, Vences M. 2006. Advertisement call and tadpole morphology of the clutch guarding frog Mantidactylus argenteus from eastern Madagascar. African Zoology 41: 164-169.

Vences M, De la Riva I. 2005. Mantidactylus majori (NCN). Male egg guarding. Herpetological Review 36: 435-436.

Vences M, Kosuch J, Glaw F, Böhme W, Veith M. 2003. Molecular phylogeny of hyperoliid treefrogs: biogeographic origin of Malagasy and Seychellean taxa and re-analysis of familial paraphyly. Journal of Zoological Systematics and Evolutionary Research 41: 205-215.

Vences M, Thomas M, Bonett RM, Vieites DR. 2005. Deciphering amphibian diversity through DNA barcoding: chances and challenges. Philosophical Transactions of the Royal Society B: Biological Sciences 360: 1859-1868.

Vences M, Chiari Y, Teschke M, Randrianiaina RD, Raharivololoniaina L, Bora P, Vieites DR, Glaw F. 2008. Which frogs are out there? A preliminary evaluation of survey techniques and identification reliability of Malagasy amphibians. Pp. 233-253 in: Andreone F. ed., A Conservation Strategy for the Amphibians of Madagascar. Monografie del Museo Regionale di Scienze Naturali di Torino 45.

Vieites DR, Wollenberg KC, Andreone F, Köhler J, Glaw F, Vences M. 2009. Vast underestimation of Madagascar's biodiversity evidenced by an integrative amphibian inventory. Proceedings of the National Academy of Sciences of the USA 106: 8267-8272.

Werner EE, Glennemeier KS. 1999. Influence of forest canopy cover on the breeding pond distributions of several amphibian species. Copeia 1999: 1-12.

Zuur AF, Ieno-Graham EN, Smith GM. 2007. Analysing Ecological Data. Springer Science + Business Media, New York.

Received: 28 May 2010

Revised and accepted: 1 December 2010

Published online: 21 February 2011

Editor: J.W. Arntzen 


\section{Appendix}

\section{Morphological descriptions of tadpoles}

Mantidactylus femoralis (Boulenger, 1882)

The following description refers to one tadpole in developmental stage 28 (field number ZCMV 3431ZSM 1736/2007, BL $11.4 \mathrm{~mm}$, TL $34 \mathrm{~mm}$ ) from the stream Andohan'i Sity (transect 1) in An'Ala forest. The 16S rDNA sequence of this specimen was $100 \%$ identical to a reference sequence of a Mantidactylus femoralis adult specimen (accession AY324812) from Andasibe.

In dorsal view, body elliptical (BW $57 \%$ of BL), maximal body width between the proximal $2 / 3$ and $3 / 5$ of the body (SBW $47 \%$ of BL), with a constriction behind the point of the maximal body width, narrowly rounded snout. In lateral view, body depressed (BW $141 \%$ of BH), maximal body height between the

Table 3. Morphometric measurements (all in mm) of all the DNA voucher specimens of tadpoles of Mantidactylus species in the subgenera Ochthomantis and Maitsomantis described in this paper. For abbreviations, see Material and methods.

\begin{tabular}{|c|c|c|c|c|c|c|c|c|}
\hline Species & M. femoralis & M. femoralis & M. femoralis & M. femoralis & M. femoralis & M. ambreensi & s M. zolitschka & M. argenteus \\
\hline Site & An'Ala & Isalo & Marojejy & Ranomafana & Vevembe & Ambre & An'Ala & An'Ala \\
\hline \multirow[t]{2}{*}{ Field number } & ZCMV & $\mathrm{T}$ & FGZC & ZCMV & TAD & FG/MV & ZCMV & ZCMV \\
\hline & 3431 & $2007-558$ & 2955 & 2640 & 2004-07 & $2002-1950$ & 3565 & 3575 \\
\hline ZSM & $1736 / 2007$ & $1928 / 2007$ & $1630 / 2007$ & $396 / 2008$ & $1385 / 2004$ & $762 / 2004$ & $1843 / 2007$ & $1573 / 2007$ \\
\hline Gos & 28 & 26 & 25 & 28 & 37 & 25 & 27 & 27 \\
\hline BL & 11.4 & 12.2 & 6.4 & 10.2 & 12.7 & 5.7 & 9.2 & 12.2 \\
\hline BW & 6.5 & 7.6 & 3.4 & 5.8 & 7.7 & 3.1 & 5.1 & 5.7 \\
\hline SBW & 5.4 & 7.1 & 3.2 & 5.0 & 9.3 & 2.5 & 3.7 & 6.1 \\
\hline BH & 4.6 & 5.0 & 2.6 & 3.5 & 5.4 & 2.5 & 3.4 & 5.2 \\
\hline SBH & 8.0 & 7.3 & 4.4 & 7.9 & 9.3 & 3.4 & 6.5 & 6.8 \\
\hline ED & 1.1 & 1.2 & 0.7 & 1.1 & 1.5 & 0.6 & 1.0 & 1.1 \\
\hline SE & 3.7 & 3.5 & 2.2 & 3.2 & 3.2 & 2.1 & 2.8 & 2.6 \\
\hline $\mathrm{EH}$ & 3.4 & 3.7 & 1.9 & 2.2 & 3.3 & 1.7 & 2.3 & 3.0 \\
\hline IOD & 3.4 & 3.6 & 2.2 & 3.6 & 3.8 & 2.1 & 2.9 & 3.6 \\
\hline ND & 0.1 & 0.1 & 0.1 & 0.1 & 0.1 & 0.1 & 0.1 & 0.1 \\
\hline $\mathrm{NH}$ & 2.8 & 3.2 & 1.8 & 1.7 & 2.5 & 1.4 & 2.0 & 2.5 \\
\hline IND & 2.0 & 2.0 & 1.2 & 2.1 & 2.3 & 1.4 & 1.8 & 1.9 \\
\hline RN & 1.7 & 1.3 & 1.0 & 1.2 & 1.2 & 0.9 & 1.1 & 1.0 \\
\hline NP & 2.0 & 2.2 & 1.2 & 2.1 & 2.1 & 1.3 & 1.7 & 1.5 \\
\hline SL & 1.8 & 2.1 & 1.1 & 3.1 & 2.3 & 0.8 & 1.6 & 1.1 \\
\hline SS & 7.4 & 7.5 & 4.2 & 7.9 & 7.8 & 4.1 & 5.7 & 6.6 \\
\hline SV & 4.0 & 3.6 & 2.2 & 2.3 & 4.9 & 1.7 & 3.5 & 5.5 \\
\hline SH & 3.2 & 3.0 & 1.4 & 1.4 & 2.8 & 1.4 & 1.4 & 2.5 \\
\hline VL & 1.5 & 1.1 & 0.5 & 1.1 & 1.7 & 0.5 & 1.0 & 1.8 \\
\hline TAL & 22.6 & 19.7 & 12.8 & 17.9 & 25.5 & 12.8 & 15.4 & 21.8 \\
\hline TMW & 3.4 & 2.7 & 1.9 & 2.5 & 3.6 & 1.7 & 2.3 & 3.4 \\
\hline TMH & 3.2 & 3.1 & 1.8 & 2.9 & 3.4 & 1.8 & 2.2 & 3.5 \\
\hline $\mathrm{TH}$ & 4.0 & 4.1 & 2.4 & 3.3 & 4.8 & 2.1 & 3.2 & 4.3 \\
\hline TMHM & 2.6 & 2.1 & 1.5 & 2.4 & 2.6 & 1.3 & 1.2 & 2.8 \\
\hline THM & 4.4 & 3.9 & 2.8 & 4.2 & 5.4 & 2.1 & 3.4 & 5.0 \\
\hline MTH & 5.1 & 4.3 & 2.9 & 4.3 & 5.5 & 2.3 & 3.6 & 5.5 \\
\hline DMTH & 9.0 & 6.0 & 5.1 & 10.1 & 11.3 & 5.8 & 6.6 & 8.0 \\
\hline DF & 1.0 & 1.0 & 0.7 & 1.1 & 1.4 & 0.4 & 1.0 & 1.2 \\
\hline VF & 1.0 & 0.9 & 0.6 & 0.7 & 1.1 & 0.3 & 0.8 & 1.1 \\
\hline HAB & 3.4 & 3.8 & 1.5 & 2.2 & 3.6 & 1.6 & 2.4 & 3.3 \\
\hline $\mathrm{TL}$ & 34.0 & 31.9 & 19.2 & 28.1 & 38.2 & 18.4 & 24.6 & 34.0 \\
\hline
\end{tabular}


proximal $3 / 5$ and $4 / 5$ of the body (SBH $70 \%$ of BL), pointed snout. Moderately large eyes (ED 10\% of BL), not visible from ventral view, positioned high (EH $73 \%$ of $\mathrm{BH}$ ) dorsally and directed laterally, situated between the proximal $3 / 10$ and $4 / 10$ of the body (SE $32 \%$ of BL), moderately wide distance between eyes (IOD 52\% of BW). Small elliptical nares (ND $1.1 \%$ of $\mathrm{BL}$ ), marked with a marginal rim, positioned high (NH $60 \%$ of $\mathrm{BH}$ ) dorsally and oriented anterolaterally, situated nearer to snout than to eye (RN $83 \%$ of $\mathrm{NP}$ ) and below eye level (NH $83 \%$ of $\mathrm{EH}$ ), moderately wide distance between nares (IND $58 \%$ of IOD), red coloured region on the back of the nares present, ornamentation absent. Short sinistral spiracle (SL 16\% of $\mathrm{BL}$ ), directed posteriorly, visible from dorsal and ventral views, perceivable from lateral view; inner wall free from body and its aperture opens posteriorly, rounded opening, situated between the proximal 3/5 and $4 / 5$ of the body (SS $65 \%$ of BL), located high on the body (SH 69\% of BH) and almost at the height of the point where the axis of the tail myotomes contacts the body (SH $96 \%$ of HAB). Moderately long dextral vent tube (VL 13\% of BL), attached to ventral fin, inner wall present. No gland. Short tail (TAL 198\% of

Table 3. continued.

\begin{tabular}{|c|c|c|c|c|c|c|c|c|c|}
\hline M. sp. 42 & M. sp. 43 & M.sp. 47 & M.sp. 47 & M. mocquardi & M. mocquardi & M. mocquard & $i$ M. sp. 64 & M. majori & M. majori \\
\hline Ambre & Marojejy & Ambatolahy & Maharira & An'Ala & Ambohitsara & Mahasoa & Namorona & Ranomafana & Vevembe \\
\hline FG/MV & FGZC & ZCMV & TAD & ZCMV & ZCMV & ZCMV & ZCMV & $\mathrm{Tad}$ & ZCMV \\
\hline $2002-1957$ & 2928 & 2699 & $2004-638$ & 3511 & 4936 & 8094 & 2646 & 6 Vevembe & 3761 \\
\hline $774 / 2004$ & $1610 / 2007$ & $456 / 2008$ & $1198 / 2004$ & $1540 / 2007$ & $72 / 2008$ & $686 / 2008$ & $401 / 2008$ & $1684 / 2007$ & $1384 / 2004$ \\
\hline 28 & 25 & 31 & 25 & 26 & 25 & 27 & 39 & 29 & 27 \\
\hline 11.1 & 7.0 & 12.1 & 8.2 & 11.4 & 7.0 & 13.8 & 10.8 & 13.1 & 13.5 \\
\hline 6.2 & 4.2 & 6.2 & 4.5 & 6.9 & 4.0 & 8.6 & 6.4 & 8.4 & 9.1 \\
\hline 7.9 & 3.8 & 8.4 & 3.4 & 5.4 & 3.8 & 6.6 & 5.2 & 6.5 & 6.5 \\
\hline 5.1 & 3.0 & 4.8 & 3.2 & 4.6 & 2.8 & 6.4 & 4.7 & 5.7 & 6.5 \\
\hline 7.6 & 5.0 & 8.3 & 5.5 & 8.3 & 4.6 & 11.2 & 7.5 & 8.9 & 10.3 \\
\hline 1.2 & 0.9 & 1.5 & 1.0 & 1.3 & 0.8 & 1.8 & 1.4 & 2.0 & 1.9 \\
\hline 3.1 & 2.8 & 3.1 & 2.5 & 4.0 & 2.6 & 4.4 & 2.9 & 4.9 & 5.3 \\
\hline 3.4 & 2.3 & 3.5 & 2.2 & 3.4 & 2.1 & 4.3 & 3.7 & 4.5 & 4.8 \\
\hline 3.5 & 2.5 & 3.7 & 3.1 & 3.7 & 2.6 & 4.7 & 4.1 & 5.5 & 5.3 \\
\hline 0.1 & 0.1 & 0.1 & 0.1 & 0.2 & 0.1 & 0.2 & 0.1 & 0.3 & 0.4 \\
\hline 2.4 & 1.9 & 2.5 & 1.5 & 2.7 & 1.6 & 3.4 & 2.9 & 3.6 & 3.9 \\
\hline 2.0 & 1.4 & 2.2 & 1.9 & 2.5 & 1.7 & 3.3 & 2.0 & 3.0 & 3.1 \\
\hline 1.1 & 1.2 & 1.0 & 0.8 & 1.6 & 0.9 & 1.7 & 0.9 & 1.8 & 2.0 \\
\hline 2.0 & 1.6 & 2.1 & 1.8 & 2.4 & 1.6 & 2.8 & 2.1 & 3.1 & 3.3 \\
\hline 1.7 & 1.1 & 1.7 & 1.2 & 1.8 & 0.7 & 1.4 & 2.0 & 2.1 & 2.4 \\
\hline 6.9 & 5.2 & 6.7 & 5.2 & 7.7 & 5.1 & 9.8 & 7.0 & 9.9 & 11.2 \\
\hline 4.0 & 1.8 & 5.4 & 3.0 & 3.7 & 1.9 & 4.0 & 3.8 & 3.2 & 2.4 \\
\hline 2.8 & 1.5 & 2.4 & 1.6 & 1.9 & 1.3 & 3.0 & 2.5 & 2.2 & 2.9 \\
\hline 1.4 & 0.5 & 1.4 & 0.4 & 1.0 & 0.6 & 1.7 & 1.1 & 1.5 & 1.0 \\
\hline 23.7 & 14.0 & 20.1 & 14.5 & 21.1 & 13.2 & 28.8 & 21.1 & 23.8 & 23.7 \\
\hline 3.9 & 2.1 & 3.9 & 2.1 & 3.5 & 1.9 & 4.9 & 3.2 & 2.2 & 4.2 \\
\hline 3.6 & 1.9 & 3.5 & 2.2 & 3.4 & 1.6 & 4.9 & 3.0 & 4.0 & 4.2 \\
\hline 4.9 & 2.8 & 4.3 & 2.6 & 4.2 & 2.5 & 6.2 & 4.2 & 5.1 & 5.8 \\
\hline 3.1 & 1.6 & 3.0 & 1.7 & 2.8 & 1.3 & 3.7 & 2.6 & 3.0 & 3.9 \\
\hline 5.3 & 3.2 & 4.4 & 2.6 & 4.7 & 2.8 & 6.9 & 4.8 & 5.4 & 7.5 \\
\hline 5.4 & 3.3 & 4.8 & 3.0 & 4.7 & 2.9 & 6.9 & 4.9 & 5.8 & 7.6 \\
\hline 9.5 & 4.4 & 8.1 & 3.9 & 8.7 & 4.8 & 14.3 & 8.9 & 9.8 & 11.3 \\
\hline 1.2 & 0.9 & 0.8 & 0.5 & 1.2 & 1.0 & 1.9 & 1.2 & 1.6 & 2.4 \\
\hline 1.4 & 0.6 & 0.7 & 0.4 & 0.7 & 0.5 & 1.3 & 1.1 & 0.8 & 1.2 \\
\hline 3.1 & 1.8 & 3.2 & 2.0 & 2.8 & 1.7 & 4.0 & 3.3 & 3.5 & 4.3 \\
\hline 34.8 & 21.0 & 32.1 & 22.7 & 32.5 & 20.2 & 42.6 & 31.9 & 36.9 & 37.3 \\
\hline
\end{tabular}


Table 4. Relative values (\%) of the morphometric parameters of the DNA voucher specimens of tadpoles of Mantidactylus species in the subgenera Ochthomantis and Maitsomantis described in this paper. For abbreviations, see Material and methods.

\begin{tabular}{|c|c|c|c|c|c|c|c|c|}
\hline \multirow{2}{*}{$\begin{array}{l}\text { Species } \\
\text { Site }\end{array}$} & \multirow{2}{*}{$\begin{array}{l}\text { M.femoralis } \\
\text { An'Ala }\end{array}$} & \multirow{2}{*}{$\begin{array}{l}\text { M.femoralis } \\
\text { Isalo }\end{array}$} & \multirow{2}{*}{$\begin{array}{l}\text { M.femoralis } \\
\text { Marojejy }\end{array}$} & \multirow{2}{*}{$\begin{array}{c}\text { M.femoralis } \\
\text { Ranomafana }\end{array}$} & \multirow{2}{*}{$\begin{array}{l}\text { M.femoralis } \\
\text { Vevembe }\end{array}$} & \multicolumn{2}{|c|}{ M. ambreensis $M$. zolitschka } & \multirow{2}{*}{$\begin{array}{l}\text { M. argenteus } \\
\text { An'Ala }\end{array}$} \\
\hline & & & & & & Ambre & An'Ala & \\
\hline Field number & ZCMV & $\mathrm{T}$ & FGZC & ZCMV & TAD & FG/MV & ZCMV & ZCMV \\
\hline & 3431 & $2007-558$ & 2955 & 2640 & 2004-07 & $2002-1950$ & 3565 & 3575 \\
\hline ZSM & $1736 / 2007$ & $1928 / 2007$ & $1630 / 2007$ & $396 / 2008$ & $1385 / 2004$ & $762 / 2004$ & $1843 / 2007$ & $1573 / 2007$ \\
\hline Gos & 28 & 26 & 25 & 28 & 37 & 25 & 27 & 27 \\
\hline $\mathrm{BW} / \mathrm{BL}$ & 57 & 62 & 53 & 57 & 61 & 55 & 55 & 47 \\
\hline SBW/BL & 47 & 58 & 49 & 49 & 73 & 43 & 40 & 50 \\
\hline BW/BH & 141 & 152 & 133 & 164 & 142 & 127 & 148 & 111 \\
\hline $\mathrm{SBH} / \mathrm{BL}$ & 70 & 60 & 69 & 77 & 73 & 60 & 71 & 56 \\
\hline ED/BL & 10 & 10 & 11 & 11 & 12 & 11 & 11 & 9 \\
\hline SE/BL & 32 & 28 & 34 & 32 & 25 & 37 & 30 & 21 \\
\hline $\mathrm{EH} / \mathrm{BH}$ & 73 & 73 & 73 & 61 & 62 & 68 & 68 & 58 \\
\hline IOD/BW & 52 & 47 & 66 & 61 & 50 & 66 & 56 & 63 \\
\hline ND/BL & 1.1 & 1.1 & 1.7 & 1.1 & 0.9 & 2.3 & 1.3 & 0.8 \\
\hline $\mathrm{NH} / \mathrm{BH}$ & 60 & 63 & 69 & 49 & 46 & 58 & 58 & 48 \\
\hline RN/NP & 83 & 61 & 82 & 57 & 57 & 67 & 61 & 68 \\
\hline NH/EH & 83 & 86 & 95 & 81 & 75 & 85 & 86 & 84 \\
\hline IND/IOD & 58 & 56 & 55 & 59 & 60 & 65 & 64 & 54 \\
\hline SL/BL & 16 & 17 & 17 & 30 & 18 & 14 & 17 & 9 \\
\hline $\mathrm{SS} / \mathrm{BL}$ & 65 & 62 & 66 & 77 & 61 & 72 & 62 & 55 \\
\hline $\mathrm{SH} / \mathrm{BH}$ & 69 & 60 & 56 & 40 & 52 & 55 & 40 & 49 \\
\hline $\mathrm{SH} / \mathrm{HAB}$ & 96 & 80 & 93 & 66 & 79 & 85 & 58 & 77 \\
\hline VL/BL & 13 & 9 & 8 & 11 & 13 & 9 & 11 & 14 \\
\hline TAL/BL & 198 & 161 & 200 & 175 & 200 & 225 & 167 & 180 \\
\hline TMW/BW & 52 & 35 & 56 & 44 & 46 & 55 & 45 & 60 \\
\hline TMH/BH & 68 & 63 & 71 & 82 & 62 & 74 & 64 & 67 \\
\hline TMH/MTH & 62 & 73 & 62 & 67 & 61 & 79 & 61 & 63 \\
\hline $\mathrm{TH} / \mathrm{BH}$ & 85 & 82 & 95 & 95 & 90 & 85 & 92 & 84 \\
\hline TMHM/ТНM & 58 & 53 & 53 & 56 & 48 & 62 & 34 & 55 \\
\hline TMHM/MTH & 50 & 48 & 50 & 55 & 47 & 55 & 33 & 51 \\
\hline THM/BH & 95 & 78 & 109 & 120 & 99 & 83 & 100 & 97 \\
\hline THM/MTH & 87 & 91 & 95 & 98 & 97 & 88 & 96 & 92 \\
\hline MTH/BH & 109 & 86 & 115 & 123 & 102 & 94 & 105 & 106 \\
\hline DMTH/TAL & 40 & 31 & 40 & 57 & 44 & 45 & 43 & 37 \\
\hline DF/TMHM & 40 & 47 & 48 & 46 & 56 & 33 & 82 & 43 \\
\hline VF/TMHM & 37 & 42 & 41 & 31 & 43 & 27 & 68 & 41 \\
\hline $\mathrm{DF} / \mathrm{VF}$ & 107 & 111 & 115 & 151 & 131 & 124 & 122 & 104 \\
\hline $\mathrm{HAB} / \mathrm{BH}$ & 72 & 75 & 60 & 61 & 66 & 65 & 70 & 64 \\
\hline
\end{tabular}

BL), maximal tail height higher than body height (MTH $109 \%$ of $\mathrm{BH})$, tail height at midtail almost equal to body height and lower than maximal tail height (THM 95\% of BH and 87\% of MTH), tail height at the beginning of the tail lower than body height (TH $85 \%$ of BH). Moderately developed caudal musculature (TMW $51 \%$ of BW, TMH $68 \%$ of BH, TMH of $80 \%$ of TH and $62 \%$ of MTH, TMHM $58 \%$ of THM and $50 \%$ of MTH). Tail muscle reaches tail tip. Very low fin type (DF $40 \%$ of TMHM, VF $37 \%$ of
MTHM), dorsal fin higher than ventral fin at mid-tail (DF $107 \%$ of VF). Dorsal fin originates on tail muscle on the proximal $1 / 5$ of the tail, increases abruptly to attain its maximal height before midtail and then progresses horizontally until the 9/10 of the tail and finally decreases gradually towards the tail tip. Ventral fin originates at the ventral terminus of the body, remains parallel with tail muscle almost to tail tip, then decreases to tail tip. Maximal tail height located between the proximal $1 / 5$ and $2 / 5$ of the tail (DMTH 
Table 4. continued.

\begin{tabular}{|c|c|c|c|c|c|c|c|c|c|}
\hline M. sp. 42 & M. sp. 43 & M.sp. 47 & M.sp. 47 & M. mocquard & li M. mocquardi & i M. mocquar & di M. sp. 64 & M. majori & M. majori \\
\hline Ambre & Marojejy & Ambatolahy & Maharira & An'Ala & Ambohitsara & Mahasoa & Namorona & Ranomafana & Vevembe \\
\hline FG/MV & FGZC & ZCMV & TAD & ZCMV & ZCMV & ZCMV & ZCMV & TAD & ZCMV \\
\hline $2002-1957$ & 2928 & 2699 & $2004-638$ & 3511 & 4936 & 8094 & 2646 & 6 Vevembe & 3761 \\
\hline $774 / 2004$ & $1610 / 2007$ & $456 / 2008$ & $1198 / 2004$ & $1540 / 2007$ & $72 / 2008$ & $686 / 2008$ & $401 / 2008$ & $1684 / 2007$ & $1384 / 2004$ \\
\hline 28 & 25 & 31 & 25 & 26 & 25 & 27 & 39 & 29 & 27 \\
\hline 56 & 60 & 52 & 55 & 60 & 58 & 63 & 59 & 64 & 67 \\
\hline 71 & 54 & 69 & 42 & 47 & 54 & 48 & 48 & 49 & 48 \\
\hline 123 & 142 & 130 & 143 & 148 & 143 & 136 & 136 & 147 & 141 \\
\hline 68 & 71 & 69 & 67 & 73 & 66 & 81 & 69 & 68 & 77 \\
\hline 11 & 13 & 13 & 12 & 12 & 11 & 13 & 13 & 15 & 14 \\
\hline 28 & 39 & 26 & 31 & 35 & 36 & 32 & 27 & 38 & 39 \\
\hline 67 & 78 & 73 & 69 & 73 & 73 & 67 & 79 & 78 & 75 \\
\hline 55 & 59 & 59 & 69 & 53 & 65 & 54 & 64 & 66 & 58 \\
\hline 1.1 & 2.0 & 1.1 & 1.1 & 1.4 & 2.0 & 1.6 & 1.3 & 2.5 & 3.3 \\
\hline 47 & 65 & 53 & 49 & 59 & 58 & 53 & 62 & 64 & 60 \\
\hline 57 & 76 & 48 & 43 & 67 & 57 & 59 & 43 & 59 & 59 \\
\hline 70 & 84 & 72 & 71 & 81 & 79 & 79 & 79 & 81 & 81 \\
\hline 57 & 58 & 58 & 60 & 68 & 64 & 70 & 48 & 53 & 58 \\
\hline 15 & 15 & 14 & 14 & 16 & 11 & 10 & 19 & 16 & 18 \\
\hline 62 & 75 & 56 & 63 & 67 & 73 & 71 & 64 & 76 & 83 \\
\hline 55 & 52 & 51 & 50 & 42 & 45 & 48 & 54 & 38 & 45 \\
\hline 89 & 85 & 76 & 81 & 70 & 76 & 76 & 76 & 61 & 67 \\
\hline 13 & 7 & 11 & 5 & 9 & 8 & 12 & 10 & 11 & 7 \\
\hline 214 & 201 & 166 & 176 & 185 & 189 & 209 & 196 & 181 & 176 \\
\hline 62 & 49 & 63 & 47 & 51 & 46 & 56 & 50 & 26 & 46 \\
\hline 72 & 64 & 73 & 71 & 74 & 56 & 78 & 64 & 70 & 66 \\
\hline 67 & 58 & 73 & 75 & 73 & 54 & 71 & 62 & 69 & 56 \\
\hline 96 & 94 & 90 & 83 & 91 & 87 & 97 & 89 & 89 & 90 \\
\hline 58 & 51 & 67 & 65 & 60 & 46 & 54 & 55 & 56 & 53 \\
\hline 57 & 50 & 62 & 56 & 59 & 44 & 54 & 53 & 52 & 52 \\
\hline 105 & 107 & 90 & 82 & 91 & 99 & 97 & 89 & 94 & 116 \\
\hline 98 & 96 & 93 & 87 & 99 & 96 & 100 & 97 & 93 & 98 \\
\hline 107 & 111 & 100 & 95 & 102 & 103 & 109 & 103 & 101 & 118 \\
\hline 40 & 31 & 40 & 27 & 42 & 36 & 50 & 42 & 41 & 47 \\
\hline 40 & 57 & 28 & 32 & 41 & 75 & 52 & 44 & 53 & 60 \\
\hline 45 & 39 & 24 & 24 & 25 & 42 & 34 & 42 & 27 & 29 \\
\hline 87 & 148 & 117 & 133 & 162 & 178 & 154 & 106 & 195 & 205 \\
\hline 62 & 60 & 67 & 62 & 60 & 60 & 63 & 70 & 62 & 67 \\
\hline
\end{tabular}

$40 \%$ of TAL), lateral tail vein and myosepta slightly visible on the proximal $3 / 4$ of the tail musculature, point where the axis of the tail myotomes contacts the body in the upper half of the body height (HAB 72\% of $\mathrm{BH}$ ), axis of the tail myotomes parallel with the axis of the trunk. Tail tip narrowly rounded.

Small reduced oral disk (ODW 24\% of BW), positioned ventrally and directed anteroventrally, not emarginated, maximal width in the middle. Oral disk visible from dorsal view, upper labium is a continua- tion of snout. Single row of marginal papillae interrupted by a moderately wide gap on the upper labium (DG $48 \%$ of ODW), gap on the lower labium absent; total number of marginal papillae 59. Sixty-nine submarginal papillae on the lower labium and laterally on upper labium. Short and moderately wide conical papillae with rounded tips, longest marginal papillae measured $0.15 \mathrm{~mm}$ and $0.16 \mathrm{~mm}$ for submarginal papillae, papillae visible from dorsal view. LTRF 3(23)/3(1-2) after Altig and McDiarmid (1999). Single 
Table 5. Comparison of the oral disk characteristics of the voucher specimens of tadpoles of Mantidactylus species in the subgenera Ochthomantis and Maitsomantis described in this paper. JW, Thorn-pap, MCL, DG, $\mathrm{A}_{1-2 \text { len }}, \mathrm{P}_{1-3 \text { len }}, \mathrm{A}_{2 \text { gap }}, \mathrm{A}_{2 \text { row }+ \text { gap }}$, Kerat len, MP len and SMP len are in mm. ODW/BW, DG/ODW, JW/ODW, MCL/JW, $\mathrm{A}_{1} / \mathrm{ODW}$ and $\mathrm{A}_{2} \mathrm{Gap} / \mathrm{A}_{2}$ are in \%. $\mathrm{A}_{1-2 \text { den }}, \mathrm{P}_{1-3 \text { den }}$, is density (number/mm). UR, LR, A 1 num, MP, SMP and Tot pap are total numbers. A: ventrally; B: anteroventrally; C: soft partially keratinised with smooth surface; D: thorn-shaped papillae, not keratinized; E: lower sheath totally hidden; F: short widely pointed; G: short

\begin{tabular}{|c|c|c|c|c|c|c|c|c|}
\hline \multirow{2}{*}{$\begin{array}{l}\text { Species } \\
\text { Site }\end{array}$} & \multirow{2}{*}{$\begin{array}{l}\text { M.femoralis } \\
\text { An'Ala }\end{array}$} & \multirow{2}{*}{$\begin{array}{l}\text { M. femoralis } \\
\text { Isalo }\end{array}$} & \multirow{2}{*}{$\begin{array}{l}\text { M.femoralis } \\
\text { Marojejy }\end{array}$} & \multirow{2}{*}{$\begin{array}{l}\text { M.femoralis } \\
\text { Ranomafana }\end{array}$} & \multirow{2}{*}{$\begin{array}{l}\text { M.femoralis } \\
\text { Vevembe }\end{array}$} & \multicolumn{2}{|c|}{ M. ambreensis M. zolitschka } & \multirow{2}{*}{$\begin{array}{l}\text { M. argenteus } \\
\text { An'Ala }\end{array}$} \\
\hline & & & & & & Ambre & An'Ala & \\
\hline Field number & ZCMV & $\mathrm{T}$ & FGZC & ZCMV & TAD & FG/MV & ZCMV & ZCMV \\
\hline & 3431 & $2007-558$ & 2955 & 2640 & 2004-07 & 2002-1950 & 3565 & 3575 \\
\hline ZSM & $1736 / 2007$ & $1928 / 2007$ & $1630 / 2007$ & $396 / 2008$ & $1385 / 2004$ & $762 / 2004$ & $1843 / 2007$ & $1573 / 2007$ \\
\hline Gos & 28 & 26 & 25 & 28 & 37 & 25 & 27 & 27 \\
\hline ODW & 2.8 & 2.5 & 1.6 & 2.2 & 3.0 & 1.1 & 2.0 & 1.8 \\
\hline LTRF & $3(2-3) / 3(1-2)$ & $3(2-3) / 3(1-2)$ & $3(2-3) / 3(1-2)$ & $3(2-3) / 3(1-2)$ & $3(2-3) / 3(1-2)$ & $2(2) / 3(1-2)$ & $3(2-3) / 3(1-2)$ & $2(2) / 3(1-2)$ \\
\hline UR & 3 & 3 & 3 & 3 & 3 & 2 & 3 & 2 \\
\hline LR & 3 & 3 & 3 & 3 & 3 & 3 & 3 & 3 \\
\hline JW & 1.3 & 1.1 & 0.6 & 1.2 & 1.1 & 0.6 & 1.0 & 0.8 \\
\hline Thorn-pap & not app & not app & not app & not app & not app & not app & not app & not app \\
\hline MCL & $0.24^{11}$ & $0.23^{11}$ & $0.14^{11}$ & 0.25 & $0.30^{11}$ & $0.10^{11}$ & $0.29^{11}$ & $0.25^{11}$ \\
\hline DG & 1.32 & 1.41 & 0.86 & 1.37 & 1.24 & 0.73 & 1.12 & 1.09 \\
\hline VG & abs & abs & abs & abs & abs & abs & abs & abs \\
\hline $\mathrm{A}_{1 \text { len }}$ & 1.23 & 1.49 & 1.02 & 1.34 & 0.97 & 0.72 & 0.93 & 1.15 \\
\hline$A_{2 \operatorname{len}}(R / L)$ & $0.20 / 0.22$ & $0.23 / 0.18$ & $0.24 / 0.29$ & $0.29 / 0.26$ & $0.16 / 0.22$ & $0.12 / 0.13$ & $0.20 / 0.19$ & $0.14 / 0.20$ \\
\hline$A_{2 \text { gap }}$ & 0.83 & 1.06 & 0.44 & 0.85 & 0.98 & 0.49 & 0.72 & 0.58 \\
\hline$A_{2 \text { row }+ \text { gap }}$ & 1.25 & 1.47 & 0.97 & 1.40 & 1.36 & 0.84 & 1.11 & 0.92 \\
\hline$A_{3 \operatorname{len}}(R / L)$ & $0.11 / 0.14$ & $0.07 / 0.11$ & $0.12 / 0.14$ & $0.20 / 0.19$ & $0.16 / 0.19$ & abs & $0.14 / 0.08$ & abs \\
\hline $\mathrm{P}_{1 \text { len }}(\mathrm{R} / \mathrm{L})$ & $0.59 / 0.61$ & $0.56 / 0.57$ & $0.43 / 0.45$ & $0.55 / 0.50$ & $0.72 / 0.62$ & $0.30 / 0.27$ & $0.60 / 0.45$ & $0.28 / 0.27$ \\
\hline $\mathrm{P}_{2 \text { len }}(\mathrm{R} / \mathrm{L})$ & $0.57 / 0.65$ & $0.62 / 0.48$ & $0.47 / 0.44$ & $0.62 / 0.50$ & $0.57 / 0.50$ & $0.26 / 0.26$ & $0.66 / 0.34$ & 0.4570 .43 \\
\hline $\mathrm{P}_{3 \text { len }}$ & 0.57 & 1.12 & 0.57 & 0.41 & 0.38 & 0.31 & 0.25 & 0.19 \\
\hline Kerat len & 0.06 & 0.06 & 0.06 & 0.07 & 0.08 & 0.04 & 0.05 & 0.06 \\
\hline MP len & 0.17 & 0.10 & 0.09 & 0.09 & 0.12 & 0.08 & 0.10 & 0.15 \\
\hline SMP len & 0.16 & 0.13 & 0.08 & 0.11 & 0.20 & 0.08 & 0.15 & 0.07 \\
\hline ODW/BW & 42 & 32 & 46 & 38 & 39 & 35 & 40 & 31 \\
\hline DG/ODW & 48 & 58 & 55 & 63 & 41 & 66 & 56 & 62 \\
\hline JW/ODW & 49 & 46 & 37 & 53 & 35 & 53 & 47 & 43 \\
\hline MCL/JW & 18 & 21 & 24 & 22 & 28 & 17 & 31 & 33 \\
\hline $\mathrm{A}_{1} / \mathrm{ODW}$ & 45 & 61 & 65 & 62 & 32 & 65 & 46 & 65 \\
\hline $\mathrm{A}_{2} \mathrm{Gap} / \mathrm{A}_{2}$ & 66 & 72 & 45 & 61 & 72 & 58 & 65 & 63 \\
\hline $\mathrm{A}_{1 \text { num }}$ & 48 & 50 & 55 & 43 & 39 & 21 & 25 & 41 \\
\hline $\mathrm{A}_{2 \text { num }}(\mathrm{R} / \mathrm{L})$ & $10 / 10$ & $10 / 7$ & $12 / 13$ & $10 / 10$ & $8 / 11$ & $6 / 6$ & $7 / 8$ & $5 / 6$ \\
\hline$A_{3 \text { num }}(R / L)$ & $7 / 6$ & $3 / 5$ & $5 / 7$ & $10 / 11$ & $5 / 9$ & abs & $7 / 3$ & abs \\
\hline $\mathrm{p}_{1 \text { num }}(\mathrm{R} / \mathrm{L})$ & $28 / 29$ & $20 / 20$ & $24 / 24$ & 30726 & $42 / 38$ & $12 / 13$ & $22 / 25$ & $8 / 9$ \\
\hline $\mathrm{P}_{2 \text { num }}(\mathrm{R} / \mathrm{L})$ & $21 / 24$ & $21 / 15$ & $21 / 22$ & $30 / 28$ & $22 / 25$ & $13 / 14$ & $20 / 20$ & $16 / 15$ \\
\hline $\mathrm{P}_{3 \text { num }}$ & 20 & 15 & 27 & 17 & 15 & 10 & 11 & 5 \\
\hline $\mathrm{MP}$ & 59 & 50 & 43 & 59 & 71 & 30 & 69 & 31 \\
\hline SMP & 69 & 69 & 30 & 65 & 60 & 18 & 46 & 18 \\
\hline Total pap & 128 & 119 & 73 & 124 & 131 & 48 & 115 & 49 \\
\hline$A_{1 \text { den }}$ & 39 & 34 & 53 & 32 & 40 & 29 & 27 & 36 \\
\hline $\mathrm{A}_{2 \mathrm{den}}$ & 48 & 33 & 47 & 54 & 53 & abs & 38 & 32 \\
\hline $\mathrm{A}_{3 \mathrm{den}}$ & 50 & 44 & 46 & 44 & 38 & abs & 46 & abs \\
\hline $\mathrm{p}_{1 \text { den }}$ & 48 & 35 & 55 & 53 & 60 & 44 & 45 & 31 \\
\hline $\mathrm{P}_{2 \text { den }}$ & 37 & 32 & 47 & 52 & 45 & 52 & 40 & 35 \\
\hline $\mathrm{P}_{3 \text { den }}$ & 35 & 39 & 47 & 41 & 39 & 32 & 44 & 26 \\
\hline OD orient & $\mathrm{B}$ & A & A & A & A & $\mathrm{B}$ & $\mathrm{B}$ & $\mathrm{B}$ \\
\hline Up sheaths & $\mathrm{C}$ & $\mathrm{C}$ & $\mathrm{C}$ & $\mathrm{C}$ & $\mathrm{C}$ & $\mathrm{C}$ & $\mathrm{C}$ & $\mathrm{C}$ \\
\hline Low sheath & $\mathrm{E}$ & $\mathrm{E}$ & $\mathrm{E}$ & $\mathrm{E}$ & $\mathrm{E}$ & $\mathrm{E}$ & $\mathrm{E}$ & $\mathrm{E}$ \\
\hline $\mathrm{MC}$ & $\mathrm{G}$ & I & $\mathrm{G}$ & I & I & $\mathrm{F}$ & $\mathrm{K}$ & $\mathrm{K}$ \\
\hline Up labium & M & M & M & M & M & M & M & M \\
\hline Papillae & $\mathrm{O}$ & $\mathrm{O}$ & $\mathrm{O}$ & $\mathrm{O}$ & $\mathrm{O}$ & $\mathrm{O}$ & $\mathrm{O}$ & $\mathrm{O}$ \\
\hline Lower row & $\mathrm{R}$ & $\mathrm{R}$ & $\mathrm{R}$ & $\mathrm{R}$ & $\mathrm{R}$ & $\mathrm{R}$ & $\mathrm{R}$ & $\mathrm{R}$ \\
\hline
\end{tabular}


widely rounded; H: moderately long widely pointed; I: moderately long widely rounded; J: moderately long narrowly pointed; K: long narrowly pointed; L: very long narrowly pointed; $\mathrm{M}$ : upper labium is a continuation of the snout; N: anterior margin is separated by a shallow crevice; O: moderately long with rounded tip; P: long, MP rounded tip, SMP pointed tip; Q: long, with pointed tip (MP and SMP); R: scattered and forming chevron; S: lower row absent; not app: not applicable; abs: absent. For further abbreviations, see Material and methods.

\begin{tabular}{|c|c|c|c|c|c|c|c|c|c|}
\hline M. sp. 42 & M. sp. 43 & M.sp. 47 & M.sp. 47 & M. mocquard & M. mocquardi & M. mocquard & M.sp. 64 & M. majori & M. majori \\
\hline Ambre & Marojejy & Ambatolahy & Maharira & An'Ala & Ambohitsara & Mahasoa & Namorona & Ranomafana & Vevembe \\
\hline FG/MV & FGZC & ZCMV & TAD & ZCMV & ZCMV & ZCMV & ZCMV & Tad & ZCMV \\
\hline $2002-1957$ & 2928 & 2699 & $2004-638$ & 3511 & 4936 & 8094 & 2646 & 6 Vevembe & 3761 \\
\hline $774 / 2004$ & $1610 / 2007$ & $456 / 2008$ & $1198 / 2004$ & $1540 / 2007$ & $72 / 2008$ & $686 / 2008$ & $401 / 2008$ & $1684 / 2007$ & $1384 / 2004$ \\
\hline 28 & 25 & 31 & 25 & 26 & 25 & 27 & 39 & 29 & 27 \\
\hline 2.3 & 2.0 & 2.3 & 2.1 & 3.0 & 1.7 & 4.0 & 2.2 & 3.4 & 3.4 \\
\hline $3(2-3) / 3(1-2)$ & $2(2) / 3(1-2)$ & $3(2-3) / 3(1-2)$ & $3(2-3) / 3(1-2)$ & not app & not app & not app & not app & not app & not app \\
\hline 3 & 2 & 3 & 3 & not app & not app & not app & not app & not app & not app \\
\hline 3 & 3 & 3 & 3 & not app & not app & not app & not app & not app & not app \\
\hline 1.2 & 0.8 & 1.2 & 0.9 & 1.3 & 0.5 & 1.9 & 1.2 & 1.8 & 1.7 \\
\hline not app & not app & not app & not app & not app & not app & not app & not app & $0.6 / 0.8 / 0.7$ & $0.5 / 0.7 / 0.5$ \\
\hline 0.21 & 0.20 & 0.23 & $0.19^{1}$ & $0.28^{1}$ & $0.24^{1}$ & 0.57 & 0.26 & not app & not app \\
\hline 1.06 & 1.03 & 1.00 & 0.92 & abs & abs & abs & abs & abs & abs \\
\hline abs & abs & abs & abs & abs & abs & abs & abs & abs & abs \\
\hline 0.74 & 0.98 & 0.95 & 0.76 & abs & abs & abs & abs & abs & abs \\
\hline $0.07 / 0.12$ & $0.15 / 0.17$ & $0.16 / 0.11$ & $0.11 / 0.16$ & abs & abs & abs & abs & abs & abs \\
\hline 0.86 & 0.73 & 0.84 & 0.60 & abs & abs & abs & abs & abs & abs \\
\hline 1.05 & 1.10 & 1.11 & 0.87 & abs & abs & abs & abs & abs & abs \\
\hline $0.07 / 0.06$ & abs & $0.50 / 0.50$ & $0.13 / 0.15$ & abs & abs & abs & abs & abs & abs \\
\hline $0.52 / 0.56$ & $0.34 / 0.40$ & $0.50 / 0.43$ & $0.41 / 0.47$ & abs & abs & abs & abs & abs & abs \\
\hline $0.45 / 0.42$ & $0.21 / 0.25$ & $0.45 / 0.34$ & $0.47 / 0.50$ & abs & abs & abs & abs & abs & abs \\
\hline 0.87 & 0.09 & 0.25 & 0.49 & abs & abs & abs & abs & abs & abs \\
\hline 0.09 & 0.07 & 0.05 & 0.04 & not app & not app & not app & not app & not app & not app \\
\hline 0.13 & 0.10 & 0.14 & 0.09 & 0.19 & 0.09 & 0.25 & 0.11 & 0.25 & 0.22 \\
\hline 0.14 & 0.08 & 0.11 & 0.10 & 0.25 & 0.12 & 0.35 & 0.15 & 0.41 & 0.52 \\
\hline 36 & 46 & 36 & 47 & 43 & 42 & 47 & 34 & 40 & 38 \\
\hline 47 & 53 & 44 & 43 & abs & abs & abs & abs & abs & abs \\
\hline 52 & 41 & 51 & 39 & 43 & 32 & 48 & 56 & 54 & 51 \\
\hline 18 & 25 & 20 & 23 & 22 & 44 & 30 & 21 & not app & not app \\
\hline 33 & 51 & 42 & 36 & not app & not app & not app & not app & not app & not app \\
\hline 82 & 66 & 76 & 69 & not app & not app & not app & not app & not app & not app \\
\hline 12 & 13 & 14 & 23 & abs & abs & abs & abs & abs & abs \\
\hline $4 / 6$ & $8 / 10$ & $5 / 5$ & $5 / 6$ & abs & abs & abs & abs & abs & abs \\
\hline $4 / 3$ & abs & $2 / 2$ & 12 & abs & abs & abs & abs & abs & abs \\
\hline $24 / 21$ & $14 / 16$ & $19 / 17$ & $17 / 18$ & abs & abs & abs & abs & abs & abs \\
\hline $19 / 19$ & $10 / 12$ & $18 / 13$ & $21 / 21$ & abs & abs & abs & abs & abs & abs \\
\hline 13 & 5 & 9 & 24 & abs & abs & abs & abs & abs & abs \\
\hline 53 & 78 & 72 & 64 & 74 & 64 & 89 & 81 & 72 & 105 \\
\hline 42 & 50 & 66 & 58 & 104 & 77 & 88 & 87 & 135 & 201 \\
\hline 95 & 128 & 138 & 122 & 178 & 141 & 177 & 168 & 207 & 306 \\
\hline 16 & 13 & 15 & 30 & not app & not app & not app & not app & not app & not app \\
\hline 53 & 56 & 35 & 39 & abs & abs & abs & abs & abs & abs \\
\hline 54 & abs & 40 & 43 & abs & abs & abs & abs & abs & abs \\
\hline 38 & 41 & 39 & 40 & abs & abs & abs & abs & abs & abs \\
\hline 44 & 63 & 39 & 43 & abs & abs & abs & abs & abs & abs \\
\hline 30 & 56 & 36 & 49 & abs & abs & abs & abs & abs & abs \\
\hline B & $\mathrm{B}$ & $\mathrm{B}$ & A & B & B & A & B & A & A \\
\hline $\mathrm{C}$ & $\mathrm{C}$ & $\mathrm{C}$ & $\mathrm{C}$ & $\mathrm{C}$ & $\mathrm{C}$ & $\mathrm{C}$ & $\mathrm{C}$ & D & D \\
\hline $\mathrm{E}$ & $\mathrm{E}$ & $\mathrm{E}$ & $\mathrm{E}$ & $\mathrm{E}$ & $\mathrm{E}$ & $\mathrm{E}$ & $\mathrm{E}$ & $\mathrm{E}$ & $\mathrm{E}$ \\
\hline $\mathrm{G}$ & $\mathrm{H}$ & $\mathrm{H}$ & $\mathrm{H}$ & $\mathrm{J}$ & $\mathrm{L}$ & $\mathrm{L}$ & $\mathrm{G}$ & not app & not app \\
\hline M & M & M & M & M & M & M & M & $\mathrm{N}$ & $\mathrm{N}$ \\
\hline $\mathrm{O}$ & $\mathrm{O}$ & $\mathrm{O}$ & $\mathrm{O}$ & $\mathrm{P}$ & $\mathrm{P}$ & $\mathrm{P}$ & $\mathrm{P}$ & Q & Q \\
\hline $\mathrm{R}$ & $\mathrm{R}$ & $\mathrm{R}$ & $\mathrm{R}$ & $\mathrm{S}$ & $\mathrm{S}$ & $S$ & $\mathrm{~S}$ & $\mathrm{~S}$ & $\mathrm{~S}$ \\
\hline
\end{tabular}




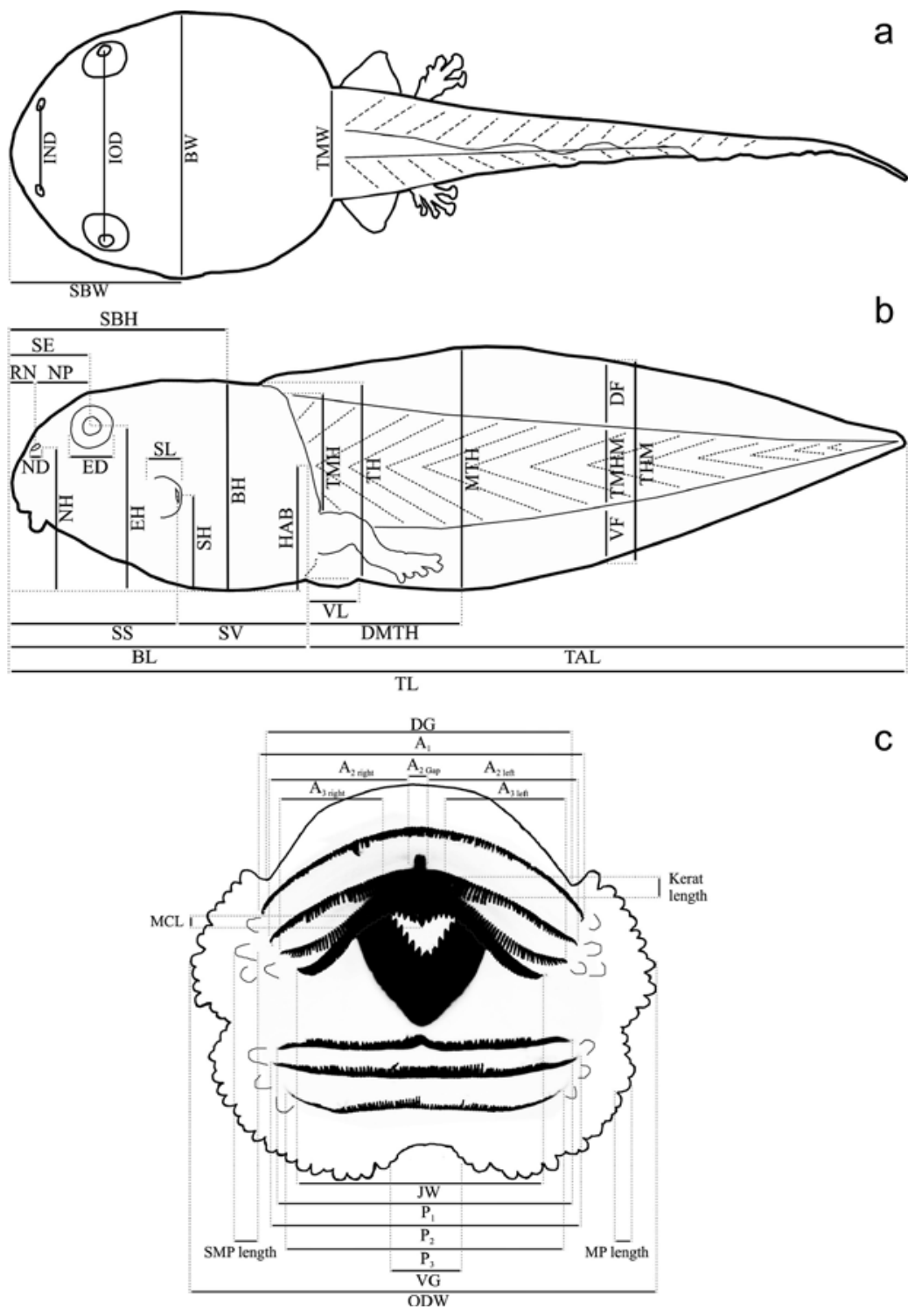

a

Fig. 9. Drawings representing the landmarks of the measurements: (a) dorsal view, (b) lateral view, (c) oral disk. row of keratondonts per ridge. Moderately long $\mathrm{A}_{1}$ row $\left(A_{1 \text { len }} 45 \%\right.$ of ODW). Density of keratodonts varies from $35 / \mathrm{mm}$ to $50 / \mathrm{mm}, \mathrm{A}_{1 \text { den }} 39 / \mathrm{mm}$ (total 48 ). Wide gap in the first anterior interrupted row $\left(\mathrm{A}_{2 \text { gap }} 66 \%\right.$ of $\mathrm{A}_{2}$ ). Row alignment irregular, lower keratodont rows form a chevron, $\mathrm{P}_{1}$ and $\mathrm{P}_{2}$ interrupted, $\mathrm{P}_{2}$ and $\mathrm{P}_{3}$ scattered. Short discernible keratodonts $(0.06 \mathrm{~mm})$. Distal keratodonts have the same lengths as those in the middle; prominent space between marginal papillae and keratodont rows. Partially keratinized upper jaw sheath, edge of the medial convexity black coloured and the rest whitish; finely pointed serrations; moderately wide jaw sheath (JW $48 \%$ of ODW) with a short widely rounded medial convexity (MCL $18 \%$ of JW). Lower jaw sheath V-shaped, partially keratinized and totally hidden by the upper jaw sheath.

Colouration in preservative. Uniformly dark brown. Brown melanic pigment positioned in deeper dermal layers, separated from a (possibly epidermal) transparent outer skin layer, covering the dorsum and flank of the body. Some dark brown patches scattered on the dorsal skin. Laterally, jugal area (under eyes and nares) and flank covered by dark brown reticulations. The spiracle is reticulated at the base and transparent at the end, and detectable, and is situated the visible intestinal coils. Lower part of the flank not pigmented. 


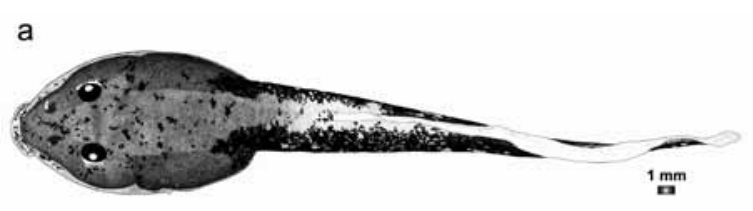

b
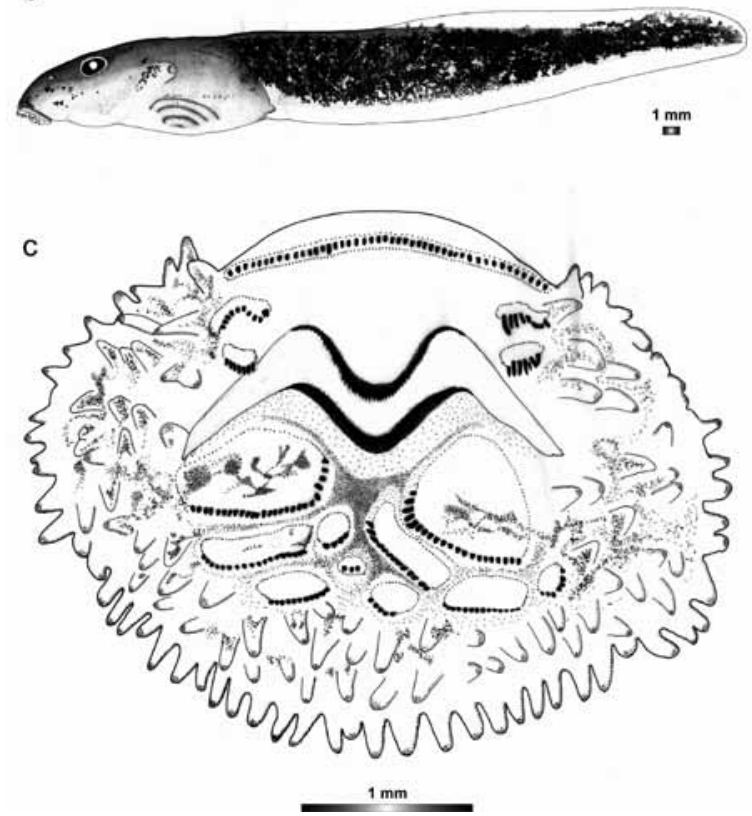

Fig. 10. Drawings of the preserved DNA voucher tadpole of Mantidactylus femoralis (ZCMV 3431-ZSM 1736/2007): (a) dorsal view, (b) lateral view, (c) oral disk.

Tail musculature overlain by dark brown reticulations. Fins pale, dorsal fin with sparse brown reticulations. Ventrally, oral disk, gular and branchial regions patched; venter pale, intestinal coils perceptible and regularly spiral shaped.

Variation. Six voucher specimen (ZSM 1554/2007ZCMV 3536, ZSM 1555/2007-ZCMV 3537, ZSM 1733/2007-ZCMV 3428, ZSM 1781/2007-ZCMV 3476, ZSM 1834/2007-ZCMV 3554, ZSM 1848/2007ZCMV 3572) from the same locality show a similar oral disk configuration.

\section{Mantidactylus ambreensis Mocquard, 1895}

The following description refers to one tadpole in developmental stage 25 (field number FG/MV 2002.1950ZSM 762/2004, BL $5.7 \mathrm{~mm}$, TL $18.4 \mathrm{~mm}$ ) from a stream crossing the track 'Voie des milles arbres' at the Montagne d'Ambre National Park. The 16S rDNA sequence of this specimen was $100 \%$ identical to a reference sequence of an adult specimen of Mantidactylus ambreensis (accession AY324822) from the same locality.

In dorsal view, body ovoid (BW 55\% of BL), maximal body width attained between the proximal $2 / 5$ and $3 / 5$ of the body (SBW $43 \%$ of BL), narrowly rounded snout. In lateral view, body depressed (BW $127 \%$ of $\mathrm{BH}$ ), maximal body height attained at the $3 / 5$ of the body (SBH $60 \%$ of BL), narrowly rounded snout. Moderately large eyes (ED 11\% of BL), not visible from ventral view, positioned high (EH 68\% of $\mathrm{BH})$ dorsally and directed laterally, situated between the proximal $3 / 10$ and $4 / 10$ of the body (SE 37\% of $\mathrm{BL}$ ), wide distance between eyes (IOD $66 \%$ of BW). Moderately large rounded nares (ND 2.3\% of BL), marked with a marginal rim, positioned moderately high (NH 58\% of $\mathrm{BH}$ ) dorsally and oriented anterolaterally, situated nearer to snout than to eye (RN 67\% of NP) and below eye level (NH 85\% of EH), wide distance between nares (IND 65\% of IOD), no dark spot on the back of the nares, ornamentation absent. Short sinistral spiracle (SL 14\% of BL), directed posteriodorsally, visible from dorsal and ventral views, perceptible from lateral view; inner wall free from body and formed such that aperture opens laterally instead of posteriorly, rounded opening, situated between the proximal $3 / 5$ and $4 / 5$ of the body (SS 72\% of $\mathrm{BL}$ ), located moderately high on the body (SH $55 \%$ of $\mathrm{BH}$ ) and below the height of the point where the axis of the tail myotomes contacts the body (SH 85\% of HAB). Short dextral vent tube (VL 9\% of BL), attached to ventral fin, inner wall present. No gland. Moderately long tail (TAL 225\% of BL), maximal tail height lower than body height (MTH 94\% of BH), tail height at midtail lower than body height and maximal tail height (THM $83 \%$ of BH and $87 \%$ of MTH), tail height at the beginning of the tail lower than body height (TH $85 \%$ of $\mathrm{BH}$ ). Developed caudal musculature (TMW $55 \%$ of BW, TMH $74 \%$ of BH, TMH of $80 \%$ of TH and $79 \%$ of MTH, TMHM $62 \%$ of THM and $55 \%$ of MTH). Tail muscle reaches tail tip. Very low fin type (DF $33 \%$ of TMHM, VF $26 \%$ of MTHM), higher than ventral fin at mid-tail (DF 124\% of VF). Dorsal fin originates between the dorsal body-tail junction and the proximal $1 / 4$ of tail, ascends to attain its maximal height before midtail and then continues straight until the proximal $3 / 4$ of the tail, and then decreases towards the tail tip. Ventral fin originates at the ventral terminus of the body, remains straight until the proximal $3 / 4$ of the tail, and then decreases towards 
the tail tip. Maximal tail height located between the proximal $2 / 5$ and $3 / 5$ of the tail (DMTH $45 \%$ of TAL), lateral tail vein not visible, myosepta perceptible on the proximal $1 / 2$ of the tail musculature, point where the axis of the tail myotomes contacts the body in the upper half of the body height (HAB 65\% of BH), axis of the tail myotomes parallel with the axis of the trunk. Tail tip narrowly rounded.

Small reduced oral disk (ODW 35\% of BW), positioned and directed ventrally, not emarginated, maximal width in the middle. Oral disk not visible from dorsal view, upper labium is a continuation of snout. Single row of marginal papillae interrupted by a wide gap on the upper labium (DG 66\% of ODW), gap on the lower labium absent; total number of marginal papillae is 30. Eighteen submarginal papillae, continuous on the lower labium and laterally on upper labium. Very short and small rounded papillae with rounded tips, longest marginal and submarginal papillae measured $0.08 \mathrm{~mm}$, papillae not visible from dorsal view. LTRF 2(2)/3(1-2) after Altig and McDiarmid (1999). Single row of kera-

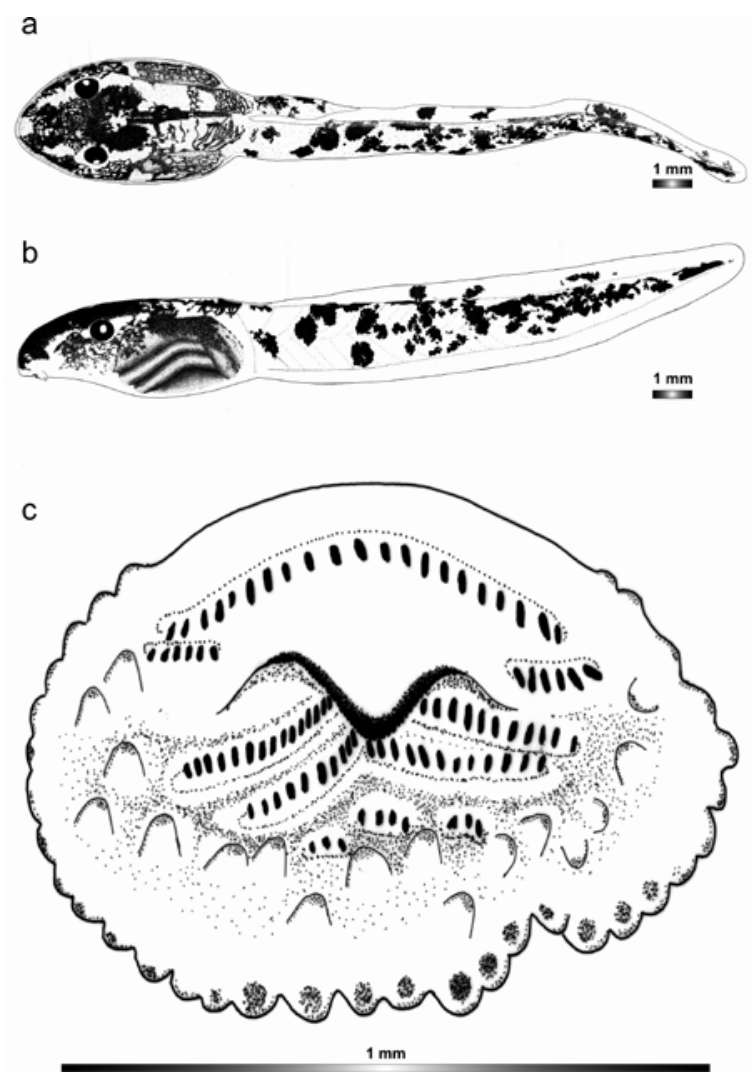

Fig. 11. Drawings of the preserved DNA voucher tadpole of Mantidactylus ambreensis (FG/MV 2002.1950-ZSM 762/2004): (a) dorsal view, (b) lateral view, (c) oral disk. tondonts per ridge. Long $A_{1}$ row $\left(A_{1 \text { len }} 65 \%\right.$ of ODW). Density of keratodonts varies from $29 / \mathrm{mm}$ to $52 / \mathrm{mm}$, $A_{1 \text { den }} 29 / \mathrm{mm}$ (total 21). Moderately wide gap in the first anterior interrupted row $\left(\mathrm{A}_{2 \text { gap }} 58 \%\right.$ of $\left.\mathrm{A}_{2}\right)$. Row alignment irregular, lower keratodont rows form a chevron, $\mathrm{P}_{1}$ and $\mathrm{P}_{2}$ interrupted, $\mathrm{P}_{3}$ scattered. Very short distinguishable keratodonts $(0.04 \mathrm{~mm})$. Distal keratodont have same length as those in the middle; prominent space between marginal papillae and keratodont rows. Partially keratinized upper jaw sheath, edge of the medial convexity black coloured and the rest whitish coloured; finely pointed serrations; moderately wide jaw sheath (JW 53\% of ODW) with a short widely pointed medial convexity (MCL 17\% of JW). Lower jaw sheath $\mathrm{V}$-shaped, partially keratinized and completely hidden by the upper jaw sheath.

Colouration in preservative. Generally beigebrownish. Dorsal sides of the head and trunk and higher part of the flank beige with light brown reticulations between nares and eyes, on the frontal, between the eyes, along the vertebral area and on the dorsolateral abdominal wall. Region between the vertebral area and the dorsolateral abdominal wall not pigmented except the area close to the body-tail junction. Laterally, jugal area and flank covered by sparse dark brown melanic reticulations leaving out a merged transparent spiracle above the well visible intestinal coils. Lower part of the flank not pigmented. Tail musculature beige with brown blotches of melanophores which fuse in some areas to form networks up to the tail tip. Fins translucent, dorsal fin with few patches. Ventrally, oral disk, gular and branchial regions pale; venter transparent, intestinal coils visible and regularly spiral shaped.

Variation. Four non-voucher specimens belonging to the same series show the same external morphology as the voucher specimen, in particular in the oral. However, LTRF varies between $2(2) / 3(1-2)$ and 3 (2-3)/3(1-2).

Mantidactylus zolitschka Glaw and Vences, 2004

The following description refers to one tadpole in developmental stage 27 (field number ZCMV 3565-ZSM $1843 / 2007$, BL $9.2 \mathrm{~mm}$, TL $24.6 \mathrm{~mm}$ ) from the stream Andohan'i Sity (transect 2) in An'Ala forest. The 16S rDNA sequence of this specimen was $100 \%$ identical to a reference sequence of an adult specimen of Mantidactylus zolitschka (accession no AY324811) from the same locality.

In dorsal view, body elliptical (BW $55 \%$ of BL), maximal body width attained at the $2 / 5$ of the body 
(SBW $40 \%$ of BL), small constriction at midbody, narrowly rounded snout. In lateral view, body depressed (BW $148 \%$ of $\mathrm{BH}$ ), maximal body height attained between the proximal $3 / 5$ and $4 / 5$ of the body (SBH $71 \%$ of BL), broadly rounded snout. Moderately large eyes (ED 11\% of BL), not visible from ventral view, positioned high (EH 68\% of BH) dorsally and directed dorsolaterally, situated between the proximal 3/10 and 4/10 of the body (SE 30\% of BL), moderately wide distance between eyes (IOD $56 \%$ of BW). Small rounded nares (ND 1.3\% of BL), marked with a marginal rim, positioned moderately high (NH $58 \%$ of $\mathrm{BH}$ ) dorsally and oriented anterolaterally, situated nearer to snout than to eye (RN $61 \%$ of NP) and below eye level (NH $86 \%$ of $\mathrm{EH})$, wide distance between nares (IND 64\% of IOD), reddish region on the back of the nares present, ornamentation absent. Short sinistral spiracle (SL 17\% of BL), directed posterodorsally, visible from dorsal view and perceivable from lateral view; inner wall free from body and its aperture opens posteriorly, rounded opening, situated between the proximal $3 / 5$ and $4 / 5$ of the body (SS $62 \%$ of BL), located moderately high on the body (SH $40 \%$ of $\mathrm{BH}$ ) and below the height of the point where the axis of the tail myotomes contacts the body ( $\mathrm{SH}$ $58 \%$ of $\mathrm{HAB}$ ). Moderately long dextral vent tube (VL $11 \%$ of BL), associated with ventral fin, inner wall present. No gland. Short tail (TAL $167 \%$ of BL), maximal tail height almost equal to body height (MTH $105 \%$ of BH), tail height at midtail equal to body height and almost equal to maximal tail height (THM $100 \%$ of BH and $95 \%$ of MTH), tail height at the beginning of the tail lower than body height (TH $92 \%$ of BH). Moderately developed caudal musculature (TMW $45 \%$ of BW, TMH $64 \%$ of $\mathrm{BH}, \mathrm{TMH}$ of $69 \%$ of TH and $61 \%$ of MTH, TMHM $34 \%$ of THM and $33 \%$ of $\mathrm{MTH}$ ). Tail muscle reaches tail tip. Low fins (DF $82 \%$ of TMHM, VF 68\% of MTHM), dorsal fin higher than ventral fin at mid-tail (DF $122 \%$ of VF). Dorsal fin originates on the dorsal body-tail junction, keeps straight and almost parallel with tail muscle until proximal $1 / 4$ of the tail, rises regularly to attain its maximal height and then declines progressively toward the tail tip. Ventral fin originates at the ventral terminus of the body, remains parallel with tail muscle until close to the tail tip where it declines toward the tail tip. Maximal tail height located between the proximal $2 / 5$ and $3 / 5$ of the tail (DMTH $43 \%$ of TAL), lateral tail vein not visible, myosepta visible on the distal $1 / 4$ of the tail musculature, point where the axis of the tail myotomes contacts the body in the upper half of the body height (HAB $70 \%$ of $\mathrm{BH})$, axis of the tail myotomes parallel with the axis of the trunk. Tail tip pointed.

Small reduced oral disk (ODW 39\% of BW), positioned and directed anteroventrally, not emarginated, maximal width in the middle. Oral disk visible from dorsal view, upper labium is a continuation of snout. Single row of marginal papillae interrupted by a moderately wide gap on the upper labium (DG 56\% of ODW), gap on the lower labium absent; total number of marginal papillae 69. Fourty-six submarginal papillae, complete on the lower labium and laterally on upper labium. Short and moderately large conical papillae with rounded tips, longest marginal papillae measured $0.10 \mathrm{~mm}$ and $0.15 \mathrm{~mm}$ for submarginal papillae, papillae visible from dorsal view. LTRF 3(2-3)/3(1-2) after Altig and McDiarmid (1999). Single row of keratondonts per ridge. Moderately long $A_{1}$ row $\left(A_{1 \text { len }} 46 \%\right.$ of ODW). Density of keratodonts varies from $27 / \mathrm{mm}$ to $45 / \mathrm{mm}, \mathrm{A}_{1 \text { den }} 27 /$ $\mathrm{mm}$ (total 25). Wide gap in the first anterior interrupted row $\left(A_{2 \text { gap }} 65 \%\right.$ of $A_{2}$ ). Row alignment irregular, lower keratodont rows form a chevron, $\mathrm{P}_{1}$ and $\mathrm{P}_{2}$ interrupted, $\mathrm{P}_{3}$ scattered. Short indiscernible keratodonts $(0.05 \mathrm{~mm})$, poorly keratinized. Distal keratodont same length as those in the middle; prominent space between marginal papillae and keratodont rows. Partially keratinized jaw sheath, edge of the medial convexity black coloured and the remainder whitish; finely pointed serrations; moderately wide jaw sheath (JW 47\% of ODW) with a long narrowly pointed medial convexity (MCL $31 \%$ of JW). Lower jaw sheath V-shaped, partially keratinized and totally hidden by the upper jaw sheath.

Colouration in preservative. Generally beigebrownish. Light brown network of melanophores positioned in deep integumental layers and covered major surface of the dorsal sides of the head and trunk and the flank, leaving a slightly transparent lateral area under the skin. Dark brown spots grouped to form patches which scatter on the dorsum skin. Region between the vertebral area and the dorsolateral abdominal wall provided by many brown distinct irregular blotches making the vertebral area detectable. Laterally, jugal area and flank covered by dark brown distinct irregular blotches which group to form slightly dense reticulations leaving a perceptible transparent spiracle above the recognizable intestinal coils. Lower part of the flank not pigmented. Dark roughly distinct irregular brown blotches form irregularly scattered networks on the tail musculature which expand on dorsal fin. Ven- 


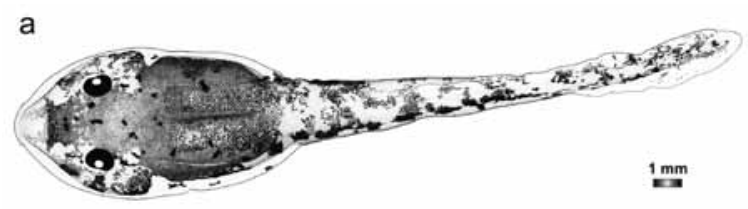

b
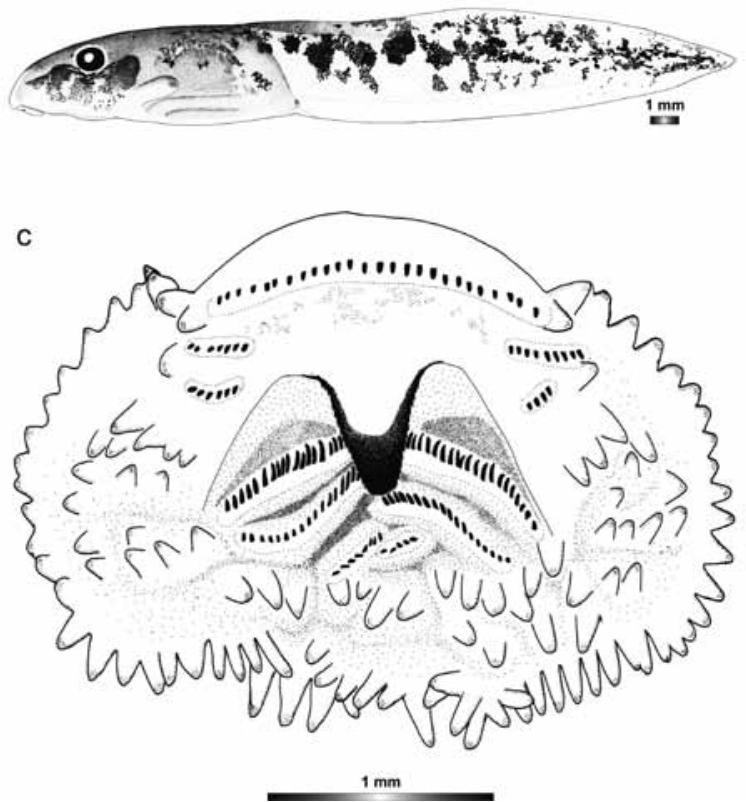

Fig. 12. Drawings of the preserved DNA voucher tadpole of Mantidactylus zolitschka (ZCMV 3565-ZSM 1843/2007): (a) dorsal view, (b) lateral view, (c) oral disk.

tral fin pale with few spots closed to tail tip. Ventrally, oral disk, gular and branchial regions beige, abdominal surface transparent, intestinal coils well visible and regularly spiral shaped.

Variation. Four voucher specimens attributed to M. zolitschka (ZSM 1741/2007-ZCMV 3436, ZSM 1759/2007-ZCMV 3455, ZSM 1768/2007-ZCMV 3464, ZSM 1841/2007-ZCMV 3563) from the same locality show the typical oral disk configuration and the pigmentation of this species and one tadpole has a LTRF of 2(2)/3(1-2).

\section{Mantidactylus argenteus Methuen, 1920}

The following description refers to one tadpole in developmental stage 27 (field number ZCMV 3575-ZSM 1573/2007, BL $12.2 \mathrm{~mm}$, TL $34 \mathrm{~mm}$ ) from the stream Andohan'i Sity (transect 3) in An'Ala forest.

In dorsal view, body elliptical (BW $47 \%$ of BL), maximal body width at mid-body (SBW $50 \%$ of BL),

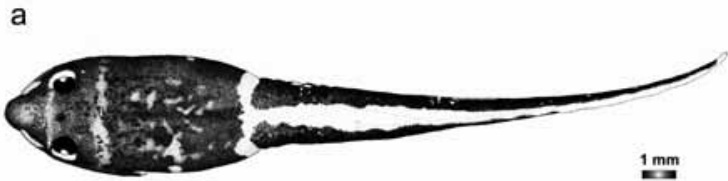

b
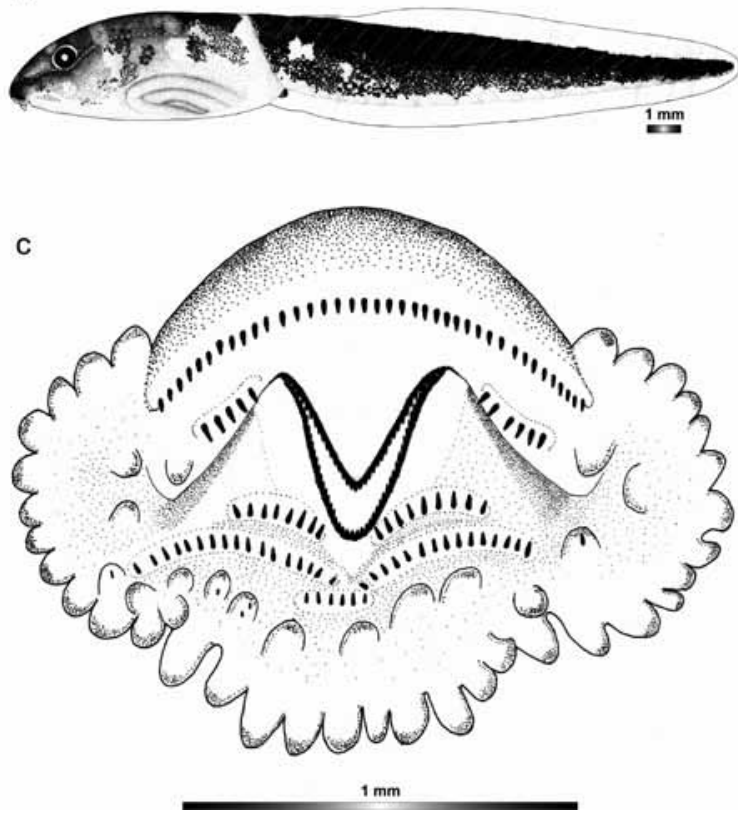

Fig. 13. Drawings of the preserved DNA voucher tadpole of Mantidactylus argenteus (ZCMV 3575-ZSM 1573/2007): (a) dorsal view, (b) lateral view, (c) oral disk.

narrowly rounded snout with protuberation. In lateral view, body depressed (BW 111\% of $\mathrm{BH}$ ), maximal body height between the proximal $2 / 5$ and $3 / 5$ of the body (SBH $56 \%$ of BL), narrowly rounded snout. Small eyes (ED 9\% of BL), not visible from ventral view, positioned moderately high (EH $58 \%$ of $\mathrm{BH}$ ) dorsally and directed laterally, situated between the proximal $2 / 10$ and $3 / 10$ of the body (SE $21 \%$ of BL), wide distance between eyes (IOD $63 \%$ of BW). Very small elliptical nares (ND $0.8 \%$ of BL), marked with a marginal rim, positioned moderately high ( $\mathrm{NH} 48 \%$ of $\mathrm{BH})$ dorsally and oriented anterolaterally, situated nearer to snout than to eye (RN 68\% of NP) and below eye level (NH $84 \%$ of $\mathrm{EH})$, moderately wide distance between nares (IND 54\% of IOD), red coloured region on the back of the nares present, ornamentation absent. Very short sinistral spiracle (SL 9\% of BL), directed posteriorly, visible from dorsal and ventral views, perceivable from lateral view; inner wall free from body and its aperture opens posteriorly, eliptical opening, 
situated between the proximal $2 / 5$ and $3 / 5$ of the body (SS $55 \%$ of BL), located moderately high on the body (SH $49 \%$ of $\mathrm{BH}$ ) and below the point where the axis of the tail myotomes contacts the body (SH 77\% of HAB). Moderately long dextral vent tube (VL 14\% of BL), attached to ventral fin, inner wall present. No gland. Short tail (TAL $180 \%$ of BL), maximal tail height higher than body height (MTH 106\% of BH), tail height at midtail almost equal to body height and lower than maximal tail height (THM 97\% of BH and $82 \%$ of MTH), tail height at the beginning of the tail lower than body height (TH $84 \%$ of $\mathrm{BH}$ ). Moderately developed caudal musculature (TMW $60 \%$ of BW, TMH $67 \%$ of BH, TMH of $80 \%$ of TH and $63 \%$ of MTH, TMHM 55\% of THM and 51\% of MTH). Tail muscle reaches tail tip. Very low fin type (DF $43 \%$ of TMHM, VF $41 \%$ of MTHM), dorsal fin higher than ventral fin at mid-tail (DF 104\% of VF). Dorsal fin originates on tail muscle on the proximal $1 / 10$ of the tail, remains almost parallel with the tail muscle up to the $1 / 4$ of the tail, where it increases abruptly to attain its maximal height and then progresses horizontally until the $3 / 4$ of the tail, finally decreases gradually towards the tail tip. Ventral fin originates at the ventral terminus of the body, remains parallel with tail muscle almost to tail tip, then decreases to tail tip. Maximal tail height located between the proximal $1 / 5$ and $2 / 5$ of the tail (DMTH $37 \%$ of TAL), lateral tail vein invisible and myosepta slightly all along the tail musculature, point where the axis of the tail myotomes contacts the body in the upper half of the body height (HAB 64\% of $\mathrm{BH}$ ), axis of the tail myotomes parallel with the axis of the trunk. Tail tip narrowly rounded. Small reduced oral disk (ODW $31 \%$ of BW), positioned ventrally and directed anteroventrally, not emarginated, maximal width in the middle. Oral disk not visible from dorsal view, upper labium is a continuation of snout. Single row of marginal papillae interrupted by a wide gap on the upper labium (DG 62\% of ODW), gap on the lower labium absent; total number of marginal papillae 31 . Eighteen submarginal papillae on the lower labium and laterally on upper labium. Short and moderately wide conical papillae with rounded tips, longest marginal papillae measured $0.15 \mathrm{~mm}$ and $0.07 \mathrm{~mm}$ for submarginal papillae, papillae not visible from dorsal view. LTRF 2(2)/3(1-2) after Altig and McDiarmid (1999). Single row of keratondonts per ridge. Long $A_{1}$ row ( $\mathrm{A}_{1 \text { len }} 65 \%$ of ODW). Density of keratodonts varies from $26 / \mathrm{mm}$ to $36 / \mathrm{mm}, A_{1 \text { den }} 36 / \mathrm{mm}$ (total 41 ). Wide gap in the first anterior interrupted row $\left(\mathrm{A}_{\text {2gap }}\right.$ $63 \%$ of $\mathrm{A}_{2}$ ). Row alignment irregular, lower keratodont rows form a chevron, $\mathrm{P}_{1}$ and $\mathrm{P}_{2}$ interrupted, $\mathrm{P}_{2}$ and $\mathrm{P}_{3}$ scattered. Short discernible keratodonts $(0.06 \mathrm{~mm})$. Distal keratodonts have the same lengths as those in the middle; prominent space between marginal papillae and keratodont rows. Partially keratinized upper jaw sheath, edge of the medial convexity black coloured and the rest whitish; finely pointed serrations; moderately wide jaw sheath (JW $43 \%$ of ODW) with a long narrowly pointed medial convexity (MCL 33\% of JW). Lower jaw sheath V-shaped, partially keratinized and totally hidden by the upper jaw sheath.

Colouration in preservative. Generally brown, dorsally marked by transversal clear bands between nares and eyes, between eyes and spiracle and before the body-tail junction, and a longitudinal clear band on the dorsum of the tail. Brown melanic pigment positioned in deeper dermal layers, separated from a (possibly epidermal) transparent outer skin layer, covering the dorsum and flank of the body. Some dark brown patches scattered on the dorsal skin. Laterally, jugal area (under eyes and nares) and flank covered by dark brown reticulations. The spiracle is reticulated at the base and transparent at the end, and detectable, and is situated the visible intestinal coils. Lower part of the flank not pigmented. Tail musculature overlain by dark brown reticulations. Fins pale, dorsal and ventral fins free from pigments. Ventrally, oral disk, gular and branchial regions patched; venter pale, intestinal coils perceptible and regularly spiral shaped.

Variation. Two voucher specimen (ZSM 1815/2007ZCMV 3516, ZSM 1849/2007-ZCMV 3566) from the same locality show similar oral disk configuration and colouration pattern.

\section{Mantidactylus sp. 42 \\ (CCS from Montagne d'Ambre)}

The following description refers to one tadpole in developmental stage 28 (field number FG/MV 2002. 1957ZSM 774/2004, BL $11.1 \mathrm{~mm}$, TL $34.8 \mathrm{~mm}$ ) from a stream crossing the track 'Voie des milles arbres' at the Montagne d'Ambre National Park. The 16S rDNA sequence of this specimen was $99.8 \%$ identical to a reference sequence of an adult specimen of Mantidactylus sp. 42 (accession FJ559267) from the same locality.

In dorsal view, body elliptical (BW $56 \%$ of BL), maximal body width between the proximal $3 / 5$ and $4 / 5$ of the body (SBW $71 \%$ of BL), narrowly rounded snout. In lateral view, body depressed (BW $123 \%$ of $\mathrm{BH}$ ), maximal body height attained between the proximal $3 / 5$ and $4 / 5$ of the body (SBH $68 \%$ of BL), broadly 
rounded snout. Moderately large eyes (ED 11\% of BL), not visible from ventral view, positioned high (EH $67 \%$ of $\mathrm{BH}$ ) dorsally and directed laterally, situated between the proximal 2/10 and 3/10 of the body (SE $28 \%$ of BL), moderately wide distance between eyes (IOD 55\% of BW). Small elliptical nares (ND 1.1\% of $\mathrm{BL}$ ), marked with a marginal rim, positioned moderately high (NH $47 \%$ of $\mathrm{BH}$ ) dorsally and oriented anterolaterally, situated nearer to snout than to eye (RN $57 \%$ of NP) and below eye level (NH 70\% of EH), moderately wide distance between nares (IND $57 \%$ of IOD), dark spot on the back of the nares present, ornamentation absent. Short sinistral spiracle (SL 15\% of BL), directed posteriorly, visible from dorsal and ventral views, perceptible from lateral view; inner wall free from body and its aperture opens laterally instead of posteriorly, rounded opening, situated between the proximal $3 / 5$ and $4 / 5$ of the body (SS $62 \%$ of BL), located moderately high on the body ( $\mathrm{SH} 55 \%$ of $\mathrm{BH}$ ) and below the height of the point where the axis of the tail myotomes contacts the body (SH $90 \%$ of HAB). Moderately long dextral vent tube (VL $13 \%$ of BL), attached to ventral fin, inner wall present. No gland. Moderately long tail (TAL $214 \%$ of BL), maximal tail height lower than body height (MTH $72 \%$ of BH), tail height at midtail higher than body height and lower than maximal tail height (THM 104\% of BH and 98\% of MTH), tail height at the beginning of the tail almost equal to body height (TH 96\% of BH). Moderately developed caudal musculature (TMW $62 \%$ of BW, TMH $72 \%$ of $\mathrm{BH}, \mathrm{TMH}$ of $75 \%$ of $\mathrm{TH}$ and $67 \%$ of MTH, TMHM 58\% of THM, and 57\% of MTH). Tail muscle reaches tail tip. Very low fins (DF 40\% of TMHM, VF $45 \%$ of MTHM), dorsal fin lower than ventral fin at mid-tail (DF $87 \%$ of VF). Dorsal fin originates at the dorsal body-tail junction, rises gradually to attain the maximal height before the midtail and then descents slightly towards the tail tip. Ventral fin originates at the ventral terminus of the body, expands until midtail, and then decreases towards the tail tip. Maximal tail height located at the $2 / 5$ of the tail (DMTH $40 \%$ of TAL), lateral tail vein visible only on the proximal $1 / 3$ of the tail, myosepta visible on the proximal $3 / 4$ of the tail musculature, point where the axis of the tail myotomes contacts the body in the upper half of the body height (HAB $62 \%$ of $\mathrm{BH}$ ), axis of the tail myotomes parallel with the axis of the trunk. Tail tip narrowly rounded.

Small reduced oral disk (ODW 36\% of BW), positioned ventrally and directed anteroventrally, not emarginated, maximal width in the middle. Oral disk visible from dorsal view, upper labium is a continua- tion of snout. Single row of marginal papillae interrupted by a moderately wide gap on the upper labium (DG $47 \%$ of ODW), gap on the lower labium absent; total number of marginal papillae 53. Fourty-two submarginal papillae complete on the lower labium and laterally on upper labium. Short and moderately large conical papillae with rounded tips, longest marginal papillae measured $0.13 \mathrm{~mm}$, and $0.14 \mathrm{~mm}$ for submarginal papillae, papillae visible from dorsal view. LTRF 3(2-3)/3(1-2) after Altig and McDiarmid (1999). Single row of keratondonts per ridge. Short $\mathrm{A}_{1}$ row $\left(\mathrm{A}_{1 \text { len }} 33 \%\right.$ of ODW). Density of keratodonts varies from $16 / \mathrm{mm}$ to $54 / \mathrm{mm}, \mathrm{A}_{1 \text { den }} 16 / \mathrm{mm}$ (total 12 ). Very wide gap in the first anterior interrupted row $\left(\mathrm{A}_{\text {2gap }} 81 \%\right.$ of $\left.\mathrm{A}_{2}\right)$. Row alignment irregular, lower keratodont rows form a chevron, $\mathrm{P}_{1}$ and $\mathrm{P}_{2}$ interrupted, $\mathrm{P}_{2}$ and $\mathrm{P}_{3}$ scattered. Short discernible keratodonts $(0.09 \mathrm{~mm})$. Distal keratodonts have the same lengths as those in the middle; important space between marginal papillae and keratodont rows. Partially keratinized jaw sheath, edge of the medial convexity black coloured and the remainder

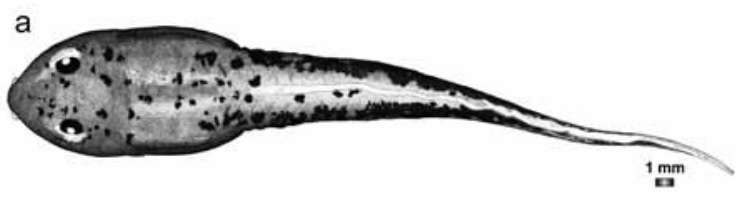

b
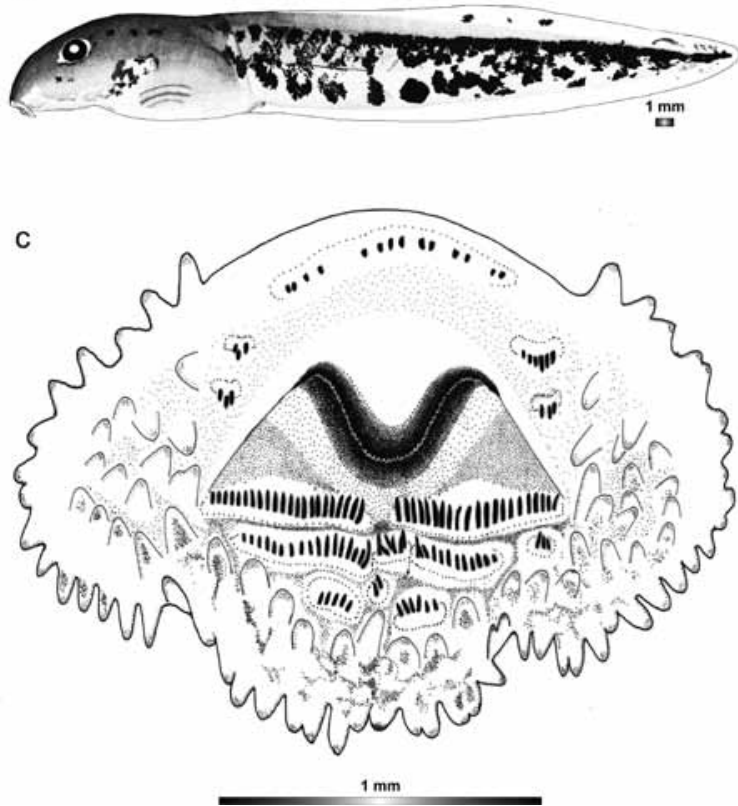

Fig. 14. Drawings of the preserved DNA voucher tadpole of Mantidactylus sp. 42 (FG/MV 2002.1957-ZSM 774/2004): (a) dorsal view, (b) lateral view, (c) oral disk. 
whitish; finely pointed serrations; moderately wide jaw sheath (JW 51\% of ODW) with a short widely rounded medial convexity (MCL 18\% of JW). Lower jaw sheath V-shaped, partially keratinized and totally hidden by the upper jaw sheath.

Colouration in preservative. Generally brownish. Brown pigments in deep integumental layers covering the dorsum and flank of the body, leaving out a narrow slightly transparent area laterally. Dark brown patches of melanophores scattered on the skin. Rather unpigmented surface on the dorsum between the body wall and the vertebral area perceivable. Irregularly shaped clear dots form a line which runs on the dorsolateral part of the abdominal region, from the body-tail junction to just behind the eyes. There it splits, the first ramification passes below the eyes and runs through the jugal area, then diverts laterally on the sagittal plan of the nares. The second ramification runs above the eyes and approaches the first line of spots on the sagittal plan of the nares and finally merges with it on the snout. Laterally, jugal area and flank covered by dark brown dense reticulation leaving a perceivable opaque reticulated spiracle. Lower part of the flank clear, intestinal coils recognizable. A line formed by irregularly shaped clear dots is visible laterally before the body-tail junction, runs on the dorsolateral part of the abdominal region and splits just behind the eyes. The first ramification passes below the eyes and ends below the nares. The second ramification passes above the eyes and the nares and terminates on the mid-height of the snout. Tail musculature pinkish with brown mottles which coalesce to form rather dense reticulations especially on the dorsolateral part. Fins speckled, dorsal fin patched, some blotches on the ventral fin close to tail tip. Ventrally, oral disk, gular and branchial regions reticulated; venter pale, intestinal coils perceptible and regularly spiral shaped.

\section{Mantidactylus sp. 43 (CCS from Marojejy)}

The following description refers to one tadpole in developmental stage 25 (field number FGZC 2928-ZSM 1610/2007, BL $7 \mathrm{~mm}$, TL $21 \mathrm{~mm}$ ) from a stream crossing the way to the Cascade in Camp Mantella at the Marojejy National Park. The 16S rDNA sequence of this specimen was $100 \%$ identical to a reference sequence of an adult specimen of Mantidactylus sp. 43 (accession FJ559268) from the same localityIn dorsal view, body elliptical (BW $60 \%$ of BL), maximal body width attained between the proximal $2 / 5$ and $3 / 5$ of the body (SBW 54\% of BL), narrowly rounded snout. In lateral view, body depressed (BW 142\% of BH), maximal body height attained between the proximal $3 / 5$ and 4/5 of the body (SBH 71\% of BL), broadly rounded snout. Moderately large eyes (ED 13\% of BL), not visible from ventral view, positioned high (EH $78 \%$ of $\mathrm{BH}$ ) dorsally and directed dorsolaterally, situated between the proximal 3/10 and 4/10 of the body (SE 39\% of BL), moderately wide distance between eyes (IOD 59\% of BW). Small rounded nares (ND 2\% of BL), marked with a marginal rim, positioned high ( $\mathrm{NH} 65 \%$ of $\mathrm{BH})$ dorsally and oriented anterolaterally, situated nearer to snout than to eye (RN 76\% of NP) and below eye level (NH $84 \%$ of $\mathrm{EH}$ ), moderately wide distance between nares (IND 58\% of IOD), dark spot on the back of the nares absent, ornamentation absent. Short sinistral spiracle (SL 15\% of BL), directed posteriorly, visible from dorsal and ventral views and perceptible from lateral view; inner wall free from body and its aperture opens posteriorly, elliptical opening, situated between the proximal $3 / 5$ and $4 / 5$ of the body (SS $75 \%$ of BL), located moderately high on the body (SH $52 \%$ of $\mathrm{BH}$ ) and below the height of the point where the axis of the tail myotomes contacts the body ( $\mathrm{SH} 85 \%$ of HAB). Short dextral vent tube (VL 7\% of BL), attached to ventral fin, inner wall present. No gland. Short tail (TAL 200\% of $\mathrm{BL}$ ), maximal tail height higher than body height (MTH $107 \%$ of $\mathrm{BH}$ ), tail height at midtail higher than body height but lower than maximal tail height (THM 107\% of $\mathrm{BH}$ and $93 \%$ of MTH), tail height at the beginning of the tail lower than body height (TH 94\% of BH). Moderately developed caudal musculature (TMW $49 \%$ of BW, TMH $64 \%$ of BH, TMH of $68 \%$ of TH and $58 \%$ of MTH, TMHM $51 \%$ of THM and $50 \%$ of MTH). Tail muscle reaches tail tip. Very low fins (DF $57 \%$ of TMHM, VF 39\% of MTHM), dorsal fin higher than ventral fin at mid-tail (DF $148 \%$ of VF). Dorsal fin originates at dorsal body-tail junction, increases to attain the maximal height before the midtail and then descents slightly towards the tail tip. Ventral fin originates at the ventral terminus of the body, continues straight until the $3 / 4$ of the tail, and then declines towards the tail tip. Maximal tail height located between the proximal 1/5 and $2 / 5$ of the tail (DMTH $31 \%$ of TAL), lateral tail vein visible only on the proximal $1 / 4$ of the tail, myosepta visible all along the tail musculature, point where the axis of the tail myotomes contacts the body in the upper half of the body height (HAB $60 \%$ of $\mathrm{BH}$ ), axis of the tail myotomes parallel with the axis of the trunk. Tail tip narrowly rounded. 


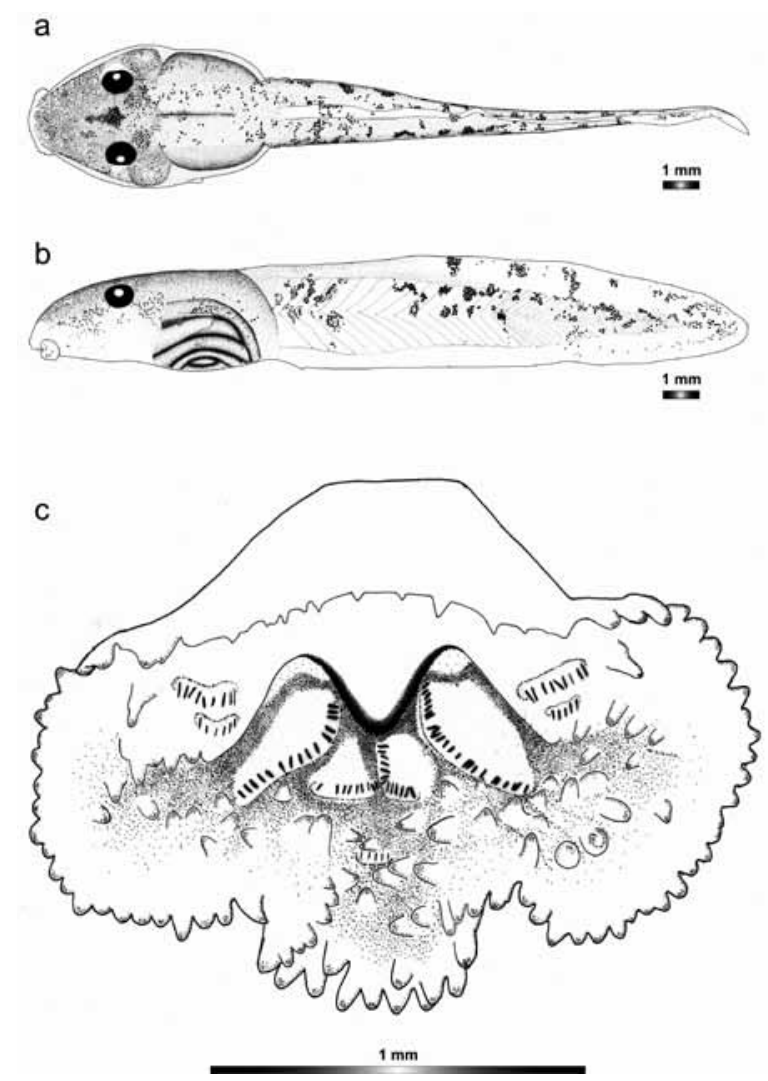

Fig. 15. Drawings of the preserved DNA voucher tadpole of Mantidactylus sp. 43 (FGZC 2928-ZSM 1610/2007): (a) dorsal view, (b) lateral view, (c) oral disk.

Moderately wide reduced oral disk (ODW $46 \%$ of BW), positioned and directed anteroventrally, not emarginated, maximal width in the middle. Oral disk visible from dorsal view, upper labium is a continuation of snout. Single row of marginal papillae interrupted by a moderately wide gap on the upper labium (DG 54\% of ODW), gap on the lower labium absent; total number of marginal papillae 78. Fifty submarginal papillae, complete on the lower labium and laterally on upper labium. Very short and moderately large conical papillae with rounded tips, longest marginal papillae measured $0.10 \mathrm{~mm}$ and $0.08 \mathrm{~mm}$ for submarginal papillae, papillae visible from dorsal view. LTRF 2(2) /3(1-2) after Altig and McDiarmid (1999). Single row of keratondonts per ridge. Moderately long $\mathrm{A}_{1}$ row $\left(\mathrm{A}_{1 \text { len }} 51 \%\right.$ of ODW). Density of keratodonts varies from $13 / \mathrm{mm}$ to $63 / \mathrm{mm}, \mathrm{A}_{1 \text { den }} 13 / \mathrm{mm}$ (total 13). The first upper row seems to have lost many of its keratodonts. Wide gap in the first anterior interrupted row $\left(\mathrm{A}_{\text {2gap }} 66 \%\right.$ of $\left.\mathrm{A}_{2}\right)$. Rows alignment irregular, lower keratodont rows form a chevron, $\mathrm{P}_{1}$ and $\mathrm{P}_{2}$ interrupted. Short discernible keratodonts $(0.07 \mathrm{~mm})$. Distal keratodont have same length as those in the middle; prominent space between marginal papillae and keratodont rows. Partially keratinized jaw sheath, edge of the medial convexity black coloured and the remainder whitish; finely pointed serrations; moderately wide jaw sheath (JW $41 \%$ of ODW) with a moderately long widely pointed medial convexity (MCL $26 \%$ of JW). Lower jaw sheath V-shaped, partially keratinized and totally hidden by the upper ones.

Colouration in preservative. Uniformly pale. Body and tail muscle dorsally flecked. Speckles in deeper dermal layers, separately from externalmost (possibly epidermal) skin layer. Darker patches dissipate between the eyes and along the vertebral area; brown irregularly shaped spots dispersed on the dorsal skin. Intestinal coils noticeable on the lateral part of the abdomen. Laterally, jugal area and flank covered by dark sparse brown melanophoric spots, leaving out an opaque, slightly blotched area around spiracle, above the detectable intestinal coils. Lower part of the flank unpigmented. Tail musculature beige with brown distinct mottles which group in some areas to form sporadic patches that extend onto the dorsal fin and their density diminishes towards tail tip. Fins translucent, speckled, especially on the proximal $1 / 4$ of the dorsal fin; brown fused mottles abundant on dorsal fin and scattered mottles on the ventral fin. Ventrally, oral disk, gular and branchial regions beige, sporadically spotted; venter transparent, intestinal coils conspicuous and regularly spiral shaped.

Mantidactylus sp. 47

(CCS from Ambatolahy and other sites around Ranomafana)

The following description refers to one tadpole in developmental stage 31 (field number ZCMV2699-ZSM 456/2008, BL $12.1 \mathrm{~mm}$, TL $32.1 \mathrm{~mm}$ ) from Imaloka river at the Ranomafana National Park. The 16S rDNA sequence of this specimen was $99.8 \%$ identical to a reference sequence of an adult specimen of Mantidactylus sp. 47 (accession FJ559272) from the same locality.

In dorsal view, body elliptical (BW 52\% of BL), maximal body width attained between the proximal $3 / 5$ and $4 / 5$ of the body (SBW $69 \%$ of BL), constriction before the point where the maximal body width is attained, narrowly rounded snout. In lateral view, body depressed (BW 130\% of BH), maximal body height attained between the proximal $3 / 5$ and $4 / 5$ of 
the body (SBH 69\% of BL), broadly rounded snout. Moderately large eyes (ED 13\% of BL), not visible from ventral view, positioned high (EH $73 \%$ of $\mathrm{BH}$ ) dorsally and directed dorsolaterally, situated between the proximal 2/10 and 3/10 of the body (SE 26\% of BL), moderately wide distance between eyes (IOD $59 \%$ of BW). Small rounded nares (ND 1.1\% of BL), marked with a marginal rim, positioned moderately high (NH 53\% of $\mathrm{BH})$ dorsally and oriented anterolaterally, situated nearer to snout than to eye (RN $48 \%$ of NP) and below eye level (NH $72 \%$ of EH), moderately wide distance between nares (IND 58\% of IOD), dark spot on the back of the nares present, ornamentation absent. Short sinistral spiracle (SL 14\% of BL), directed posterodorsally, not visible from either dorsal or ventral view, perceivable from lateral view; inner wall free from body and its aperture opens posteriorly, rounded opening situated between the proximal $2 / 5$ and $3 / 5$ of the body and almost at midbody (SS 55\% of BL), located moderately high on the body (SH $51 \%$ of $\mathrm{BH}$ ) and below the height of the point where the axis of the tail myotomes contacts the body (SH 76\% of HAB). Moderately long dextral vent tube (VL $11 \%$ of BL), attached to ventral fin, inner wall present. No gland. Short tail (TAL $166 \%$ of BL), maximal tail height equal to body height (MTH $100 \%$ of $\mathrm{BH}$ ), tail height at midtail lower than body height and maximal tail height (THM 90\% of BH and 93\% of MTH), tail height at the beginning of the tail lower than body height (TH $90 \%$ of BH). Developed caudal musculature (TMW $63 \%$ of BW, TMH $73 \%$ of $\mathrm{BH}$, TMH of $81 \%$ of TH and $73 \%$ of MTH, TMHM $67 \%$ of THM and $62 \%$ of MTH). Tail muscle reaches tail tip. Very low fins (DF $28 \%$ of TMHM, VF $24 \%$ of MTHM), dorsal fin higher than ventral fin at mid-tail (DF $117 \%$ of VF). Dorsal fin originates on the proximal $1 / 5$ of the tail, rises gradually and then progresses horizontally to the tail tip, then decreases. Ventral fin originates at the ventral terminus of the body, remains parallel with tail muscle almost to tail tip, then decreases. Maximal tail height located at the $2 / 5$ of the tail (DMTH $40 \%$ of TAL), lateral tail vein visible only on the proximal $1 / 4$ of the tail, myosepta slightly visible all along the tail musculature, point where the axis of the tail myotomes contacts the body in the upper half of the body height (HAB 67\% of $\mathrm{BH}$ ), axis of the tail myotomes parallel with the axis of the trunk. Tail tip narrowly rounded.

Small reduced oral disk (ODW 36\% of BW), positioned and directed anteroventrally, not emarginated, maximal width in the middle. Oral disk not visible from dorsal view, upper labium is a continuation of snout. Single row of marginal papillae interrupted by a moderately wide gap on the upper labium (DG $44 \%$ of ODW), gap on the lower labium absent; total number of marginal papillae 72. Sixty-six submarginal papillae complete on the lower labium and laterally on upper labium. Short and moderately large conical papillae with rounded tips, longest marginal papillae measured $0.14 \mathrm{~mm}$ and $0.11 \mathrm{~mm}$ for submarginal papillae, papillae not visible from dorsal view. LTRF 3(2-3)/3(1-2) after Altig and McDiarmid (1999). Single row of keratondonts per ridge. Moderately long $A_{1}$ row $\left(A_{1 \text { len }} 42 \%\right.$ of ODW). Density of keratodonts varies from $15 / \mathrm{mm}$ to $40 / \mathrm{mm}, \mathrm{A}_{1 \text { den }} 15 / \mathrm{mm}$ (total 14 ). Wide gap in the first anterior interrupted row $\left(\mathrm{A}_{\text {2gap }}\right.$ $76 \%$ of $A_{2}$ ). Row alignment irregular, lower keratodont rows form a chevron, $\mathrm{P}_{1}$ and $\mathrm{P}_{2}$ interrupted, $\mathrm{P}_{3}$ scattered. Short discernible keratodonts $(0.05 \mathrm{~mm})$. Distal keratodont same length as those in the middle; important space between marginal papillae and keratodont rows. Partially keratinized jaw sheath, edge of the medial convexity black coloured and the remainder whitish; finely pointed serrations; moderately wide jaw sheath (JW $51 \%$ of ODW) with a moderately long widely pointed medial convexity (MCL 20\% of JW). Lower jaw sheath V-shaped, partially keratinized and totally hidden by the upper jaw sheath.

Colouration in life. Typically light brownish with irregular variegated pattern. Dorsal skin irregularly covered by brown melanophores and some gold iridophoric spots or patches. Dorsolaterally and laterally with the same pattern as dorsally. Rather non-pigmented spiracle perceptible. Tail musculature yellowish with roughly distinct, irregular brown blotches that group to form irregular patches. Their density diminishes towards the tail tip. Sporadic golden iridopohoric spots perceptible. Fins translucent, dorsal fin with many dark patches, ventral fin unpigmented. Ventrally, oral disk and gular region not pigmented and bordered by a reticulated body wall; branchial area reddish, gills and beating heart visible; venter transparent, intestinal coils visible and regularly spiral shaped.

Colouration in preservative. Largely brownish. Brown flecks in deep integumental layers cover the dorsum and condense mainly on the vertebral area and the very dark abdominal part. Light brown flecks dispersed on the skin. Roughly distinct irregular brown blotches grouped to form irregularly scattered networks, largely between the eyes and between the vertebral area and the abdominal region. Noticeable transversal lines occur between the vertebral area and the abdominal region 
showing noticeable abdominal-like structure. Laterally, jugal area and flank covered by irregular brown blotches which fuse to form networks mainly below the nares and between the eyes, and on the abdominal surface leaving a spotted spiracle diverged above the discernible intestinal coils. Lower part of the flanks not pigmented. Tail musculature beige with roughly distinct irregular brown blotches that group to form irregular patches. Their density diminishes towards the tail tip. Fins translucent, dorsal fin with many patches, ventral fin unpigmented. Ventrally, oral disk and gular region beige and bordered by a reticulated body wall; venter pale, intestinal coils visible and regularly spiral shaped.

Variation. Five voucher specimens (ZSM 1697/2007ZCMV 3774, ZSM 254/2008-ZCMV 3669, ZSM 315/2008-ZCMV 3620, ZSM 478/2008-ZCMV 3724, ZSM 506/2008-ZCMV 3791) attributed to this species from the same locality and many non-voucher specimens belonging to these series indicate the identical oral disk configuration and the external pigmentation of

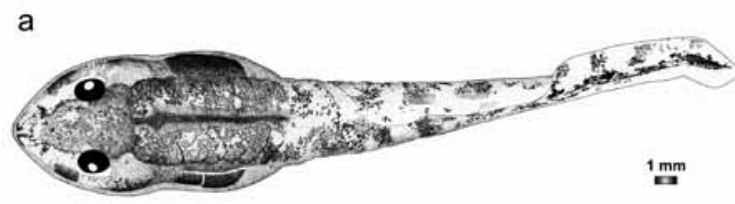

b
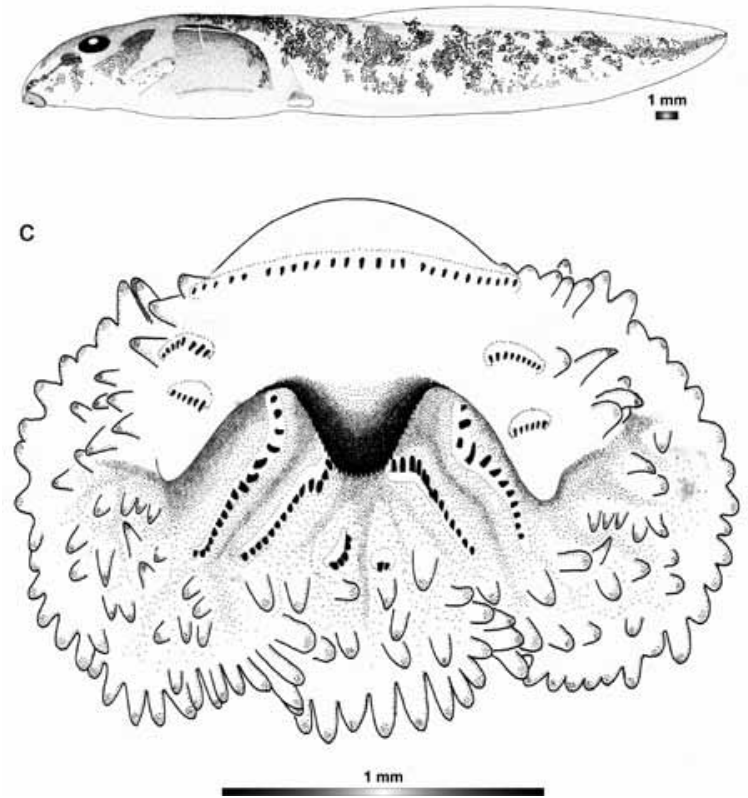

Fig. 16. Drawings of the preserved DNA voucher tadpole of Mantidactylus sp. 47 (ZCMV 2699-ZSM 456/2008): (a) dorsal view, (b) lateral view, (c) oral disk. this species. Only the LTRF is variable: $2(2) / 3(1-2)$ and $3(2-3) / 3(2-3)$.

\section{Mantidactylus mocquardi Angel, 1929}

The following description refers to one tadpole in developmental stage 26 (field number ZCMV 3511-ZSM 1540/2007, BL $11.4 \mathrm{~mm}$, TL $32.5 \mathrm{~mm}$ ) from the stream Andohan'i Sity (transect 2) in An'Ala forest. The 16S rDNA sequence of this specimen was $99.3 \%$ identical to a reference sequence of an adult specimen of $M$. mocquardi (accession FJ559269; ZCMV 5865; referred to as Mantidactylus sp. 44 by Vieites et al., 2009) from Ambohitsara-Tsitolaka.

In dorsal view, body elliptical (BW 60\% of BL), maximal body width attained between the proximal $2 / 5$ and $3 / 5$ of the body (SBW $47 \%$ of BL), narrowly rounded snout. In lateral view, body depressed (BW $148 \%$ of $\mathrm{BH}$ ), maximal body height attained between the proximal $3 / 5$ and $4 / 5$ of the body (SBH $73 \% \mathrm{BL}$ ),

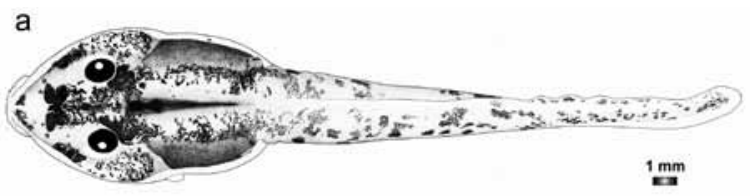

b
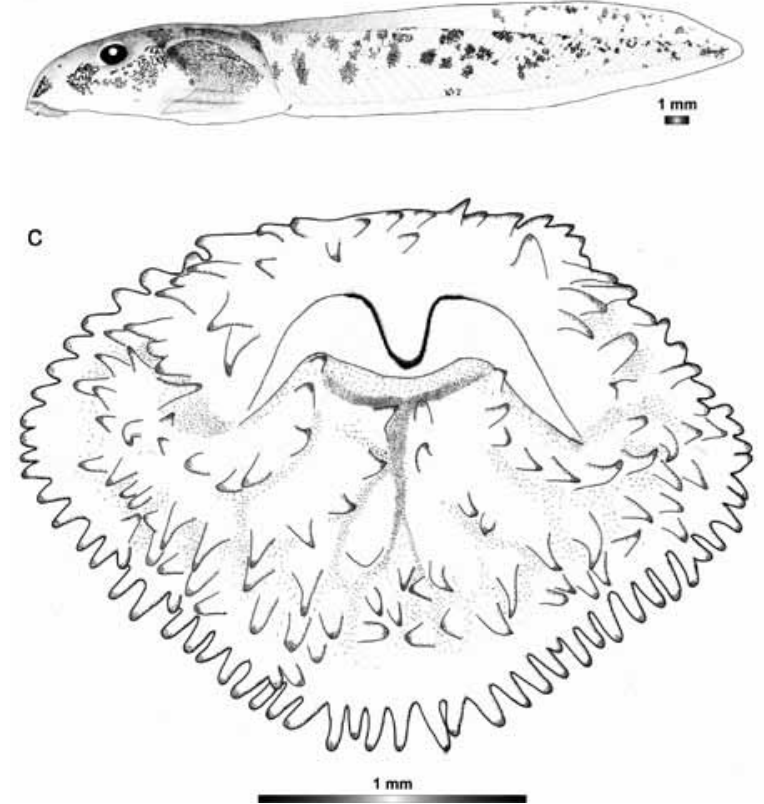

Fig. 17. Drawings of the preserved DNA voucher tadpole of Mantidactylus mocquardi (ZCMV 3511-ZSM 1540/2007): (a) dorsal view, (b) lateral view, (c) oral disk. 
broadly rounded snout. Moderately large eyes (ED 12\% of $\mathrm{BL}$ ), not visible from ventral view, positioned high (EH 73\% of BH) dorsally and directed dorsolaterally, situated between the proximal $3 / 10$ and $4 / 10$ of the body (SE $35 \%$ of BL), moderately wide distance between eyes (IOD 53\% of BW). Small rounded nares (ND 1.4\% of BL), marked with a marginal rim, positioned dorsally moderately high ( $\mathrm{NH} 59 \%$ of $\mathrm{BH})$ and oriented anterodorsolaterally, situated nearer to snout than to eye (RN 67\% of NP) and below eye level (NH $81 \%$ of $\mathrm{EH}$ ), wide distance between nares (IND $68 \%$ of IOD), reddish region on the back of the nares present, ornamentation absent. Short sinistral spiracle (SL 16\% of BL), directed posteriorly, visible from dorsal, ventral and lateral views; inner wall free from body and formed such that aperture opens laterally instead of posteriorly, rounded opening, situated between the proximal $3 / 5$ and $4 / 5$ of the body (SS 68\% of $\mathrm{BL}$ ), located moderately high on the body ( $\mathrm{SH} 42 \%$ of $\mathrm{BH}$ ) and below the height of the point where the axis of the tail myotomes contacts the body ( $\mathrm{SH} 70 \%$ of HAB). Short dextral vent tube (VL $9 \%$ of BL), attached to ventral fin, inner wall present. No gland. Short tail (TAL $185 \%$ of BL), maximal tail height equal to body height (MTH 102\% of BH), tail height at midtail lower than body height, but equal to maximal tail height (THM 91\% of BH and 99\% of MTH), tail height at the beginning of the tail lower than body height (TH $91 \%$ of $\mathrm{BH}$ ). Developed caudal musculature (TMW $51 \%$ of BW, TMH $74 \%$ of BH, TMH of $81 \%$ of TH and $73 \%$ of MTH, TMHM $60 \%$ of THM and $60 \%$ of MTH). Tail muscle reaches tail tip. Very low fins (DF 41\% of TMHM, VF 25\% of MTHM), dorsal fin higher than ventral fin at mid-tail (DF 161\% of VF). Dorsal fin originates on the proximal $1 / 3$ of the tail, rises suddenly up to its maximal height, then progresses parallel with caudal musculature, then decreases towards the tail tip at the proximal $1 / 4$ of the tail. Ventral fin originates at the ventral terminus of the body, remains almost parallel with tail muscle up to almost tail tip, then decreases. Maximal tail height located between the proximal $2 / 5$ and $3 / 5$ of the tail (DMTH $42 \%$ of TAL), lateral tail vein not visible, myosepta visible on the distal $3 / 4$ of the tail musculature, point where the axis of the tail myotomes contacts the body in the upper half of the body height (HAB 60\% of $\mathrm{BH}$ ), axis of the tail myotomes parallel with the axis of the trunk. Tail tip pointed.

Moderately wide reduced oral disk (ODW $43 \%$ of BW), positioned and directed anteroventrally, not emarginated, maximal width in the middle. Oral disk visible from dorsal view, upper labium is a continuation of snout. Single row of marginal papillae, gap on the upper and lower labium absent; total number of marginal papillae 74. One hundred and four submarginal papillae complete on the lower labium and laterally on upper labium. Moderately long and large elongated papillae with rounded tips on the marginal papillae and pointed tips on the submarginal papillae. Longest marginal papillae measured $0.19 \mathrm{~mm}$ and $0.25 \mathrm{~mm}$ for submarginal papillae, papillae visible from dorsal view. Keratodonts absent. Partially keratinized jaw sheath, only the edge of the medial convexity is weakly brown coloured and the remainder whitish; finely pointed serrations; moderately wide jaw sheath (JW 43\% of ODW) with a moderately long narrowly pointed medial convexity (MCL $22 \%$ of JW). Lower jaw sheath V-shaped, partially keratinized and totally hidden by the upper jaw sheath.

Colouration in preservative. Broadly light beigebrownish. Brown blotches in deep integumental layers form dark patches principally along the vertebral area and the abdominal region, leaving out laterally a slightly translucent area. Some dark brown patches scattered irregularly on the skin between nares and eyes, between the eyes, on the jugal area, and on the area between the vertebral and the abdominal area. Light brown flecks spread over the dorsum. Reddish region on the back of the nares present. Laterally, jugal area and flank covered by distinct irregular brown blotches that dissipate on the abdominal region and condense to form sparse networks on the jugal region, mainly on the lateral area between nares and eyes and between the eye and the spiracle, and leaving a visible transparent spiracle diverged above the recognizable intestinal coils. Lower part of the flank spotted. Tail musculature beige with distinct irregular brown blotches which group to form irregularly scattered patches. Their density diminishes towards the tail tip. Fins pale, with brown sporadic patches on the dorsal fin, ventral fin not pigment. Ventrally, oral disk, gular and branchial regions beige; venter transparent, intestinal coils well visible and regularly spiral shaped.

Variation. Nine other voucher specimens (ZSM 1539/2007-ZCMV 3510, ZSM 1541/2007-ZCMV 3513, ZSM 1746/2007-ZCMV 3441, ZSM 1761/2007ZCMV 3457, ZSM 1771/2007-ZCMV 3469, ZSM 1805/2007-ZCMV 3447, ZSM 1813/2007-ZCMV 3509, ZSM 1844/2007-ZCMV 3567, ZSM 1846/2007ZCMV 3570) and one voucher specimen from Ambohitsara-Tsitola (ZSM 72/2008-ZCMV 4936) assigned 
to this species from the same locality reveal the identical oral disk configuration and external pigmentation of this species.

\section{Mantidactylus mocquardi (Mahasoa)}

A further description of a tadpole assigned to M. mocquardi but with some morphological differences refers to one tadpole in developmental stage 27 (field number ZCMV 8094-ZSM 686/2008, BL 13.8 mm, TL 42.6 $\mathrm{mm}$ ) from Mahasoa forest. The 16S rDNA sequence of this specimen was $100 \%$ identical to a reference sequence of an adult specimen of Mantidactylus mocquardi (ZCMV 8818) from the same locality, and 99\% identical to an adult of M. mocquardi from Ambohitsara (accession number FJ559269).

In dorsal view, body elliptical (BW 63\% of BL), maximal body width attained between the proximal $2 / 5$ and $3 / 5$ of the body (SBW $48 \%$ of BL), narrowly rounded snout. In lateral view, body depressed (BW $136 \%$ of BH), maximal body height attained at the distal $1 / 5$ of the body (SBH $81 \%$ of BL), broadly rounded snout. Moderately large eyes (ED 13\% of BL), not visible from ventral view, positioned high (EH $67 \%$ of $\mathrm{BH}$ ) dorsally and directed dorsolaterally, situated between the proximal $3 / 10$ and $4 / 10$ of the body (SE 32\% of BL), moderately wide distance between eyes (IOD $54 \%$ of BW). Small rounded nares (ND $1.6 \%$ of BL), marked with a marginal rim, positioned moderately high (NH 53\% of BH) dorsally and oriented anterodorsolaterally, situated nearer to snout than to eye (RN $59 \%$ of NP) and below eye level (NH 79\% of EH), wide distance between nares (IND 70\% of IOD), dark spot on the back of the nares absent, ornamentation absent. Short sinistral spiracle (SL 10\% of BL), directed posteriorly, visible from dorsal and ventral views, recognizable from lateral view; inner wall free from body, its aperture opens posteriorly, elliptical opening, situated between the proximal $3 / 5$ and $4 / 5$ of the body (SS 71\% of BL), located moderately high on the body (SH $48 \%$ of $\mathrm{BH}$ ) and below the height of the point where the axis of the tail myotomes contacts the body (SH 76\% of HAB). Moderately long dextral vent tube (VL $12 \%$ of $\mathrm{BL}$ ), attached to ventral fin, inner wall present. No gland. Moderately long tail (TAL 209\% of $\mathrm{BL}$ ), maximal tail height higher than body height (MTH 109\% of BH), tail height at midtail equal to body height and to maximal tail height (THM 97\% of $\mathrm{BH}$ and $100 \%$ of MTH), tail height at the beginning of the tail equal to body height (TH 97\% of BH). Developed caudal musculature (TMW 56\% of BW, TMH
$78 \%$ of $\mathrm{BH}, \mathrm{TMH}$ of $80 \%$ of $\mathrm{TH}$ and $71 \%$ of $\mathrm{MTH}$, TMHM 54\% of THM and 54\% of MTH). Tail muscle reaches tail tip. Very low fins (DF 52\% of TMHM, VF $34 \%$ of MTHM), dorsal fin higher than ventral fin at mid-tail (DF $154 \%$ of VF). Dorsal fin originates at the proximal $1 / 5$ of the tail, rises progressively up to its maximal height and then declines towards the tail tip. Ventral fin originates at the ventral terminus of the body, remains almost parallel with tail muscle almost up to the tail tip, then decreases. Maximal tail height located at midtail (DMTH 50\% of TAL), lateral tail vein not visible, myosepta visible on the proximal $3 / 4$ of the tail musculature, point where the axis of the tail myotomes contacts the body in the upper half of the body height (HAB 63\% of $\mathrm{BH}$ ), axis of the tail myotomes parallel with the axis of the trunk. Tail tip pointed.

Moderately wide reduced oral disk (ODW $47 \%$ of $\mathrm{BW}$ ), positioned and directed ventrally, not emarginated, maximal width in the middle. Oral disk not visible from dorsal view, upper labium is a continuation of
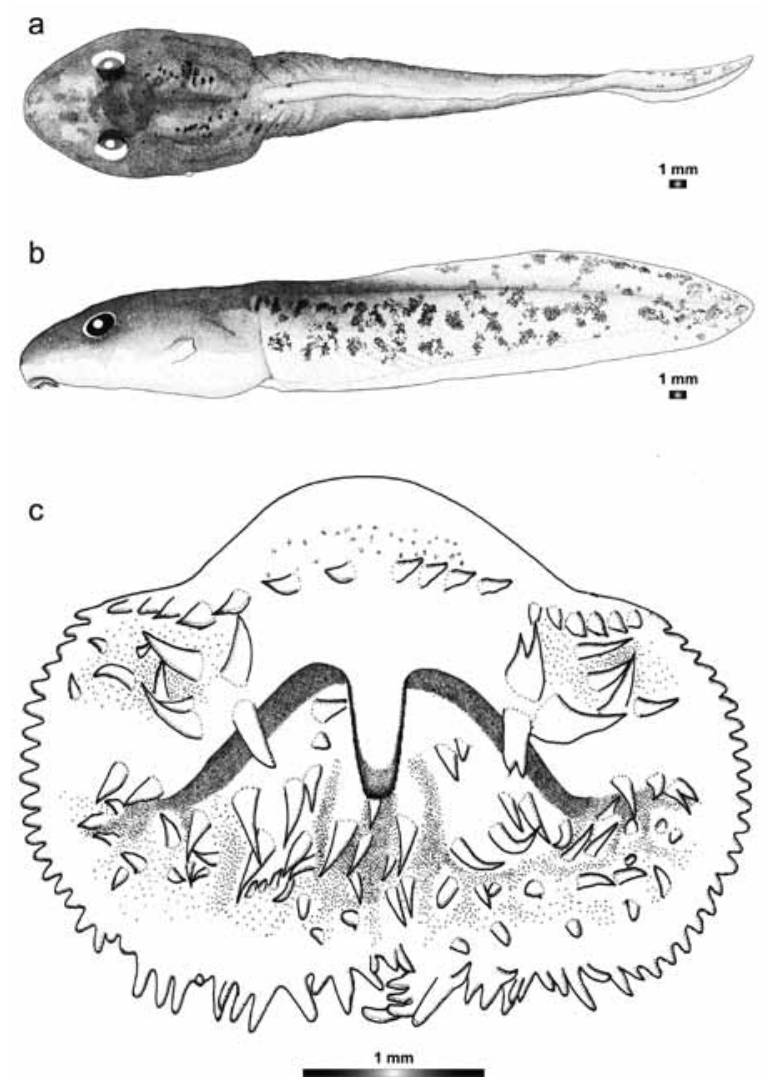

Fig. 18. Drawings of the preserved DNA voucher tadpole of Mantidactylus mocquardi from Mahasoa (ZCMV 8094-ZSM 686/2008): (a) dorsal view, (b) lateral view, (c) oral disk. 
snout. Single row of marginal papillae, gap on the upper and lower labium absent; total number of marginal papillae 89. Eighty-eight submarginal papillae complete on the lower labium and laterally on upper labium. Long and large elongated papillae with rounded tips on the marginal and pointed tips on the submarginal papillae, longest marginal papillae measured $0.25 \mathrm{~mm}$ and $0.35 \mathrm{~mm}$ for submarginal papillae, papillae not visible from dorsal view. Two submarginal papillae on the upper labium beside (left and right) the medial convexity project in the same direction as the medial convexity. Keratodonts absent. Partially keratinized jaw sheath, only the edge of the medial convexity is weakly brown coloured and the remainder whitish; finely pointed serrations; moderately wide jaw sheath (JW $48 \%$ of ODW) with a very long narrowly pointed medial convexity (MCL 57\% of JW). Lower jaw sheath V-shaped, partially keratinized and totally hidden by the upper jaw sheath.

Colouration in preservative. Predominantly palebrownish. Light pale brown melanophoric pigment covered the dorsum and condensed to form dark patches especially between the eyes, on the vertebral and the abdominal area. Some dark brown patches scattered on the skin. Irregularly shaped clear dots form a line which runs on the dorsolateral part of the abdominal regions, from the body-tail junction to just behind the eyes where it splits, the first ramification passes bellow the eyes and runs through the jugal area, before it diverts laterally on the sagittal plan of the nares. The second ramifications pass above the eyes and approach each other on the sagittal plan of the nares and finish to merge in the snout. Laterally, jugal area and flank covered by speckles leaving an conspicuous flecked spiracle on the pale body wall. Lower part of the flanks unpigmented, intestinal coils laterally not visible. The line formed by irregularly shaped clear dots is visible laterally before the body-tail junction. It runs on the dorsolateral part of the abdominal region and splits just behind the eyes. The first ramification passes below the eyes and ends below the nares. The second ramification passes above the eyes and the nares and terminates on the mid-height of the snout. Tail musculature with irregular brown blotches which group to form irregularly scattered patches. Their density diminishes towards the tail tip. Fins pale, dorsal fin with brown spots which group to form patches, sporadic patches spread around tail tip on ventral fin. Ventrally, oral disk, gular and branchial regions beige with brown spots; venter pale, intestinal coils merge under the abdominals-like structure and regularly spiral shaped.
Variation. Four additional specimens belonging to the same series (but not identified by DNA barcoding) and having the same external morphology as the voucher specimen reveal the identical oral disk configuration and morphological parameters.

Mantidactylus sp. 64

(CCS from Namorona and other sites around Ranomafana)

The following description refers to one tadpole in developmental stage 39 (field number ZCMV 2646-ZSM 401/2008, BL $10.8 \mathrm{~mm}$, TL $31.9 \mathrm{~mm}$ ) from the Namorona river in front of Hotel Manja in Ranomafana village. The 16S rDNA sequence of this specimen was 96\% identical to a reference sequence of an adult specimen of Mantidactylus sp. 47 (accession GU975698) from Ambatolahy in the Ranomafana National Park. Since we found morphologically different tadpoles that $100 \%$ genetically matched adults of $M$. sp. 47, we conclude that adults of $M$. sp. 64 are so far unknown and the CCS status for this species is based on the distinct morphology of tadpoles that are genetically divergent and occur in sympatry with $M$. sp. 47 .

In dorsal view, body elliptical (BW 59\% of BL), maximal body width attained between the proximal $2 / 5$ and $3 / 5$ of the body (SBW $48 \%$ of BL), narrowly rounded snout. In lateral view, body depressed (BW $136 \%$ of $\mathrm{BH})$, maximal body height attained between the proximal $3 / 5$ and $4 / 5$ of the body (SBH $69 \%$ of BL), narrowly rounded snout. Moderately large eyes (ED $13 \%$ of BL), not visible from ventral view, positioned high (EH $79 \%$ of $\mathrm{BH}$ ) dorsally and directed dorsolaterally, situated between the proximal $2 / 10$ and $3 / 10$ of the body (SE $27 \%$ of BL), moderately wide distance between eyes (IOD 64\% of BW). Small rounded nares (ND 1.3\% of BL), marked with a marginal rim, positioned high ( $\mathrm{NH} 62 \%$ of $\mathrm{BH}$ ) dorsally and oriented anterolaterally, situated nearer to snout than to eye (RN 59\% of NP) and below eye level (NH 79\% of EH), wide distance between nares (IND 70\% of IOD), dark spot on the back of the nares present, ornamentation absent. Short sinistral spiracle (SL 10\% of BL), directed posteriorly, visible from dorsal and ventral view and perceptible from lateral view; inner wall free from body and formed such that aperture opens laterally instead of posteriorly, rounded opening, situated between the proximal 3/5 and 4/5 of the body (SS 71\% of BL), located moderately high on the body (SH $54 \%$ of $\mathrm{BH}$ ) and below the height of the point where the axis of the tail myotomes contacts the body (SH $76 \%$ of HAB). 
Moderately long dextral vent tube (VL $12 \%$ of BL), attached to ventral fin, inner wall present. No gland. Moderately long tail (TAL 209\% of BL), maximal tail height higher than body height (MTH 109\% of BH), tail height at midtail equal to body height and maximal tail height (THM 97\% of BH and 100\% of MTH), tail height at the beginning of the tail lower than body height (TH $97 \%$ of BH). Moderately developed caudal musculature (TMW $56 \%$ of BW, TMH $78 \%$ of $\mathrm{BH}$, TMH of $72 \%$ of TH and $71 \%$ of MTH, TMHM $54 \%$ of THM and 54\% of MTH). Tail muscle reaches tail tip. Very low fins (DF $52 \%$ of TMHM, VF $34 \%$ of MTHM), dorsal fin higher than ventral fin at mid-tail (DF 117\% of VF). Dorsal fin originates at the proximal $1 / 10$ of the tail, rises gradually to attend its maximal height before mid tail and then progresses horizontally up to the distal $1 / 5$ of the tail, where it decreases. Ventral fin originates at the ventral terminus of the body, remains parallel with tail muscle almost up to the tail tip, where it decreases. Maximal tail height located between the proximal 2/5 and 3/5 of the tail (DMTH $42 \%$ of TAL), lateral tail vein not visible, myosepta slightly visible on the proximal $1 / 4$ of the tail musculature, point where the axis of the tail myotomes contacts the body in the upper half of the body height (HAB 70\% of $\mathrm{BH}$ ), axis of the tail myotomes parallel with the axis of the trunk. Tail tip narrowly rounded.

Moderately wide reduced oral disk (ODW $47 \%$ of BW), positioned ventrally and directed anteroventrally, not emarginated, maximal width in the middle. Oral disk not visible from dorsal view, upper labium is a continuation of snout. Single row of marginal papillae, gap on the upper and lower labium absent; total number of marginal papillae 81. Eighty-seven submarginal papillae complete on the lower labium and laterally on upper labium. Short and moderately large conical papillae with rounded tips, longest marginal papillae measured $0.11 \mathrm{~mm}$ and $0.15 \mathrm{~mm}$ for submarginal papillae, papillae not visible from dorsal view. Keratodonts absent. Partially keratinized jaw sheath, edge of the medial convexity weakly brown coloured and the remainder whitish; finely pointed serrations; moderately wide jaw sheath (JW 55\% of ODW) with a moderately long widely rounded medial convexity (MCL $21 \%$ of JW). Lower jaw sheath V-shaped, partially keratinized and totally hidden by the upper jaw sheath.

Colouration in life. Typically reddish-brown. Body and tail covered by brown blotches which condense and give a dark brown colouration to the tadpole. Golden irridophoric pigments spread over the skin. Dorsolaterally and laterally identical to the dorsal pat- tern. Rather non-pigmented spiracle perceptible. Tail musculature yellowish with roughly distinct, irregular brown blotches condensed to form networks. Their density extends towards the tail tip. Fins translucent, dorsal fin provided by some dark patches and ventral fin unpigmented. Ventrally, oral disk and gular and branchial reticulated, gills and beating heart perceptible; venter transparent, intestinal coils visible and regularly spiral shaped.

Colouration in preservative. Largely dark. Brown melanophoric pigment covering the skin gave almost uniform dorsal colouration; merged light patches occurred between the eyes, on the vertebral area and on the abdominal region. Sparse dark mottles dispersed mainly on the back of the nares between the eyes and on the dorsum, condensed on the dorsolateral part of the abdomen closed to the body-tail junction to form networks. Perceivable transversal lines occur between the vertebral area and the abdominal region showing noticeable abdominals-like structure. Irregularly

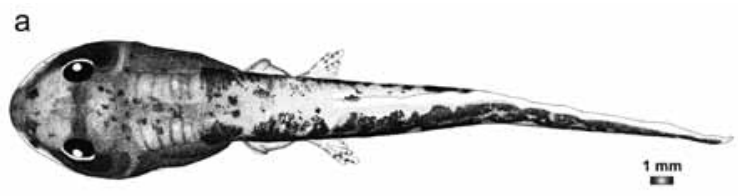

b
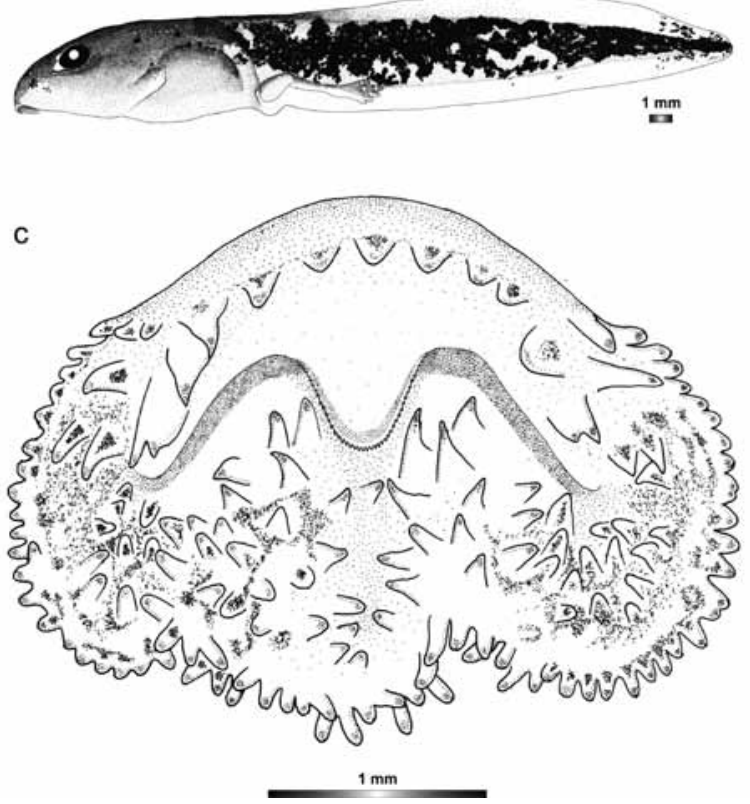

Fig. 19. Drawings of the preserved DNA voucher tadpole of Mantidactylus sp. 64 (ZCMV 2646-ZSM 401/2008): (a) dorsal view, (b) lateral view, (c) oral disk. 
shaped roughly clear dots form a line that runs on the dorsolateral part of the abdominal region, from the body-tail junction to just behind the eyes where it splits, the first ramification passes bellow the eyes and goes through the jugal area, until diverting laterally close to the sagittal plan of the nares. The second ramification passes above the eyes and fades off on the anterior limit of the eyes. Laterally, jugal area and flank covered by dense dark brown melanophoric reticulations leaving a noticeable reticulated spiracle diverged above intestinal coils. Lower part of the flanks unpigmented. The line formed by the irregularly shaped clear dots is conspicuous laterally, before the body-tail junction, runs on the dorsolateral part of the abdominal region and splits just behind the eye, the first ramification passes below the eyes and ends below the nares. The second ramification passes above the eye and fades at the anterior limit of the eye. Tail musculature pale and covered by dark brown reticulations. Their density increases towards the tail tip. Fins pale, with brown reticulations close to the tail tip. First part of dorsal fin mottled. Ventrally, oral disk reticulated, gular and branchial regions patched; venter pale, intestinal coils perceptible and regularly spiral shaped.

Variation. The picture of one uncatalogued voucher specimen (ZCMV 9291) from Sakaroa in Ranomafana National Park, designated to this species, displays the same external pigmentation. The examination of its oral disk is not possible due to the unavailability of this specimen.

\section{Mantidactylus majori Boulenger, 1896}

The following description refers to one tadpole in developmental stage 29 (field number ZCMV 3761-ZSM 1684/2004, BL $11.4 \mathrm{~mm}$, TL $36.9 \mathrm{~mm}$ ) from the Sahamalaotra stream in the Ranomafana National Park. The 16S rDNA sequence of this specimen was $100 \%$ identical to a reference sequence of an adult specimen of Mantidactylus majori (accession AY848187) from the same locality.

In dorsal view, body elliptical (BW 64\% of BL), maximal body width attained almost at midbody (SBW $49 \%$ of BL), narrowly rounded snout. In lateral view, body depressed (BW 147\% of $\mathrm{BH}$ ), maximal body height attained between the proximal $3 / 5$ and $4 / 5$ of the body (SBH 68\% of BL), broadly rounded snout. Large eyes (ED 15\% of BL), not visible from ventral view, positioned high (EH 78\% of $\mathrm{BH}$ ) dorsally and directed laterally, situated between the proximal 3/10 and $4 / 10$ of the body (SE $38 \%$ of BL), wide distance between eyes (IOD 66\% of BW). Moderately large elliptical nares (ND $2.5 \%$ of BL), marked with a marginal rim, positioned high ( $\mathrm{NH} 64 \%$ of $\mathrm{BH}$ ) dorsally and oriented anterolaterally, situated nearer to snout than to eye (RN $59 \%$ of NP) and below eye level (NH $81 \%$ of $\mathrm{EH}$ ), moderately wide distance between nares (IND 54\% of IOD), dark spot on the back of the nares present, ornamentation absent. Short sinistral spiracle (SL 16\% of BL), directed posteriorly, visible from dorsal and ventral view, conspicuous from lateral view; inner wall free from body and its aperture opens posteriorly, rounded opening, situated between the proximal $3 / 5$ and $4 / 5$ of the body (SS $76 \%$ of BL), located low on the body (SH 38\% of $\mathrm{BH}$ ) and below the height of the point where the axis of the tail myotomes contacts the body (SH $61 \%$ of HAB). Moderately long medial vent tube with lateral displacement (VL $11 \%$ of BL), attached to ventral fin. No gland. Short tail (TAL $181 \%$ of BL), maximal tail height equal to body height (MTH $101 \%$ of BH), tail height at midtail lower than body height and maximal tail height (THM 94\% of BH and 93\% of MTH), tail height at the beginning of the tail lower than body height (TH $88 \%$ of BH). Moderately developed caudal musculature (TMW $26 \%$ of BW, TMH $70 \%$ of BH, TMH of $79 \%$ of TH and $69 \%$ of MTH, TMHM $56 \%$ of THM and $52 \%$ of MTH). Tail muscle reaches tail tip. Very low fins (DF 52\% of TMHM, VF 27\% of MTHM), dorsal fin higher than ventral fin at mid-tail (DF 195\% of VF). Dorsal fin originates at the dorsal body-tail junction, progresses horizontally until the $1 / 4$ of the tail, then ascends abruptly to attain the maximal height before the midtail, progresses more or less horizontally until the 3/4 of the tail, then decreases abruptly towards the tail tip. Ventral fin originates at the ventral terminus of the body, continues parallel with the caudal musculature until midtail, and then decreases continuously towards the tail tip. Maximal tail height located between the proximal $2 / 5$ and $3 / 5$ of the tail (DMTH $41 \%$ of TAL), lateral tail vein not visible, myosepta slightly visible on the proximal $3 / 4$ of the tail musculature, point where the axis of the tail myotomes contacts the body in the upper half of the body height (HAB $62 \%$ of $\mathrm{BH}$ ), axis of the tail myotomes parallel with the axis of the trunk. Tail tip narrowly rounded.

Moderately wide highly modified oral disk (ODW $40 \%$ of BW), positioned and directed ventrally, not emarginated, maximal width in the middle. Oral disk not visible from dorsal view, anterior margin is separated with the snout by a shallow crevice. Single row of marginal papillae, gap on the upper and lower labium 
absent; total number of marginal papillae 72. One hundred and thirty-five submarginal papillae complete on the lower labium and upper labium. Very long and very large elongated papillae with pointed tips, longest marginal papillae measured $0.25 \mathrm{~mm}$ and $0.41 \mathrm{~mm}$ for submarginal papillae, papillae not visible from dorsal view. Keratodonts absent. Moderately wide jaw sheath (JW 54\% of ODW), upper jaw sheath transformed into three immense flexible slightly curved thorn-shaped papillae (right $0.56 \mathrm{~mm}$, middle $0.81 \mathrm{~mm}$, left 0.66 $\mathrm{mm})$. A similar papilla is situated laterally to the bases of the two outer papillae. 12 large papillae project from near the base of what appears to be a non-pigmented, non-keratinized, non-serrated lower jaw sheath, which is totally hidden by the upper ones.

Colouration in life. Broadly yellowish-orange with brown patches. Brown melanophoric patches in deep integumental layers extended especially between the eyes and on the vertebral region. Dark brown to black melanophoric patches spread sporadically over the skin, golden iridophoric mottles group to form irregular patches mainly on the dorsum. Laterally, body wall overlain by dark patches of melanophores on the jugal region, below the eye and between the eye and the spiracle. Partly reticulated transparent spiracle diverged on the dark abdominal wall. Blotches of iridophores scattered irregularly. Tail musculature orange-yellowish with brown dots forming irregularly scattered patches. Fins translucent, dorsal fin with scattered patches, ventral fin almost unpigmented. Lateral tail vein reddish. Ventrally, oral disk and gular region yellowish; branchial regions reddish, gills and beating heart clearly visible; abdominal surface transparent with golden iridophoric patches, intestinal coils visible and regularly spiral shaped.

Colouration in preservative. Generally beige. Brown patches in deep integumental layers extend between eyes and nares, between the eyes, on the vertebral and abdominal areas, leaving out laterally a slightly transparent area. Light brown flecks cover the dorsal surface and dark brown blotches dissipate irregularly on the dorsal skin. Laterally, jugal area and flank covered by irregular brown blotches that are sparsely spread and that condense to form sparse networks mainly on the lateral area between nares and eyes, and between the eye and the spiracle, leaving out a visible opaque spiracle diverged above the visible intestinal coils. Lower part of the flank not pigmented. Tail musculature orange-yellowish with brown dots consolidated to form irregularly scattered patches. Fins translucent, dorsal fin with scattered patches, ventral fin almost un- pigmented. Ventrally, oral disk, gular and branchial regions beige; venter transparent, intestinal coils visible and regularly spiral shaped.

Variation. 32 other voucher specimens (ZSM 42/ 2007-ZCMV 4155, ZSM 93/2007-ZCMV 4132, ZSM 335/2007-T 172, ZSM 379/2007-ZCMV 4235, ZSM 495/2007-ZCMV 4699, ZSM 502/2007-ZCMV 4517, ZSM 609/2007-T 410, ZSM 682/2007-ZCMV 5391, ZSM 954/2007-ZCMV 5979, ZSM 1062/2007-T 32, ZSM 1063/2007-T 168, ZSM 1078/2007-T 38, ZSM 1285/2007-ZCMV 4417, ZSM 1328/2007-T 156, ZSM 1382/2007-ZCMV 4534, ZSM 1653/2007ZCMV 3722, ZSM 1676/2007-ZCMV 3749, ZSM 1684/2007-ZCMV 3761, ZSM 1699/2007-ZCMV 3776, ZSM 1700/2007-ZCMV 3777, ZSM 1701/2007ZCMV 3778, ZSM 171/2008-ZCMV 3806, ZSM 202/2008-ZCMV 3835, ZSM 203/2008-ZCMV 3836, ZSM 229/2008-ZCMV 3627, ZSM 256/2008-ZCMV 3672, ZSM 429/ 2008-ZCMV 2674, ZSM 441/2008ZCMV 2686, ZSM 447/2008-ZCMV 2694, ZSM
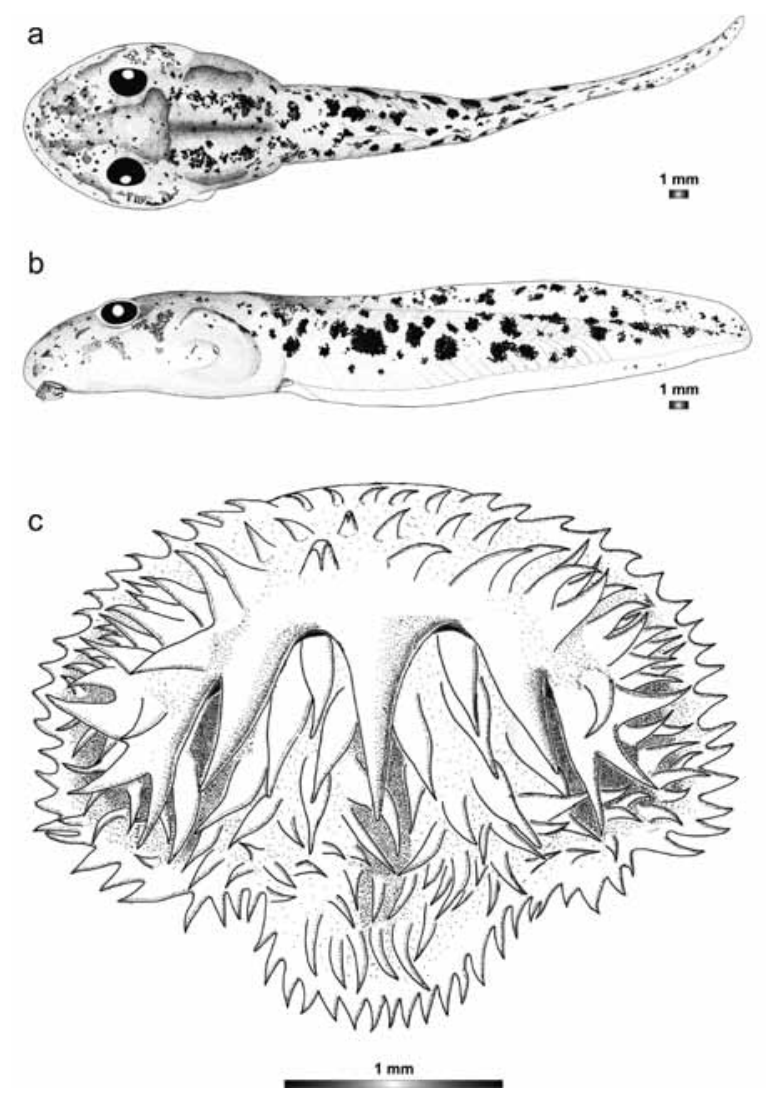

Fig. 20. Drawings of the preserved DNA voucher tadpole of Mantidactylus majori (ZCMV 3762-ZSM 1684/2007): (a) dorsal view, (b) lateral view, (c) oral disk. 
445/2008-ZCMV 2690, ZSM 455/2008-ZCMV 2698, ZSM 473/2008-ZCMV 3704) from the same locality and one voucher specimen from Vevembe forest (ZSM 1384/2004-TAD 6 Vevembe) attributed to this species reveal the identical oral disk configuration, external pigmentation and other morphological parameters.

Supplementary online material: Morphological descriptions of additional tadpole specimens. 
